\title{
Inflation Stabilization and BOP Crises in Developing Countries*
}

\author{
Guillermo A. Calvo \\ University of Maryland \\ Carlos A. Végh ${ }^{\dagger}$ \\ UCLA
}

Revised: December 1997

\section{Introduction}

High and persistent inflation has been one of the distinguishing macroeconomic characteristics of many developing countries - particularly in Latin America since the end of World War II. Pazos (1972) coined the term "chronic inflation" to refer to this phenomenon. In his view, chronic inflation is quite a different creature from the much more spectacular hyperinflations studied by Cagan (1956). First, unlike hyperinflations whose duration is measured in terms of months, chronic inflation may last for decades. Second, countries learn how to live with high and persistent inflation by creating various indexation mechanisms which, in turn, tend to perpetuate the inflationary process. As a result, inflation does not have an inherent propensity to accelerate and, if it does, soon reaches a new plateau.

Countries afflicted by chronic inflation, however, do not take their fate lightly. Quite to the contrary, in the last four decades they have engaged in repeated stabilization attempts which, more often than not, have failed. The end of stabilizations - in particular those which rely on a pegged exchange rate - has often involve dramatic balance of payments crises with costly devaluations and losses of international reserves. With increasingly open capital markets, some of these crises now send shock waves throughout the world, as

* This paper has been prepared for publication in the Handbook of Macroeconomics (North Holland), edited by John Taylor and Michael Woodford. We are grateful to Francesco Daveri, David Gould, Amartya Lahiri, Carmen Reinhart, Sergio Rodriguez, Jorge Roldos, Julio Santaella, John Taylor, Aaron Tornell, Martin Uribe, Sara Wong, Mike Woodford, Carlos Zarazaga, participants at the conference on "Recent Developments in Macroecononomics", organized by the Federal Reserve Bank of New York (February 1997), and, especially, Ratna Sahay and Miguel Savastano for insightful comments and discussions.

$\dagger$ Corresponding author. Department of Economics, UCLA, 405 Hilgard Avenue, Los Angeles, CA 90095-1477. E-mail: cvegh@ucla.edu. Website: http://vegh.sscnet.ucla.edu. 
vividly illustrated by the Mexican crisis of December 1994. In the last ten years, however, countries such as Chile, Israel, and Argentina have succeeded in reducing inflation close to international levels. Still, most developing countries continue to struggle through stabilization attempts, and some former socialist economies have also begun to face similar cycles of inflation and stabilization. The currency crises that hit South East Asia during the second half of 1997 were also a startling reminder that no region is immune to boom-bust cycles which were once thought as being mainly a Latin American disease.

Over the course of the last four decades, a myriad of major stabilization plans went by, leaving behind a rich legacy of issues and puzzles. In retrospect, the stabilization plans implemented in the late 1970s in the Southern Cone countries - Argentina, Chile, and Uruguay - proved to be a turning point. Designed by U.S.-trained technocrats, these plans were in some sense the first ones to openly recognize the constraints imposed on monetary policy by open financial markets. Trying to make the most of such constraints, policymakers decided to abandon the "closed-economy" monetary policies of the past — aimed primarily at controlling the money supply — and switch to "open-economy" policies based on setting a declining rate of devaluation which would quickly bring domestic inflation in line with tradable-goods inflation (given by world inflation plus the rate of devaluation). To the consternation of policymakers, however, the inflation rate failed to converge to tradable-goods inflation, which resulted in a large real appreciation of the domestic currency. More puzzling still, in spite of the real appreciation, real economic activity - particularly private consumption - expanded in the early years of the programs. Later in the programs, a recession set in, even before the programs collapsed.

In the mid-1980s, major programs in Argentina, Brazil, and Israel brought back to life some of the same, and still mostly unresolved, issues. In spite of the use of wage and price controls to supplement an exchange rate peg, real appreciation remained an integral part of the picture. More puzzling, however, was the reemergence of the pattern of an initial boom and a later recession. The Israeli recession was viewed as particularly hard to rationalize because of its occurrence in a fiscally-sound and largely successful stabilization program. Based on these new programs - and a reexamination of older programs going back to the 1960s - Kiguel and Liviatan (1992) and Végh (1992) argued that the outcome observed in the Southern-Cone stabilizations is a pattern common to most stabilization plans which have relied on the exchange rate - as opposed to a monetary aggregate - as the main nominal anchor. Specifically, the beginning of an exchange rate-based stabilization is characterized by an economic boom and sustained real appreciation. Later in the programs - and often aggravated by the collapse of the program - a contraction takes hold.

In contrast, the scanty evidence on money-based stabilization in chronic inflation countries lends support to the notion that, as in low inflation countries, the recession takes place at the beginning of the program (Calvo and Végh (1994b)). Hence, it would appear that under money-based stabilization, the 
costs (in terms of output losses) would be paid up-front, whereas, under exchange rate-based stabilization, these costs would be postponed until a later date. The intriguing idea that choosing between the two nominal anchors may imply choosing not if but when to bear the costs of disinflation has been dubbed the "recession-now-versus-recession-later" hypothesis.

The twin puzzles of the boom-recession cycle in exchange rate-based stabilizations and the recession-now-versus-recession-later hypothesis have been the driving force behind recent developments in the area of inflation stabilization in developing countries. An emerging empirical literature has attempted to document these phenomena in a systematic way, while an extensive theoretical literature has advanced various hypotheses - such as inflation inertia and lack of credibility - to explain the real effects of disinflation. A critical review and evaluation of this literature constitutes the core of this chapter. ${ }^{1}$

A third puzzle is the fact that most exchange rate-based stabilizations end up in balance of payments (BOP) crises. The literature, however, has had precious little to say so far about the possible links between the dynamics of exchange rate-based stabilizations and BOP crises. The Mexican crisis of December 1994 - which put an end to an exchange rate-based stabilization plan initiated seven years earlier - brought back to life some of the key questions: Do exchange rate-based stabilizations sow the seeds of their own destruction by unleashing "unsustainable" real appreciations and current account deficits? Or are credibility problems and self-fulfilling prophecies at the root of these crises? The remainder of the chapter is devoted to analyzing the main ideas behind this unfolding literature. Of course, the potential for BOP crises is a more general issue, which goes back to Krugman's (1979) seminal contribution, and applies to any pegged exchange rate system. Hence, while many of the issues to be discussed have broader relevance, we focus on factors which may be of particular importance for developing countries.

The chapter proceeds as follows. Section 2 focuses on how to explain the existence of chronic inflation in a world of rational economic agents. Section 3 undertakes an empirical examination of the main empirical regularities of inflation stabilization in chronic inflation countries. Section 4 begins the theoretical discussion on exchange rate-based stabilization by focusing on two key factors: inflation inertia and lack of credibility. Section 5 continues the analysis of exchange rate-based stabilization by highlighting the role of consumer durables, credit market segmentation, supply-side effects, and fiscal policy. Section 6 ex-

\footnotetext{
${ }^{1}$ Not suprisingly, most of the literature has been inspired by the experiences of chronic inflation countries, which constitute a rich laboratory for the discussion of inflation and stabilization in developing countries. To focus the discussion, we follow this tradition and confine our discussion on inflation and stabilization mostly to chronic inflation countries. We will thus ignore some rare episodes of full-blown hyperinfations (like Bolivia in the mid-1980s) which have more in common with Cagan's classic hyperinflations (see Végh (1992)). We will also mostly ignore the inflationary experience of the transition economies, as the dramatic transformation from plan to market raises some special issues (see, for example, De Melo, Denizer, and Gelb (1995), and Sahay and Végh (1996)).
} 
amines money-based stabilization. Section 7 examines the causes and mechanics of balance-of-payments crises. Section 8 concludes.

\section{Understanding chronic inflation}

For the purposes of this paper, the rate of inflation in period $t$ is defined as the proportional rate of growth of the price level (usually the consumer price index) from period $t-1$ to period $t$. An essential ingredient in the definition of inflation is the "price level," that is to say, the relative price of goods in terms of money. Therefore, one cannot have inflation without money, and one cannot have inflation without goods. During high inflation - unless something very unusual is happening to the demand for money or to the demand for or supply of goods - the supply of money also grows at a high rate. Hence, although inflation is a phenomenon that results from the interaction of monetary and real phenomena, monetary factors are likely to dominate.

The situation, however, is not symmetric: it does not follow from the above observations that real phenomena, like output or domestic absorption, are largely independent of money. This would be true only under very special circumstances, including (i) no nominal rigidities, and (ii) no effects of changes in nominal interest rates on consumption (see below). As the ensuing analysis will reveal, the channel from money to output is particularly relevant during stabilization programs.

The empirical evidence is quite clear about the following two points: inflation is closely tracked by money supply, and inflation - particularly, changes in the rate of inflation - affects real variables. The latter represents a formidable challenge faced by stabilization programs. As will be argued below, however, the real effects of either inflation or stopping inflation are not necessarily rooted in fundamentals but may, to a large extent, be due to factors - like policy credibility — which suitable institutional/political arrangements may help to modify.

Under ideal circumstances, stopping inflation may be a socially painless process. Those circumstances, however, require appropriate fiscal adjustment. One serious difficulty in that respect is that there is more than one way to effect a fiscal adjustment, and each of these ways has different implications for various groups in society. Consequently, it is not easy to reach wide consensus on any particular policy. This has two important consequences: (i) delayed stabilization, and (ii) adoption of incomplete stabilization programs. Point (i) rationalizes inflation persistence, while point (ii) explains the prevalence of short-lived stabilization programs.

But what sets inflation in motion in the first place? And, in particular, how can the phenomenon of high and persistent inflation be explained in a world of rational economic agents? ${ }^{2}$ Although it would seem fair to say that

\footnotetext{
${ }^{2}$ An alternative explanation for the existence of chronic inflation is simply that policymak-
} 
the profession is still struggling to provide an answer to these questions and is far from reaching a consensus, the existing literature provides several useful insights.

\subsection{Inflation as an optimal tax}

One explanation, due to Phelps (1973), is that in a world of distorting taxes, governments may find it optimal to depart from Friedman's (1969) celebrated optimum quantity of money rule, which calls for setting the nominal interest rate to zero. Phelps's (1973) result is quite intuitive. It follows from the observation that at Friedman's optimum quantity of money rule, the marginal cost of the inflation tax (i.e., the nominal interest rate) is, by definition, nil. Thus, at the margin, increasing fiscal revenue through money creation has no cost. In contrast, the marginal benefit of lowering any distorting tax is unambiguously positive. Therefore, starting from a zero nominal interest rate, it is welfareimproving to increase the inflation tax and lower any other distorting tax used to collect revenue. Thus, Phelps's result calls for a positive inflation tax. ${ }^{3}$

A key assumption in Phelps (1973) and the ensuing literature is that there is no fundamental difference between the inflation tax and other "conventional" taxes. It has long been recognized, however, that the costs of collection, enforcement, and evasion associated with the inflation tax are negligible compared to those of other taxes. As Keynes (1924, p. 46) put it, inflationary finance "is the form of taxation which the public finds hardest to evade and even the weakest Government can enforce, when it can enforce nothing else." An inefficient tax system may make it optimal to resort to the inflation tax even in cases in which Friedman's optimum quantity of money rule would otherwise be optimal (see Aizenman (1987) and Végh (1989)).

The above arguments - valid as they may be as normative propositions - appear rather insufficient to rationalize chronic high inflation in developing countries. First, high inflation is a phenomenon that the society is typically trying to get rid of and, thus, could hardly be expected to be optimal in accord with Phelps's (1973) prescriptions. Second, while the evidence does show a long-run relationship between fiscal deficits and inflation (see, for example, Fischer, Sahay, and Végh (1997)), cross-country econometric studies for developing countries have not found support for the main empirical implication of Phelps's

ers in these countries are systematically ignorant or incompetent. We find this explanation both implausible as a description of the real world and uninteresting from a theoretical point of view (given that we do not have good theories of "ignorance" or "incompetence"). Hence, the basic premise of this section is that chronic inflation is a phenomenon in search of a "rational" explanation.

${ }^{3}$ A large literature has developed which analyzes the robustness of Phelp's (1973) findings (see the critical survey by Woodford (1990)). Modeling money as an intermediate input, Kimbrough (1986) shows an interesting case in which Friedman's rule holds even though all available taxes are distorting. Kimbrough's result, however, holds only under rather restrictive assumptions (see Woodford (1990), Guidotti and Végh (1993), and Correia and Teles (1996)). 
(1973) hypothesis that there should be a positive correlation between the inflation tax and other conventional taxes (see Edwards and Tabellini (1991)). In fact, the inflation tax appears to act more as a residual source of government revenue. Third, empirical estimates show that inflation is often larger than the level that maximizes revenue from inflation (see, for example, Easterly and Schmidt-Hebbel (1994)). ${ }^{4}$ This implies that lower inflation and higher revenues from inflation could be simultaneously achieved - a glaring contradiction of Phelps's (1973) prescription.

In sum, although the optimal taxation approach could explain perhaps the persistence of low levels of inflation, it would seem that other factors are needed to explain the actual pattern of inflation observed in chronic inflation countries.

\subsection{Shocks and accommodation}

While fiscal deficits may constitute the original sin that gives rise to inflation, the persistence of inflation may involve policy accommodation which transforms temporary domestic or external shocks into permanent increases in the inflation rate (see, in particular, Bruno and Fischer (1986) and Bruno (1993, Chapter $3)$ ). For example, consider a shock which calls for a real appreciation of the domestic currency. Authorities may dislike real appreciation because, say, it might be detrimental to exports. Therefore, incipient real appreciation would lead authorities to devalue. Since conditions after the shock require a more appreciated equilibrium real exchange rate, such a policy reaction cannot provide a definitive solution to the authorities' problem. After the first devaluation, domestic prices will rise to regain lost ground and attempt, once again, to climb a little higher (in order to generate the equilibrium real appreciation). Thus, another devaluation will eventually follow - and, of course, prices will continue rising, setting in motion an inflationary process quite unrelated to fiscal revenue considerations à la Phelps. ${ }^{5}$

More generally, monetary accommodation is typically reflected in the fact that key nominal variables - the rate of devaluation, the rate of monetary growth, and nominal wage growth - are linked to past inflation through accommodative policy rules and institutional arrangements such as backward-looking wage indexation. A greater degree of accommodation will be reflected in more inflation inertia. Bruno (1993) shows how nominal variables linked to past inflation may generate an autoregressive process for the inflation rate. Under these circumstances, temporary shocks to the inflation rate lead to permanent

\footnotetext{
${ }^{4}$ Although measuring the seigniorage-maximizing inflation rate is not without problems (see Easterly, Mauro, and Schmidt-Hebbel (1995)).

${ }^{5}$ Empirical evidence on the inflationary consequences of real exchange rate targeting in Brazil, Chile, and Colombia may be found in Calvo, Reinhart, and Végh (1995). At a theoretical level, the inflationary consequences of real exchange rate targeting have been analyzed by Adams and Gros (1986), Lizondo (1991), Montiel and Ostry (1991), Calvo, Reinhart, and Végh (1995), Uribe (1995), and Lahiri (1997). See also Heyman and Leijonhufvud (1995) for a more general analysis of these issues.
} 
increases in the inflation rate. Bruno and Melnick (1994) further show that the higher is the degree of monetary accommodation, the higher is the new inflation plateau.

While the process of shocks and accommodation captures some important elements of chronic inflation processes, it is less clear whether it can be argued that inflation is unduly high, in the sense of not being socially optimal. Presumably, policymakers accommodate shocks because not doing so would bring about undesirable consequences. In fact, one can show simple examples in which, in response to temporary shocks, it may be optimal to keep constant the real exchange rate by generating higher inflation (see Calvo, Reinhart, and Végh (1995)). In the same vein, it is often argued that not accommodating expected inflation by printing money could bring about a severe liquidity crunch and thus lower output. Hence, this view leaves unresolved the issue of why society would periodically wish to get rid of inflation.

\subsection{Multiple equilibria}

A more clear-cut case of socially suboptimal inflation is multiple equilibria. An example that we find particularly relevant (Calvo (1992)) is one in which there is a stock of public debt denominated in domestic currency, $D$. Let the oneperiod nominal interest rate be denoted by $i$. Then, next period's full service of the debt (i.e., principal plus interest) will be $(1+i) D$. Let us choose units of measurement so that the present price level equals 1 , and indicate the oneperiod expected inflation rate by $\pi^{e}$. Thus, if, say, the equilibrium real interest rate is zero, we have that $i=\pi^{e}$. Therefore, if actual inflation is zero, the real burden of servicing domestic debt would be $\left(1+\pi^{e}\right) D$. This could very well be a large number. On the other hand, if the government fulfills the private sector's expectations and sets actual inflation equal to expected inflation, the real burden of the debt is just $D$. Thus, the temptation not to stop inflation in its tracks may be irresistible.

A numerical example may help bringing the above point home. Suppose that the stock of debt is just 20 percent of GDP, and consider the case of Brazil (in the late 1980s) where the monthly rate of inflation was about 30 percent. If inflation is stopped but the private sector expected it to continue at previous levels, the nominal interest rate will remain at 30 percent per month. Therefore, just interest on the debt will amount to 6 percent of GDP per month. This sizable cost of stopping inflation may, quite plausibly, lead authorities to relent by either keeping inflation at the original high levels, or adopting a very gradual stabilization program.

\subsection{The "provinces" effect}

Another explanation is what one might call the "provinces effect." Provinces, municipalities, state enterprises, etc., are entities that, at best, attempt to max- 
imize social welfare by controlling a small set of levers. In particular, for these institutions, inflation is a public good, generated by total government expenditure, to which their individual expenditure adds an insignificant amount. Therefore, in choosing "provincial" expenditure, each entity will overlook the adverse welfare consequences of inflation on all other entities. Consequently, like with any other public good, too much inflation (i.e., too little price stability) will be generated. ${ }^{6}$ While this approach provides an attractive rationale for the existence of inflation, it still needs to explain cross-sectional variation in inflation outcomes. In other words, why should this effect be more relevant in, say, Argentina than in the United States?

\subsection{Delayed stabilization}

We now come to a more recent explanation for the persistence of high inflation; namely, the "war of attrition." This is an extremely useful idea formally developed by Alesina and Drazen (1991). ${ }^{7}$ Suppose that inflation is unduly high for any of the reasons discussed above. Thus, policymakers would know that inflation could be brought under control if institutions were changed, or some appropriate transfers were put in place. So, why do they not act upon this knowledge and stop inflation in its tracks? Alesina and Drazen's (1991) explanation is that, since there is more than one way to get out of the inflation quagmire, and each way has different welfare implications across groups, it may be optimal for each group to wait for another group to give in. Eventually, the most "anxious" group will give in, adjustment will take place, and inflation will stop. In the meantime, inflation will remain high. Note, however, that Alesina and Drazen's (1991) model per se does not rationalize the advent of high inflation. Thus, Alesina and Drazen's model would need to be appended with some inflation-causing factor, or factors, in order to be able to track empirical evidence.

An interesting application of the Alesina-Drazen framework is the formalization of the idea that, in practice, things must get worse before they get better; that is, that often times societies need to go through a truly devastating hyperinflationary outburst before a political consensus for a stabilization emerges. In the war-of-attrition framework just described, Drazen and Grilli (1993) show how a higher rate of inflation may be welfare-improving by bringing forward the expected time of resolution. The earlier resolution of the war of attrition may thus more than offset the short-term costs of higher inflation.

\footnotetext{
${ }^{6}$ See Aizenman (1992), Velasco (1993), Sanguinetti (1994), Mondino, Sturzenegger, and Tomasi (1996), Zarazaga (1996), and Jones, Sanguinetti, and Tomassi (1997).

${ }^{7}$ Of course, the perception of inflation as the outcome of an unresolved distributive struggle is not new, and goes back to Hirshman (1963) (see Heyman and Leijonhufvud (1995) for a detailed discussion). It should also be noted that these last two factors - the "provinces" effect and delayed stabilization - are part of a large, and growing, literature on the polical economy of reform (see Tommasi and Velasco (1996) for a survey).
} 


\subsection{In conclusion}

Based on the analysis thus far, we believe there is no single explanation for the phenomenon of chronic inflation. In fact, we would argue that, when taken together and in the proper dynamic sequence, the five factors discussed above probably explain the key features of processes of chronic inflation. At a fundamental level, governments with inefficient tax-systems will always find it optimal to resort to some inflation (inflation as an optimal tax). The "provinces effect" is likely to add another - socially suboptimal - layer to the optimal public finance level of inflation. Once inflation has emerged, the economy as a whole naturally develops various indexation mechanisms (including accommodative policy rules) aimed at minimizing, for a given inflation rate, the real effects of inflation. Heavy indexation of the economy makes relative prices less responsive to various shocks, which sets the stage for temporary shocks to have permanent effects on the rate of inflation (the "shocks and accommodation" view). At this stage, the inflationary process will probably bear little relation to its original cause (the fiscal deficit), fueling the perception that putting the fiscal house in order may, after all, not help in dealing with the inflation problem.

By now, the government's incentives to tackle seriously the problem are greatly diminished. After inflation has become entrenched in the public's mind, it may be too costly for the government not to validate the public's expectations (multiplicity of equilibria). In addition, and even if the government finally managed to credibly commit to a low level of inflation, political battles over the distribution of the fiscal adjustment needed to implement a stabilization may prolong chronic inflation (delayed stabilization). In the end, things may indeed need to get worse - by, say, having a hyperinflationary outburst — before they get better.

\section{Evidence on the real effects of stabilization in chronic inflation countries}

It is perhaps fair to say that until recently the dominant opinion in the profession was that stopping inflation would bring about a sharp fall in output and domestic absorption. In fact, the notion that disinflation is contractionary is so entrenched in the literature that the question asked has typically been not if but by how much output would fall in response to an anti-inflationary program. The best-known manifestation of this approach is the so-called "sacrifice ratio," or cumulative percent output loss per percentage point reduction in inflation. Okun (1978, p. 348), summarizing the findings of several papers on the United States, argues that "the cost of a 1 point reduction in the basic inflation rate is 10 percent of a year's GNP, with a range of 6 percent to 18 percent." Fischer (1986b) estimates a sacrifice ratio of 5 to 6 - at the lower end of the Okun range - for the United States for the period 1979-1986. Based on a review 
of fourteen episodes in eight countries, Gordon (1982) concludes that, by and large, contractionary policies - especially "cold turkey" policies — aimed at bringing down inflation have entailed large output costs. More recently, Ball (1994) examines 28 disinflation episodes in nine OECD countries using quarterly data and finds that, with one exception, disinflation is always costly, with the sacrifice ratio ranging from 2.9 for Germany to 0.8 in France and the United Kingdom.

The conventional view about the output costs of disinflation has also been taken to apply to open economies. Indeed, in traditional open-economy models, disinflation is expected to cause an initial recession regardless of the nominal anchor which is used (the exchange rate or the money supply), as argued by Fischer (1986a). Therefore, the choice of the nominal anchor is based on a comparison of the sacrifice ratio involved in the two alternative strategies. By examining the sacrifice ratio under different parameter configurations, Fischer (1986a) concludes that the exchange rate should be the preferred nominal anchor. A similar conclusion is reached by Chadha, Masson, and Meredith (1992). Based on simulations using MULTIMOD (a large-scale, multi-region macroeconometric model), they conclude that, for the United Kingdom, the sacrifice ratio is cut almost in half under an exchange rate anchor compared to a money anchor.

The intuition behind the view that "disinflation is always and everywhere contractionary" owes much to the unemployment-inflation trade-off, Phillipscurve literature. Particularly influential has been the staggered-contracting approach pioneered by Fischer (1977) and Taylor $(1979,1980)$. In these models, wage contracts are preset for a number of periods. Hence, credibility of the policy is not enough to generate a costless disinflation. Only a fully-credible gradual disinflation, which would take into account the structure of labor contracts, could reduce inflation with no output cost. For the case of the United States, Taylor (1983) concludes that it would take four years to disinflate from a rate of wage increase of 10 percent per year to 3 percent without creating unemployment.

The conventional view has not gone unchallenged. In an influential paper, Sargent (1982) has argued that inflation was stopped virtually overnight with little or no output costs in the hyperinflations which developed in Austria, Germany, Poland, and Hungary in the aftermath of World War I. Based on this evidence, he argues that disinflation need not be contractionary if it is accompanied by a credible change in regime, which drastically alters the public's perceptions about future government policies. However, even if Sargent's (1982) conclusions regarding the output costs of stopping hyperinflation were accepted, such hyperinflations are seen as extreme episodes whose lessons are not necessarily applicable to much more mundane, garden-variety inflations. ${ }^{8}$

\footnotetext{
${ }^{8}$ Notice that the average monthly rate of inflation in these four episodes in the twelve months preceding stabilization ranged from a low of 33.3 percent in Hungary to a high of
} 
Perhaps a more fundamental challenge to the conventional view began to emerge in the late 1970s when major stabilization plans were implemented in the Southern-Cone countries of Latin America (Argentina, Chile, and Uruguay). The cornerstone of these programs was the announcement of a predetermined path for the exchange rate, which involved setting a declining rate of devaluation. ${ }^{9}$ Contrary to Phillips-curve based predictions, the resulting decline in inflation was accompanied by a boom in consumption and no signs of higher unemployment. Moreover, the expansion took place in spite of a sharp appreciation of the real exchange rate. The contractionary costs associated with disinflation appeared only later in the programs, often before the programs finally collapsed.

As it turned out, the puzzling phenomenon of an initial expansion followed by a later recession observed during the Southern-Cone "tablitas" appears to be a common pattern of exchange rate-based stabilizations (see Kiguel and Liviatan (1992) and Végh (1992)). In sharp contrast, money-based stabilizations which are much less common in chronic-inflation countries - have typically led to an initial recession, as the conventional view would have it. The remainder of this section takes a detailed look at some of the empirical evidence on these issues.

\subsection{Exchange rate-based stabilization: empirical regular- ities}

Table 1 lists twelve major exchange rate-based stabilizations in chronic inflation countries in the last 35 years. These programs - which took place in Argentina, Brazil, Chile, Israel, Mexico, and Uruguay - have been studied in great detail and constitute the main motivation behind much of the literature in the area. ${ }^{10}$ 11 Based on these episodes, the literature has identified the following main

455.1 percent in Germany (see Végh (1992), Table 2). Garber (1982) and Wicker (1986) have both taken issue with Sargent's (1982) conclusions. See also Végh (1992) and Bruno (1993, Chapter 1).

${ }^{9}$ In popular parlance, the announced schedule would be referred to as the "tablita" (Spanish for "little table"). In Chile, the exchange rate was eventually fixed.

${ }^{10}$ Case studies include - but are certainly not limited to - the following. On the Argentine plans, see De Pablo (1974), Fernandez (1985), Canavese and Di Tella (1988), Heymann (1991), and Dornbusch (1995). On the Brazilian plans, see Kafka (1967), Modiano (1988), and Cardoso (1991). On Chile, see Corbo (1985) and Edwards and Cox Edwards (1991). On the Israeli plan, see Bruno (1993) and Bufman and Leiderman (1995). On Mexico, see Dornbusch and Werner (1994) and Santaella and Vela (1996). On the Uruguayan plans, see Finch (1979), Hanson and de Melo (1985), Viana (1990), and Talvi (1995). See also Foxley (1980), Diaz-Alejandro (1981), Ramos (1986), Corbo, De Melo, and Tybout (1986), Kiguel and Liviatan (1989), Edwards (1991), and Agénor and Montiel (1996, Chapter 8).

${ }^{11}$ The literature has often distinguished between "orthodox" programs (which do not rely on prices and/or wages controls) and "heterodox" programs (which do, and thus have "multiple nominal anchors"). Of the programs listed in Table 1, five were "orthodox" plans (the three "tablitas", the Argentine 1991 Convertibility plan, and the Uruguayan 1990 plan); the rest were "heterodox" plans. Except for the behavior of inflation and domestic real interest rates (see below), the response of key macroeconomics variables to major stabilization plans has 
empirical regularities associated with exchange rate-based stabilization: ${ }^{12}$

(i) Slow convergence of the inflation rate (measured by the CPI) to the rate of devaluation. In heterodox programs, inflation has typically fallen faster due to temporary price controls. ${ }^{13}$

(ii) Initial increase in real activity - particularly, real GDP and private consumption - followed by a later contraction. It is less clear whether the same pattern applies to investment. ${ }^{14}$

(iii) Real appreciation of the domestic currency.

(iv) Deterioration of the trade balance and current account balance.

(v) Ambiguous impact response of domestic real interest rates. Ex-post domestic real interest rates have generally decreased in the initial stages of orthodox plans. However, they appear to have increased substantially in the early stages of the heterodox programs of the mid-1980s.

To take a closer look at the main stylized facts, we constructed a panel of annual observations for four countries (Argentina, Chile, Israel, and Uruguay), which covers 16 years (1978-1993), for a total of 64 observations. ${ }^{15}$ The panel includes seven of the twelve exchange rate-based stabilizations listed in Table 1 (the "tablitas" implemented in 1978 in Argentina, Chile, and Uruguay, the Israeli 1985 plan, the Argentine 1985 Austral plan, the Uruguayan 1990 plan, and the Argentine 1991 Convertibility plan) and ten macroeconomic variables (devaluation rate, inflation rate, rates of growth of GDP, private consumption, durable goods consumption, fixed investment, and public consumption, all expressed in per capita terms, real exchange rate, current account deficit as a proportion of GDP, and real lending rate). ${ }^{16}$

been very similar, regardless of whether the plans were orthodox or heterodox. Hence, for the purposes of our analysis, not much will be made of this distinction. It should be noted, however, that the policy debate over the desirability of price and wage controls has been intense; see, for instance, Dornbusch and Simonsen (1987), Dornbusch, Sturzenegger, and Wolf (1990), Bruno (1993), Leiderman (1993), and Meltzer (1994).

${ }^{12}$ See Kiguel and Liviatan (1992), Végh (1992), Calvo and Végh (1994b), Reinhart and Végh (1994, 1995b), and De Gregorio, Guidotti and Végh (1998).

${ }^{13}$ Although less well-documented, casual empiricism suggests that wholesale price inflation (which captures the behavior of tradable goods inflation) converges quite rapidly.

${ }^{14}$ Both Kiguel and Liviatan (1992) and Reinhart and Végh (1995b) report mixed results for investment. Real estate boom-bust cycles also appear to be a hallmark of many of these programs; see Rebelo and Végh (1995) and Guerra (1997b). Some spotty data also suggests that output in the non-tradable sector typically expands more rapidly than in the tradable sector (Rebelo and Végh (1995)).

${ }^{15}$ The numerous caveats that apply to the empirical exercises which follow are discussed at the end of the section.

${ }^{16}$ The sample chosen was dictated by data availability. The sources of data are as follows. Data on GDP, private consumption, and durable goods consumption were provided by the Central Banks of Argentina, Israel, Uruguay, and the Chilean Ministry of Finance. For Argentina and Uruguay, durable goods consumption is proxied by car sales. Real exchange rate data for Israel were provided by the Bank of Israel. All other data are from International Finance Statistics (IMF). Fixed investment corresponds to gross fixed capital formation adjusted by the GDP deflator. (Ideally, we would have liked to have private fixed investment, but data are hard to come by.) The real exchange rate is a real effective exchange rate, as 
Stabilization time profiles As a first pass at the data and to illustrate the dynamic response of the different variables to the implementation of an exchange rate-based stabilization program, we constructed profiles in "stabilization" time (as opposed to "calendar" time). ${ }^{17}$ Stabilization time is denoted by $T+j$, where $T$ is the year in which the stabilization program was implemented and $j$ is the number of years preceding or following the year of stabilization $(j=-2, \ldots, 4){ }^{18}$ We then compute the average value of each variable in stabilization time. The resulting stabilization time profiles, presented in Figures 1 and 2, thus portray the dynamic behavior of key macroeconomic variables for a "representative" exchange rate-based stabilization plan. Vertical bars indicate the year before stabilization (time $T-1$ ) and, where applicable, dashed lines denote the mean of the corresponding variable for the entire sample (i.e., for all 64 observations).

Panel A in Figure 1 illustrates the behavior of the rates of devaluation and inflation. ${ }^{19}$ The U-shaped profile for the rate of devaluation (the nominal anchor) reflects the fact that, more often than not, policymakers either switch to a more flexible exchange rate arrangement (often after a brief period with a fixed exchange rate) or abandon the program altogether. While inflation is highly responsive to the reduction in the rate of devaluation, it remains above the rate of devaluation and then lags it as the rate of devaluation increases. Panel B shows that the real exchange rate (set to 100 in the year before the stabilization) appreciates for three consecutive years (falling below 80 in year $T+2$ ) before beginning to depreciate, following the higher rate of devaluation. The current account deteriorates up to year $T+3$ - reaching a deficit of 4.8 percent of GDP - and then reverses course (Panel C).

While the rate of growth of public consumption falls in the year of stabilization - presumably reflecting an initial fiscal adjustment - it shows no

computed by the IMF, defined as a nominal effective exchange rate index adjusted for relative movements in national price or cost indicators of the home country and its main trading partners. Following common practice, the index is presented in such a way that an increase reflects a real depreciation. Real interest rates were computed by deflating nominal rates by the same year's inflation rate. Population series from International Finance Statistics (IMF) were used to compute per capita figures.

${ }^{17}$ Fischer, Sahay, and Végh (1996) have used this approach to analyzing stabilization policies in transition economies. See also Easterly (1996).

${ }^{18}$ If the program began in the last quarter of a given year, the following year is taken as $T$. Thus, $T$ is 1978 for the Chilean tablita, 1979 for the Argentine and the Uruguayan tablitas, 1985 for the Austral and Israeli plans, and 1991 for the Convertibility and the Uruguayan 1990 plans. We should also note that we did not allow for any overlapping (i.e., any given year in calendar time corresponds to at most one point in stabilization time). Hence, in the case of Argentina, the first observation in stabilization time for the Austral plan is 1984 (which corresponds to $T-1)$ and the last one is $1988(T+3)$. Finally, note that the number of observations for each year in stabilization time may differ, since some stabilizations episodes do not have observations for all years in stabilization time (i.e., from $T-2$ through $T+4$ ). For instance, there are 7 observations for $T-1, T$, and $T+1$, but only 4 for $T+4$ and 3 for $T-2$.

${ }^{19}$ Since the mean is essentially the same (179.3 percent for the devaluation rate and 177.9 percent for the inflation rate), the panel contains only one horizontal line. 
systematic behavior afterwards. Panels $\mathrm{E}$ and $\mathrm{F}$ show the behavior of domestic real interest rates. ${ }^{20}$ Real interest rates fall in the year the plan is implemented (with the real lending rate falling for two consecutive years) and increase sharply afterwards. As indicated earlier, the accepted wisdom is that real interest rates have increased on impact in heterodox plans. This does not show up in annual data, suggesting that the initial rise in real interest rates in heterodox plans has manifested itself basically as "spikes" immediately after the implementation of the plans. ${ }^{21}$

Figure 2 presents the evidence related to the boom-recession cycle in the growth of per capita GDP, consumption, and fixed investment. Panel A shows that real GDP growth increases above the sample mean in the year of stabilization and peaks in $T+1$. In $T+2$, growth is back to its mean and decreases sharply thereafter. The same pattern is observed for private consumption (Panel $\mathrm{B})$ and durables consumption (Panel C). In orders of magnitude, however, the cycle in durables goods is much more pronounced than the one in private consumption, which is in turn more pronounced than the one in real GDP. At the peak, durable goods consumption is rising at 47.7 percent per year, private consumption at 8.9 percent, and real GDP at 4.7 percent. Fixed investment growth follows a similar pattern (Panel D). Finally, Panels E and F show the behavior of private consumption and fixed investment as a proportion of GDP. It can be seen that the boom in private consumption is also quantitatively important even relative to GDP. At its peak (in $T+1$ ), the ratio of private consumption to GDP reaches 74.3 percent (compared to a mean of 68.8 percent). In contrast, Panel $\mathrm{F}$ shows that the ratio of fixed investment to GDP falls in $T$ and surpasses its mean level only in $T+3$ before falling precipitously.

The stabilization time profiles thus point out to the presence of a boomrecession cycle associated with exchange rate-based stabilization. Although it is empirically difficult to distinguish a late recession in both successful and unsuccessful programs from the output collapse that typically accompanies the end of failed programs, Figures 1 and 2 are consistent with the idea that the late recession may take hold before the programs collapse. Notice that real activity (i.e., GDP and consumption in Figure 2, Panels A and B) slows down already at $T+2$ and falls below the sample mean at $T+3$, which could reflect the effects of rising real interest rates (Figure 1, panels $\mathrm{E}$ and $\mathrm{F}$ ) and cumulative real exchange appreciation (Figure 1, Panel B). The fact that this contraction is taking place while the current account deficit continues to grow (Figure 1, Panel C) suggests that the contraction is not related to the real effects of an eventual collapse.

\footnotetext{
${ }^{20}$ Some observations are missing for these two variables. The available sample consisted of 59 observations for the real lending rate and 57 observations for the real deposit rate. Note also the different scales used in Panels E and F.

${ }^{21}$ This idea is supported by the quarterly data presented in Végh (1992) and the evidence in Kaminsky and Leiderman (1996)). These "spikes" are partly related to the sudden drop in inflation when wages and price controls are part of the stabilization package.
} 
Panel regressions By and large, the profiles in stabilization time presented in Figures 1 and 2 are consistent with the stylized facts that have been emphasized in the recent literature. However, while the raw data presented in this manner is clearly suggestive, these plots cannot answer the key questions of whether the boom-recession cycle in GDP, consumption, and investment has been significant in a statistical sense or whether it may have been caused by factors other than the exchange rate-based stabilization programs themselves. While a definite answer to these questions is far from trivial - and remains a challenge for future research - some simple econometric exercises may shed light on these important issues. Specifically - and following Reinhart and Végh $(1994,1995)$ — we ran panel regressions on dummy variables intended to capture the early and late stages of a program, and test whether growth in per capita GDP, consumption, and fixed investment during those periods was significantly different from trend growth. ${ }^{22}$ We also test for the significance of the time pattern of public consumption. ${ }^{23}$ The regressions control for common external shocks, as suggested by Echenique and Forteza (1997). ${ }^{24}$ The sample for the panel regressions remains the same as that used for the stabilization time profiles: four countries (Argentina, Chile, Israel, and Uruguay) with 16 observations each (1978-1993) for a total of 64 observations.

We define the "early" dummy as taking a value of one in the first three years of the programs. ${ }^{25}$ If the program lasted less than three years (as was the case for the Argentine "tablita" and the Austral plan), then the "early" dummy takes a value of one in the first two years of the program. In all cases, the "late" dummy takes a value of one in the two years immediately following the "early" stage. ${ }^{26}$ Notice that the "late" dummy has been defined for all programs, regardless of whether they actually failed or not. While this makes the criterion more stringent (compared to defining the "late" dummy only for

\footnotetext{
${ }^{22}$ See also De Gregorio, Guidotti, and Végh (1998), Gould (1996), and Echenique and Forteza (1997).

${ }^{23}$ As will become clear in Section 5, this evidence is relevant for some theories that have emphasized the effects of fiscal policy in explaining the real effects of exchange rate-based stabilization.

${ }^{24}$ Of course, one would like to control also for the effects of domestic reforms, which have accompanied several (although certainly not all) of these programs. To that effect, one could construct a "liberalization index" — which would take into account trade, financial, and structural reforms - along the lines of work by De Melo, Denizer, and Gelb (1995) for transition economies. This remains an issue for future research.

${ }^{25}$ The year in which the program was implemented is included as part of the "early" dummy if the program started in the first three quarters. Otherwise, the following year is taken as the first year of the "early" dummy.

26 Specifically, the years in which the "early" and "late" dummies take a value of one are the following: Argentine tablita, early $=1$ for 1979 and 1980, late $=1$ for 1981 and 1982; Austral plan, early $=1$ for 1985 and 1986, late $=1$ for 1987 and 1988; Convertibility plan, early = 1 for 1991, 1992, and 1993; Chilean tablita, early $=1$ for 1978, 1979, and 1980, late = 1 for 1981 and 1982; Israel 1985, early $=1$ for 1985,1986 , and 1987 , late $=1$ for 1988 and 1989 ; Uruguayan tablita, early $=1$ for 1979, 1980 and 1981, late $=1$ for 1982 and 1983; Uruguay 1990 , early $=1$ for 1991,1992 , and 1993 .
} 
those programs that fail), it is more in accordance with the idea that the late recession takes place in both successful and unsuccessful programs. As control variables, we chose the Libor rate (adjusted by U.S. inflation), average growth in OECD countries - both of which are intended to capture the world business cycle - and terms of trade. ${ }^{27}$

The summary results of the panel regressions are reported in Table 2. Let us first focus on the first three columns (GDP, private consumption, and durables consumption). The "early" and "late" dummies have the expected signs (positive for "early" and negative for "late") and are significant (at least at the 10 percent level) in all three cases. For example, column (2) indicates that growth in private consumption per capita is 3.33 percent higher (relative to trend growth) during the early stages of the program and 4.60 lower in the late stages. The size of the coefficients also tends to support the idea - suggested by Figure 2 - that the boom-recession cycle is the most pronounced for durable goods and the least pronounced for GDP, with consumption falling somewhere in between. The initial rise in durable goods consumption is more than four times larger than the rise in private consumption, which is in turn almost twice as high as the rise in GDP per capita. Increases in Libor (in real terms) negatively affects all three variables (and are always significant). This result is consistent with the notion that fluctuations in international interest rates also play a key role in generating boom-busts cycles in developing countries (see, for example, Calvo, Leiderman, and Reinhart (1993)). OECD growth matters only for GDP growth, while the effects of terms of trade are never significant.

In sharp contrast, the cycle in fixed investment is not statistically significant (Table 2, column (4)). Changes in real world interest rates (i.e., real Libor) fully explain the cycles in fixed investment. In any event, this should perhaps not come as a big surprise since casual evidence for a majority of programs suggests that the main force behind the expansionary phase is the sharp increase in private consumption. It is also consistent with evidence from Bruno and Easterly (1995) and Easterly (1996), who find that growth following inflation crises is not driven by investment. Finally, column (5) in Table 2 indicates that the initial fall in public consumption is not statistically significant.

We may thus conclude that the econometric evidence is consistent with the notion that exchange rate-based stabilization leads to boom-recession cycles in real GDP, private consumption, and consumption of durable goods, even when account is taken of external factors. The evidence is inconclusive with regard to investment.

Do exchange rate-based stabilizations sow the seeds of their own destruction? A notable aspect of exchange rate-based stabilization programs is

\footnotetext{
${ }^{27}$ All data were obtained from the International Monetary Fund. Both Libor and OECD growth are expressed in percentage terms. The terms of trade index measures the relative price of exports in terms of imports.
} 
that, as noted in Table 1, a vast majority have ended in balance of payments crises. In fact, of all the major programs listed in Table 1, the Argentine 1991 Convertibility plan is so far the only successful plan which has maintained the exchange rate at the level chosen at the inception of the program. ${ }^{28}$ Eight of the twelve plans ended in full-blown crises with large losses of international reserves. Naturally, the stabilization time profiles in Figures 1 and 2 appear to capture this pattern. In $T+4$, the current account sharply reverses course (Figure 1, Panel C), suggesting that a "crisis" has occurred. ${ }^{29}$ This "crisis" time coincides with a resumption of high inflation, a real exchange rate depreciation, and a collapse in GDP, consumption, and investment.

As argued by Reinhart and Végh (1995), the dynamics unleashed by exchange rate-based stabilization plans are likely to be partly responsible for the demise of several programs. Prolonged periods of real exchange rate appreciation and growing current account deficits are seldom sustainable, especially when domestic and external shocks compound the problems. Corrective devaluations do not always work, particularly in a world of increasing financial globalization, as the example of Mexico in December 1994 dramatically showed. These regimes are also prone to financial and speculative attacks which may be unrelated to problems of current account sustainability. The evidence thus suggests that understanding the links between the dynamics of exchange ratebased stabilizations and the eventual collapse of most of these programs should be an integral part of the research agenda (an analysis of these issues is carried out in Section 7).

\subsection{Money-based stabilization: empirical regularities}

Money-based programs in chronic inflation countries have been much less common than programs based on the exchange rate. ${ }^{30}$ Table 3 presents the main features of five major money-based programs undertaken in the last 25 years. ${ }^{31} \mathrm{As}$ the table makes clear, monetary regimes vary across episodes and pure moneybased programs (i.e., a clean floating regime) are rare. ${ }^{32}$ Hence, for the pur-

\footnotetext{
${ }^{28}$ The Israeli 1995 plan was also a successful plan in terms of obtaining a lasting reduction in inflation. However, there were several devaluations along the way and finally an exchange rate band was adopted.

${ }^{29}$ Kaminsky and Reinhart (1995) show that BOP crises are associated with a sharp rise in exports, which should lead to a dramatic improvement in both the trade and current account balances.

${ }^{30}$ As discussed below, there are good reasons to expect the exchange rate to be the preferred anchor in chronic inflation countries.

${ }^{31}$ For case studies, see Harberger (1982), Corbo (1985), Edwards and Cox Edwards (1991), Medeiros (1994), Kiguel and Liviatan (1996), and Favaro (1996).

${ }^{32}$ Note that, by definition, a pure money-based program implies a clean floating. The reverse, however, is not necessarily true: a clean floating might be adopted in conjunction with, say, interest rate or inflation targeting (see, for instance, Masson, Savastano, and Sharma (1997) and Végh (1997)). These monetary regimes, however, have not been observed in any major stabilization effort in high inflation countries.
} 
poses of this paper, the term "money-based" stabilization should be broadly understood as including assorted dirty floating regimes and dual exchange rate systems with a fixed commercial rate (or equivalent systems). The rationale for lumping these regimes together is that in all cases the monetary authority has, to a lesser or greater extent, control over the money supply. This is, of course, in contrast to an exchange rate-based regime (under perfect capital mobility) in which the money supply is fully endogenous. As will be discussed in detail in Section 5, one should expect regimes in which the monetary authority has control over the money supply to deliver similar outcomes to those that would obtain under a pure money-based. Hence, to contrast stylized facts with theory, it makes sense to adopt such a classification.

The following empirical regularities have been identified in money-based programs (see Calvo and Végh (1994b)):

(i) Slow convergence of inflation to the rate of growth of the money supply.

(ii) Real appreciation of the domestic currency.

(iii) No clear-cut response of the trade balance and the current account. If anything, there seems to be a short-run improvement in the external accounts.

(iv) Initial contraction in economic activity. A sharp, though short-lived, contraction in real GDP, consumption, and investment seems to follow the implementation of money-based programs.

(v) Initial increase in domestic real interest rates.

These empirical regularities are less surprising in that they seem to broadly conform with available evidence for industrial countries. To illustrate some of these empirical regularities, we constructed a panel with five countries (Argentina, Brazil, Chile, Dominican Republic, and Peru) with 25 years of annual data (1971-1995), for a total of 125 observations. ${ }^{33} 34$

The stabilization time profiles are illustrated in Figure 3. Panel A shows that the inflation rate falls dramatically in the first year after stabilization but begins to rise again soon afterwards. ${ }^{35}$ Although the inflation rate does remain above the rate of money growth, inflation persistence appears to be much less pronounced that in exchange rate-based programs (recall Figure 1, Panel A). Real GDP growth falls in the year of stabilization from -3.8 to -7.3 percent, but recovers soon after and is above the sample mean in $T+3$ (Panel B). The evidence is thus consistent with a short-lived but sharp contraction in economic

\footnotetext{
${ }^{33}$ Again, data availability dictated the sample size. Since we now focus on a smaller number of variables, the time series available are longer than before. However, the small number of programs and the rather short duration of some of them calls for caution in the interpretation of the evidence.

${ }^{34}$ For these programs, $T$ is 1975 for the Chilean plan and 1990 for the Collor, Bonex, Dominican Republic, and Peruvian plans. To avoid overlapping with other, exchange ratebased plans - and giving priority to the actual plan which was in effect - the Bonex plan is associated with two dummies (1989 and 1990), the Collor plan goes back only until $T-1$, and the Chilean 1975 plan goes forward only until $T+1$.

${ }^{35}$ The fact that inflation actually rises in the year of stabilization $(T)$ is heavily influenced by the Peruvian program.
} 
activity. It should be noted, however, that real GDP growth is already below its mean in the year before the program. The real exchange rate appreciates throughout the program (Panel C), while the current account shows no clear pattern (Panel D). Lack of data prevented us from looking at real interest rates. Quarterly data presented in Calvo and Végh (1994b), however, is consistent with the notion of an initial rise in real interest rates.

\subsection{Recession now versus recession later}

A comparison of the real activity in money-based and exchange rate-based stabilizations raises an important issue. The timing of the recessionary effects of disinflation programs appears to differ across nominal anchors: in money-based plans the contraction occurs early in the program, while in exchange rate-based programs it seems to occur late in the program (compare Figure 2, Panel A with Figure 3, Panel B). This phenomenon has been dubbed the "recessionnow-versus-recession-later" hypothesis.

To test this hypothesis, we carried out two econometric exercises for the rate of growth of real per capita GDP for as large a sample as possible. The sample includes the period 1971-1995 for eight countries (Argentina, Brazil, Chile, Dominican Republic, Israel, Mexico, Peru, and Uruguay) for a total of 200 observations. The sample comprises 14 stabilization plans: 9 exchange ratebased stabilizations (all of those described in Table 1 except for the first three) and the five money-based stabilizations listed in Table 3.

Table 4 shows the results of fixed effects regressions on stabilization dummies, controlling for external factors. ${ }^{36}$ Three regressions are shown: the first two ("individual regressions") attempt to identify the effects of exchange ratebased stabilization time dummies and money-based stabilization time dummies separately (i.e., each regression includes only the time dummies corresponding to a particular anchor). The third ("joint regression") includes all stabilization time dummies simultaneously.

Let us first focus on exchange-rate based stabilization. First, regressions (1) and (3) indicate that growth in the two years before exchange rate-based stabilization is not statistically different from trend growth. ${ }^{37}$ Hence, exchange rate-based stabilizations appear to have been implemented in "normal" times. ${ }^{38}$ Growth in the first two years of stabilization $(T$ and $T+1)$ is significantly above trend growth in the individual regression. In the joint regression, growth is significantly above trend in $T+1$. In both cases, growth is significantly below

\footnotetext{
${ }^{36}$ For the 12 plans analyzed before, $T$ remains the same. For the two new plans in the sample (Cruzado and Mexican plan), $T$ is 1986 for the Cruzado plan and 1988 for the Mexican plan. We do not allow for overlapping.

${ }^{37}$ Of course, since all regressions include fixed effects, trend growth varies across countries.

${ }^{38}$ This casts doubts on the idea that the booms associated with exchange rate-based stabilizations began prior to the implementation of the programs, as has been argued by Kydland and Zaraga (1997).
} 
trend four years after stabilization (i.e., in $T+4$ ). External factors have the expected signs and are always significant.

In money-based stabilizations, growth in the two years before stabilization is significantly below trend growth (regressions (2) and (3)). Money-based stabilizations thus appear to have been implemented in "bad" times. Growth is sharply below trend in the year of stabilization and continues to be significantly below trend in the first year (in both the individual and joint regressions) and second year after stabilization (in the individual regression). External factors have the expected signs and are always significant.

These results are thus consistent with the idea of an early recession in moneybased stabilization, and an early boom followed by a contraction in exchange rate-based stabilization. A caveat to be noticed is the fact that growth was significantly below trend before the stabilization in money-based programs. This raises the possibility that the initial recession might simply be the continuation of that trend. ${ }^{39}$

While the regressions reported in Table 4 are certainly revealing, they may be asking too much of the data. The reason is that we are really interested in the behavior of growth in the "early" and "late" stages of stabilization programs, rather than in specific years (i.e., we are interested in "joint significance"). Hence, as before, we ran panel regressions with early and late dummies, and control variables. ${ }^{40}$ Table 5 shows the same regression estimated by three different methods: OLS, fixed effects, and a 2-step GLS with fixed effects. The results do not vary much across different method of estimations. In all cases, the early and late dummies for exchange rate-based stabilization are significant and so is the early dummy for money-based stabilization. In other words, growth in the early stages of an exchange rate based stabilization is significantly higher than trend growth and significantly below trend growth in the late stages. In money-based stabilizations, growth is significantly below trend growth in the early stages and not significantly different from trend growth in the late stages. Of the control variables, real Libor and OECD growth are always significant. These results are thus consistent with the recession-now-versus-recession-later hypothesis.

\footnotetext{
${ }^{39}$ In addition, Gould (1996) has argued that the state of the economy before stabilization influences the choice of the nominal anchor, with "bad" times inducing policymakers to choose money as the main anchor.

${ }^{40}$ For the seven plans which were already part of the previous sample, the dummies are the same but, since the sample is now longer, the late dummy takes a value of 1 during 1994 and 1995 for both the Convertibility plan and the Uruguayan 1990 plan. For the seven new plans, the years in which "early" and "late" take a value of 1 are the following: Bonex plan; early $=1$ in 1990 (no late dummy); Cruzado plan; early = 1 for 1986, late = 1 for 1987 and 1988; Chile 1975, early $=1$ for 1975 and 1976, late $=1$ for 1977 ; Dominican Republic, early $=1$ for 1990, 1991 and 1992, late $=1$ for 1993 and 1994; Mexico, early = 1 for 1988, 1989, and 1990, late $=1$ for 1991 and 1992; Peru, early $=1$ for 1990, 1991, and 1992, late = 1 for 1993 and 1994.
} 


\subsection{A word of caution}

A final word of caution is in order. Empirical research on the empirical regularities of stabilization in chronic inflation countries is still very much work in progress. In fact, we would argue that too little empirical work - relative to theoretical work - has been done in the area. Needless to say, this type of analysis faces formidable obstacles, including small samples (in particular of money-based programs), the definition of inflation stabilization episodes, the classification of episodes by type of nominal anchor, the quality of the data, and the need to control for other shocks (both domestic and external). Much work remains to be done and the results presented here should be taken as suggestive and pointing out directions to follow, rather than as conclusive evidence.

At a methodological level, we think it is important to distinguish between two alternative approaches. One approach - the one adopted in this section might be dubbed the "episodic" approach. This approach involves selecting the best-known stabilization episodes, which have received a great deal of attention. At the other extreme, we have a "mechanical" approach, where stabilization episodes are defined based on the behavior of inflation. For example, Easterly (1996) defines a stabilization as an episode characterized by a switch from a period of two years or more with an annual rate of inflation above 40 percent to a period of two years or more with an annual rate of inflation below 40 percent.

Both approaches have problems. The "episodic" approach is subjective and will tend to omit lesser-known episodes. ${ }^{41}$ The "mechanical" approach defines a stabilization by its outcome, which is clearly problematic. Conceptually, an inflation stabilization program involves a drastic reduction in the rate of growth of a policy instrument (the exchange rate or the money supply) and not necessarily the attainment of policy objective (a fall in the inflation rate). In fact, both theory and evidence provide numerous examples of stabilizations which involve a rather slow reduction (or even an initial increase) in inflation. Whatever the merits of both approaches, in the second-best world of empirical analyses, there is surely something to be learned from both of them.

Within the episodic approach, Echenique and Forteza (1997) argue that the results reported in Reinhart and Végh $(1994,1995)$ - in particular, the initial boom under exchange rate-based stabilization - are not robust to the inclusion of external factors (they do not look at either private consumption or durable goods consumption). The revised estimates reported above do not support such a claim, except for investment. In any event, controlling for other factors - both domestic and external - is clearly an important endeavor as it would imply that, quantitatively speaking, models of exchange rate-based stabilization should be able to account only for a fraction of the actual booms

\footnotetext{
${ }^{41}$ It should be noted, though, that omitting smaller programs is not necessarily a bad thing. To isolate better the effects of a given phenomenon, it makes sense to select episodes in which the phenomenon in question - relative to many other factors which are difficult to control for - was of overriding importance.
} 
observed. Gould (1996) argues that, after adjusting for initial conditions which make the choice of the nominal anchor endogenous, growth actually improves in either case.

Using the "mechanical approach" described above, Easterly (1996) argues that stabilization from high inflation has been expansionary (in terms of GDP and consumption) regardless of the nominal anchor. In other words, he does not find evidence of money-based stabilization being contractionary. The difference may reflect the very different sample - out of 28 episodes, Easterly (1996) classifies all but 9 as money-based stabilization - and the fact that he considers only successful programs. In accordance with our findings, however, Easterly (1996) also argues that higher investment is absent in the early stages of stabilization. The notion that inflation stabilization may be associated with higher growth also receives support from the transition economies. Using a 25-country sample, Fischer, Sahay, and Végh (1996) conclude that inflation stabilization has been expansionary for the transition economies - regardless of the nominal anchor - but that resorting to a fixed exchange rate has had an additional positive effect on growth.

A more general critique is that of Kydland and Zarazaga (1997) who argue based on a review of the literature on disinflation in chronic inflation countries and an analysis of business cycles in Argentina - that nominal exchange rate shocks do not seem to have had any noticeable real effects, even during exchange rate-based stabilizations. More specifically, they argue that business cycles in Argentina could be explained by real shocks. It is worth stressing, however, that the stabilization literature has certainly not claimed that stabilizations are the main source of business fluctuations in high inflation countries; it has only claimed that stabilization programs have real effects. The latter is, of course, perfectly consistent with the idea that real shocks may be the main source of business cycle fluctuations over long periods of time. ${ }^{42}$ Furthermore, for any given country, major stabilizations are relatively rare events. This small-sample problem has led researchers in this area to work with panels (i.e., cross-country analysis). It is thus doubtful whether time-series, business-cycle analysis for a particular country might be able to pick up the real effects of stabilization. Even if such effects were there, the "recurrent" sources of business cycle fluctuations - whatever they may be, and this literature certainly takes no position on this — would probably dominate.

\footnotetext{
${ }^{42}$ A case in point is Uruguay. Hoffmaister and Végh (1996) find that over the period 19751990 nominal shocks explain only a small fraction of output movements. For the tablita period (1979-1983), however, a historical decomposition suggests that nominal shocks played a central role.
} 


\section{Exchange rate-based stabilization I: inflation inertia and lack of credibility}

Given the main characteristics of chronic inflation processes - decades of high inflation and a rich history of failed stabilization attempts - it is perhaps not surprising that the two main explanations advanced for the stylized facts discussed in Section 3 rely on inflation inertia and lack of credibility.

\subsection{Inflation inertia}

Rodriguez (1982) was the first to point out that, under conditions of high capital mobility, a credible decline in the rate of devaluation may provoke an initial expansion. The main motivation behind his model was the fall in real interest rates observed in the initial stages of the Argentine tablita (see also Fernandez (1985)). In the model, a reduction in the devaluation rate leads, through the interest parity condition, to lower domestic nominal interest rates. If inflationary expectations are sticky (i.e., adaptive expectations à la Cagan), then the real interest rate will fall, stimulating aggregate demand in the short run. The initial expansion, however, will eventually be followed by a contraction, as inflation inertia leads to a sustained real exchange rate appreciation. Rodriguez's (1982) major contribution was thus to show that, even though Phillips-curve type implications will eventually hold, short-run dynamics may push the economy in the opposite direction. Notice, incidentally, that the argument relies on some form of expectational inertia. ${ }^{43}$

The above explanation has prima facie high predictive power, as it reproduces quite well the stylized facts documented in the previous section, including the boom-recession cycle and the U-shaped path of the real exchange rate. It also provides us with a simple model suggesting the possible traps that one might encounter in a stabilization effort. For example, if the process is not well understood, policymakers may reach the conclusion that stabilization has generated a higher sustainable level of output and economic activity. Since expansion is normally accompanied by higher fiscal revenue, policymakers may be induced to slacken their control on government expenditure, enhancing the economy's overheating and further widening the fiscal deficit when recession sets in. Further, as emphasized at the time by Dornbusch (1982) - and more recently by Dornbusch and Werner (1994) - sticky-inflation based models call attention to the problem of "overvaluation" and the public's expectations that a corrective devaluation would have to take place at some point to restore "equilibrium" relative prices.

\footnotetext{
${ }^{43}$ Dornbusch (1982), in contrast, assumes that agents display rational expectations (i.e, are forward-looking), but that the inflation rate is predetermined and thus exhibits a large degree of inertia. While Dornbusch (1982) does not focus on the initial output effects of disinflation, he emphasizes the eventual recession brought about by the cumulative real appreciation of the domestic currency.
} 
Rodriguez's (1982) model postulates reduced-form aggregate demand functions which depend on the real interest rate and the real exchange rate. In particular, the model assumes that a higher real interest rate unambiguously lowers aggregate demand. These appear to be highly plausible assumptions. However, Calvo and Végh (1994a) show that such assumptions are rather strong and are not necessarily supported by models consistent with optimizing behavior. This can be illustrated by a simple example.

Consider a small open economy perfectly integrated with the rest of the world in goods and capital markets. The representative household's instantaneous utility depends (separably) on consumption of tradables, $c^{T}$, non-tradables (or home goods), $c^{N}$, and real monetary balances in terms of tradables, $m .^{44}$ Thus, lifetime utility as of time 0 can be written as:

$$
\int_{0}^{\infty}\left[v\left(c_{t}^{T}\right)+u\left(c_{t}^{N}\right)+z\left(m_{t}\right)\right] \exp (-\beta t) d t
$$

where $\beta(>0)$ is the rate of time preference, and $v(),. u($.$) , and z($.$) are strictly$ increasing and strictly concave functions.

The individual has a constant endowment flow of tradable goods, $y^{T}$, while output of nontradables, $y_{t}^{N}$, is demand-determined (i.e., in equilibrium, $y_{t}^{N}=c_{t}^{N}$ for all $t$ ). The law of one price holds for the tradable good. The (constant) world real interest rate is denoted by $r$. (It will be assumed that there is no foreign inflation, so that $r$ is also the world nominal interest rate.) Therefore, the individual's lifetime constraint is given by:

$$
b_{0}+m_{0}+\int_{0}^{\infty}\left(y^{T}+\frac{y_{t}^{N}}{e_{t}}+\tau_{t}\right) \exp (-r t) d t=\int_{0}^{\infty}\left(c_{t}^{T}+\frac{c_{t}^{N}}{e_{t}}+i_{t} m_{t}\right) \exp (-r t) d t
$$

where $b_{0}$ denotes the individual's initial stock of net foreign assets, $e_{t}$ denotes the real exchange rate (i.e., the relative price of tradable goods in terms of nontradable goods), $i_{t}$ is the nominal interest rate, and $\tau$ are government lump-sum transfers. Given perfect capital mobility, the interest parity condition $i_{t}=r+\varepsilon_{t}$ holds, where $\varepsilon_{t}$ is the rate of devaluation.

To abstract from fiscal issues, we assume that the government returns back to the consumer all of its revenues. Hence, the government's lifetime budget constraint indicates that the present value of transfers must equal the initial stock of government-held foreign assets (i.e., international reserves), denoted by $R_{0}$, and revenues from money creation:

$$
\int_{0}^{\infty} \tau_{t} \exp (-r t) d t=R_{0}+\int_{0}^{\infty}\left(\dot{m}_{t}+\varepsilon_{t} m_{t}\right) \exp (-r t) d t
$$

\footnotetext{
${ }^{44}$ As will become clear below, the other assumptions in the present example make our key results invariant with respect to the price deflator in the definition of real money balances.
} 
Combining (2) and (3), taking into account non-tradable goods market equilibrium, the interest parity condition, and the transversality condition $\lim _{t \rightarrow 0} m_{t} \exp (-r t)=$ 0 , yields the economy's resource constraint

$$
k_{0}+\frac{y^{T}}{r}=\int_{0}^{\infty} c_{t}^{T} \exp (-r t) d t
$$

where $k(\equiv b+R)$ is the economy's net stock of foreign assets. Equation (4) thus constrains this small economy's lifetime consumption of tradable goods to be equal to tradable goods wealth.

Maximization of lifetime utility (1) with respect to the budget constraint (2) yields the following first-order conditions: ${ }^{45}$

$$
\begin{aligned}
v^{\prime}\left(c_{t}^{T}\right) & =\lambda, \\
u^{\prime}\left(c_{t}^{N}\right) & =\frac{\lambda}{e_{t}}, \\
z^{\prime}\left(m_{t}\right) & =\lambda i_{t},
\end{aligned}
$$

where $\lambda$ is the time-invariant Lagrange multiplier. Equations (5) and (6) are the familiar conditions whereby, at an optimum, the household equates the marginal utility of consumption to the shadow value of wealth, $\lambda$, times the relative price of the good (unity in the case of tradables and 1/e in the case of non-tradables). Similarly, at an optimum, the marginal utility of real money balances is set equal to the shadow value of wealth times the opportunity cost of holding real money balances, $i$ (equation (7)).

Equation (5) indicates that optimal consumption of tradable goods is constant along a perfect foresight path. From (4), it then follows that $c_{t}^{T}=r k_{0}+y^{T}$, a constant, for all $t \geq 0$. Further, notice that unanticipated changes in the devaluation rate will not affect consumption of tradable goods. Consequently, from (5), the Lagrange multiplier, $\lambda$, is invariant with respect to (unanticipated) changes in the rate of devaluation. ${ }^{46}$ This feature will greatly simplify the ensuing analysis.

Backward-looking indexation is introduced along the lines of Calvo and Végh (1994a). The home goods sector operates under sticky prices (i.e., the nominal price of home goods, $P^{N}$, is a predetermined variable). Let the rate of inflation (of non-tradables) be indicated by $\pi$. We assume that

$$
\pi_{t}=\omega_{t}+\theta\left(c_{t}^{N}-\bar{y}^{N}\right), \quad \theta>0,
$$

where $\bar{y}_{t}^{N}$ stands for full-employment output of non-tradables, and $\omega$ is a predetermined variable which satisfies:

\footnotetext{
${ }^{45}$ As usual, we assume that $\beta=r$ to eliminate inessential dynamics.

${ }^{46}$ Of course, the multiplier is always invariant to anticipated changes.
} 


$$
\dot{\omega}_{t}=\gamma\left(\pi_{t}-\omega_{t}\right), \quad \gamma>0
$$

The variable $\omega$ can be interpreted as the rate of growth of nominal wages. Hence, equation (8) says that inflation of home goods is equal to the rate of growth of nominal wages plus excess aggregate demand. ${ }^{47}$ In turn, equation (9) indicates that wage inflation increases (decreases) as price inflation (in terms of nontradables) exceeds (falls short of) wage inflation. This assumption is meant to capture backward-looking wage indexation mechanisms, whereby the rate of growth of nominal wages is adjusted whenever the inflation rate exceeds the current level of wage growth.

To illustrate the implications of this set-up, integrate backwards (9) and substitute the resulting expression for $\omega_{t}$ into (8) to obtain:

$$
\pi_{t}=\int_{-\infty}^{t} \pi_{s} \exp [-\gamma(t-s)] d s+\theta\left(c_{t}^{N}-\bar{y}^{N}\right)
$$

Equation (10) shows that current inflation depends on a weighted average of past inflation rates - with inflation rates in the recent past receiving the greatest weight - and current excess aggregate demand, which is what the notion of "inflation inertia" is usually taken to mean (see, for instance, Dornbusch and Simonsen (1987)).

We will now study the implications of a once-and-for-all reduction in the rate of devaluation, which is the central exercise in Rodriguez (1982). Given the invariance of the Lagrange multiplier with respect to changes in $\varepsilon_{t}$, it follows from first-order condition (6) that we can safely write $c_{t}^{N}$ as an increasing function of the real exchange rate, $e_{t}$; that is, $c_{t}^{N}=\phi\left(e_{t}\right)$, with $\phi^{\prime}\left(e_{t}\right)>0$. Hence, by equations (8) and (9), we have

$$
\dot{\omega}_{t}=\gamma \theta\left[\phi\left(e_{t}\right)-\bar{y}^{N}\right] .
$$

Furthermore, by definition, $e_{t} \equiv E_{t} P^{T *} / P_{t}^{N}$, where $E_{t}$ is the nominal exchange rate (in units of domestic currency per unit of foreign currency, $P^{T *}$ is the (constant) foreign-currency price of the tradable good and $P_{t}^{N}$ is the price of home goods. ${ }^{48}$ Using this definition and equation (8), it follows that

$$
\frac{\dot{e}_{t}}{e_{t}}=\varepsilon_{t}-\omega_{t}-\theta\left[\phi\left(e_{t}\right)-\bar{y}^{N}\right] .
$$

Equations (11) and (12) constitute a system of differential equations in $\omega_{t}$ and $e_{t}$, which can be shown to be locally stable. ${ }^{49}$ Since both $\omega_{t}$ and $e_{t}$ are

\footnotetext{
${ }^{47}$ Note that, in this specification, $\pi$ is not a predetermined variable (i.e., it could jump on impact if consumption of home goods does so).

${ }^{48}$ Note that the real exchange rate is a predetermined variable because $E$ is a policy variable and $P^{N}$ is a predetermined variable.

${ }^{49}$ The trace of the matrix associated with the linear approximation around the steady-state is $-e_{s s} \theta \phi^{\prime}\left(e_{s s}\right)<0$ (where a subscript "ss" denotes steady-state values) and the determinant
} 
predetermined variables, this ensures that under perfect foresight - and for a given set of parameters - all equilibrium paths converge to the steady-state.

Suppose that initially (i.e., for $t<0$ ), the devaluation rate is expected to remain constant at the value $\varepsilon^{H}$. Hence, in the initial steady-state (point $\mathrm{A}$ in Figure 4$), \pi_{s s}=\varepsilon^{H}$ and $\phi\left(e_{s s}\right)=\bar{y}^{N}$. At time 0 , policymakers announce an unanticipated and permanent reduction in the devaluation rate from $\varepsilon^{H}$ to $\varepsilon^{L}$. The new steady-state is denoted by point $\mathrm{B}$, where inflation of home goods is $\varepsilon^{L}$, while the real exchange rate remains unchanged. The dynamics of the adjustment to the new steady-state are illustrated by the arrowed path in Figure 4 .

The time path of the main variables is illustrated in Figure 5. Nominal wage growth falls monotonically over time (Panel B). The real exchange rate declines (appreciates) in the early stages of the program, and then returns to its initial steady-state value (Panel C). Given that consumption of tradables remains constant, consumption of nontradables (Panel D) falls in the early stages (as its relative price, $1 / e$, increases) and increases later on. Hence, during the initial stages of the stabilization program, consumption of home goods (and thus output of home goods) falls - i.e., it does not rise in line with the stylized facts. At some point in time (denoted by $t_{1}$ in Figure 5 ), inflation of home goods must fall below its long-run equilibrium value (Panel E) in order for the real exchange rate to return to its unchanged steady-state value.

It is this protracted period of deflation needed to restore equilibrium relative prices which underlies the call for a step devaluation at some point during the adjustment program (see, for instance, Dornbusch and Werner (1994)). Indeed, in this model, a devaluation at time $t_{1}$ in Figure 5 (which corresponds to point $\mathrm{C}$ in Figure 4) would immediately take the economy to its new steady-state, provided that workers also agreed to reduce the rate of nominal wage growth, $\omega$, to $\varepsilon^{L}$.

It should be noticed that consumption of non-tradables falls in the early stages of the program in spite of the fact that the domestic real interest rate, $r^{d}(\equiv i-\pi)$, decreases on impact (Figure 5, Panel $\mathrm{F}$ ). The reason is that, in utility-maximization models, the real interest rate determines the slope of the consumption path but not the level of consumption. Hence, the initial fall in $r^{d}$ implies that, as long as $r^{d}<r$, consumption of non-tradable goods will follow a declining path.

Calvo and Végh (1994a) extend this analysis to the case in which instantaneous utility is represented by a constant-elasticity-of-substitution utility function. They show that the results obtained in the context of Dornbusch-Rodriguez models hold true only if the intertemporal elasticity of substitution exceeds the elasticity of substitution between tradables and nontradables. In that case, consumption of both tradable and non-tradables goods increases on impact, which

is $\gamma e_{s s} \theta \phi^{\prime}\left(e_{s s}\right)>0$, which implies that both roots have negative real parts. For expositional simplicity, roots will be assumed to be real 
implies that the current account goes into deficit. The relative magnitude of these parameters is, of course, an empirical issue. Estimates provided by Ostry and Reinhart (1992), however, cast some doubts on the relevance of backwardlooking models since they show that, for a number of developing countries, the intertemporal elasticity of substitution is typically smaller than that between tradables and nontradables. ${ }^{50}$

An important feature of Calvo and Végh's (1994a) formulation is that the stabilization does not bring about a wealth effect, in the sense that wealth in terms of tradable goods remains unchanged. This appears as the natural assumption to make when the purpose of the exercise is to isolate the effects of inflation inertia on the outcome of an exchange rate-based stabilization. However, in a more general model with capital accumulation and endogenous labor supply, the wealth effect associated with a permanent reduction in the rate of devaluation will cause an increase in consumption of tradable goods and, given that the real exchange rate cannot change on impact, a corresponding increase in consumption of non-tradable goods (see Rebelo and Végh (1995), Figure 11). Hence, wealth effects associated with supply-side effects (analyzed in more detail below) could help explain the initial boom under backward-looking indexation even under the more plausible parameter configuration in which the intertemporal elasticity of substitution is smaller than the elasticity of substitution between tradables and non-tradables goods.

\subsection{Lack of credibility}

A common characteristic of stabilization plans is imperfect credibility. As pointed out in Section 2, there are fundamental reasons for stabilization programs to be less than fully credible. Since stabilization is costly from a political point of view, why would anybody expect that, as a general rule, stabilization programs have no chance to fail? Implementing a program that succeeds in all states of nature is unlikely to be optimal from the policymaker's point of view.

Suppose, for the sake of concreteness, that authorities announce a stabilization plan in which the exchange rate is set at a lower and constant level forever, but the private sector believes that the program may eventually be abandoned. To keep matters simple, let us further assume that everybody believes that the program will be abandoned at time $T>0$ (where time 0 represents "today"), and the rate of devaluation will, once again, become high after time $T$ (see Figure 6, Panel A). Assuming perfect capital mobility, the latter implies that the nominal interest rate will be low from time 0 to $T$, and expected to be high

\footnotetext{
${ }^{50}$ The more common criticism of Rodriguez (1982) is the assumption of adaptive expectations - an assumption that has fallen out of favor among the profession. This criticism is, however, misplaced since Rodriguez's (1982) results still hold under rational expectations, as shown in Calvo and Végh (1994a). In other words, the key assumption in Rodriguez (1982) is not adaptive expectations but rather that aggregate demand depends negatively on the real interest rate (provided, of course, that there is some other source of inflation inertia).
} 
afterwards. ${ }^{51}$ Will this have real effects?

The answer is negative in the money-in-the-utility-function framework used in subsection 4.1 to illustrate the effects of backward-looking indexation. In that model, the nominal interest rate does not affect any goods-markets equilibrium condition. Thus, the real economy (under flexible prices) would be undisturbed by the monetary experiment. However, separability between money and goods in the utility function is a very special, and probably unrealistic, assumption. It implies that the marginal utility of money is independent of expenditure, a condition that is likely not to hold if money is used for transactions. ${ }^{52}$

Following Calvo (1986), let us assume that transactions require holding cash in advance. ${ }^{53}$ Thus, using the same notation as before, we postulate: ${ }^{54}$

$$
m_{t}=\alpha\left(c_{t}^{T}+\frac{c_{t}^{N}}{e_{t}}\right), \quad \alpha>0
$$

The consumer's preferences are now given by:

$$
\int_{0}^{\infty}\left[v\left(c_{t}^{T}\right)+u\left(c_{t}^{N}\right)\right] \exp (-\beta t) d t
$$

After substituting (13) into (2), we obtain a lifetime constraint that involves only $c_{t}^{N}$ and $c_{t}^{T}$ as choice variables (and whose corresponding Lagrange multiplier will be denoted by $\tilde{\lambda}$ ). Maximization of (14) subject to this lifetime budget constraint yields:

$$
\begin{aligned}
v^{\prime}\left(c_{t}^{T}\right) & =\tilde{\lambda}\left(1+\alpha i_{t}\right), \\
u^{\prime}\left(c_{t}^{N}\right) & =\frac{\tilde{\lambda}}{e_{t}}\left(1+\alpha i_{t}\right) .
\end{aligned}
$$

The term involving the nominal interest rate $i, 1+\alpha i$, has a straightforward interpretation. Under the present assumptions, individuals must hold a stock of cash before making purchases. This means that, in addition to the market price of the good (unity for the tradable good and $1 / e$ for the non-tradable good), the cost of the good is augmented by the opportunity cost of holding the needed

\footnotetext{
${ }^{51}$ Note that, formally, lack of credibility is modeled as a temporary stabilization, which explains the label "temporariness hypothesis," often used in the literature.

${ }^{52}$ It should be noted, however, that the basic results of subsection 4.1 hold true even under non-separability of real money balances (say, under the cash-in-advance specification explored below). Since we studied a permanent reduction in the devaluation rate, it would still be the case that consumption of traded goods remains unchanged under a cash-in-advance specification.

${ }^{53}$ We adopt a cash-in-advance, flexible-prices specification to illustrate the essential mechanisms behind lack-of-credibility in the simplest possible model. The same results would obtain under a money-in-the-utility-function specification provided that the cross-derivative between consumption and real money balances is positive (see Calvo (1986)).

${ }^{54}$ For the derivation of the cash-in-advance constraint in continuous time, see Feenstra (1985).
} 
real money balances, given by $\alpha i$. The effective price of consumption is thus $1+\alpha i$ for tradable goods and $(1+\alpha i) / e$ for non-tradables.

For the present discussion, we can simplify the supply side even further and assume that the domestic supply of tradables and nontradables is fixed at $y^{T}$ and $y^{N}$, respectively. Then, by (15), (16), and home goods-market equilibrium (i.e., $\left.c_{t}^{N}=y^{N}\right)$, it follows that

$$
e_{t}=\frac{v^{\prime}\left(c_{t}^{T}\right)}{u^{\prime}\left(y^{N}\right)}
$$

Hence, in equilibrium, the real exchange rate and consumption of tradable goods move in opposite direction. In other words, any shock that causes consumption of tradable goods to increase will also entail a real exchange rate appreciation (i.e., a fall in $e_{t}$ ).

Consider now the effects of a non-credible stabilization program as described above (Figure 6). Since the representative individual expects a policy reversal at time $T$, it implies that he/she will expect the nominal interest rate $i$ to be low from 0 and $T$, and high afterwards. Thus, by equation (15), consumption of tradables will be high between 0 and $T$ and low afterwards. Given that the present discounted value of $c^{T}$ must satisfy the resource constraint (4), the path of consumption of tradable goods must look like that in Figure 6, Panel B. Intuitively, since the consumer expects the good to be cheaper between 0 and $T$ than after $T$, he/she substitutes consumption away from the future (when consumption is expected to be relatively expensive) and towards the present (when consumption is cheaper). The current account deteriorates on impact and worsens throughout the stabilization as debt service increases (or net interest income falls), as illustrated in Figure 6, Panel C. Unlike tradable goods - whose supply is rendered perfectly elastic by the rest of the world - non-tradable goods are in fixed supply. Hence, the excess demand for non-tradable goods between 0 and $T$ will have to be met by a rise in their relative price (i.e., a fall in $e_{t}$ ), as follows from (17) (Panel Figure 6, Panel D).

At the beginning of the program there is thus a boom in the consumption of tradables and a real appreciation, which is eventually followed by a contraction in the consumption of tradables and a real depreciation. ${ }^{55}$ Thus, this model displays two basic stylized facts that have accompanied exchange-rate based stabilization programs, as argued in Section 3. It is also noteworthy that, unlike the previous explanation based on inflation inertia, this model does not rely on an initial fall in real interest rates. Hence, it could also explain the stylized facts even in programs in which only nominal, but not necessarily real, interest rates fall in the early stages. ${ }^{56}$

\footnotetext{
${ }^{55}$ The real effects at time $T$ will occur regardless of whether the program is actually abandoned or not, provided that if it is not abandoned, the program becomes fully credible at $T$. Formally, it can be shown that permanent changes in the rate of devaluation are everywhere superneutral.

${ }^{56} \mathrm{An}$ interesting extension of the basic model is to assume that $T$ is a stochastic variable,
} 
By introducing price stickiness into this model, Calvo and Végh (1993) have shown that a temporary stabilization may account for other key stylized facts discussed in Section 3: (i) the joint occurrence of an output boom and a real exchange rate appreciation in the early stages of the program; (ii) a recession in the non-tradable goods sector (i.e., a fall in output below its full-employment level) which may take place before the program is discontinued; and (iii) inflation remaining above the rate of devaluation until the time at which the program is expected to be discontinued. ${ }^{57}$ Hence, in this case, inflation persistence is not due to some ad-hoc backward-looking mechanism but rather to lack of policy credibility. The model thus suggests that the fact that inflation remains high is not prima-facie evidence of stickiness in the rate of inflation. ${ }^{58}$

It should be noted that in the exercise illustrated in Figure 6, lack of credibility is socially costly, because a central planner would set consumption of tradables constant and equal to $r k_{0}+y^{T}$, instead of setting a path displaying the boom-bust pattern displayed in Figure 6, Panel B. Hence, even though consumption rises as a non-credible exchange-rate-based stabilization program is put into effect, the stabilization still proves to be a socially costly process. This conclusion, though, depends critically on the fact that, in cash-in-advance models (with no labor-leisure choice), there are no benefits associated with a reduction in inflation (i.e., the real equilibrium is independent of permanent changes in the inflation rate). In contrast, in transaction-costs models, lower inflation is beneficial because it frees time for productive activities. In such a set-up, a temporary stabilization may be welfare-improving if the benefits (in terms of freed resources) of temporarily-lower inflation more than offset the intertemporal distortion caused by a non-constant path of the nominal interest rate (see Reinhart and Végh (1995a)). Hence, policymakers may still find it optimal to implement stabilizations plans that may not be fully credible, provided they command a "reasonable" level of credibility.

Lack of credibility thus provides a rich framework to explain the main styl-

as in Calvo and Drazen (1997), which leads to richer dynamic patterns for consumption. In particular, they show that in the absence of state-contingent assets, consumption rises on impact and continues to increase as long as the policy is in effect. See also Lahiri (1996a, 1996b), Mendoza and Uribe (1997), and Venegas-Martinez (1997). Further variations of the basic model include Obtsfeld (1985), who studies a gradual, tablita-type stabilization, and Talvi (1996), who analyzes the endogenous impact of higher consumption on fiscal revenues.

${ }^{57}$ In this model, the domestic real interest rate falls on impact. As discussed in Section 3, however, real interest rates have typically increased on impact in heterodox programs. This often reflects tight credit policy in the early stages of the programs. For instance, the Israeli 1985 plan had an explicit target for bank credit, which was to be achieved by a combination of higher reserves requirements and a higher discount rate (Barkai (1990)). The idea is for money to act as an additional nominal anchor in the early stages of the plan. This could be modeled by assuming that the stock of money is predetermined at each point in time due to the presence of capital controls (Calvo and Végh (1993)). Agenor (1994) incorporates fiscal considerations into a model with imperfect capital mobility to address this issue.

${ }^{58}$ Within this framework, Ghezzi (1996) has analyzed the important - but still little understood - question of when to abandon an initial peg and switch to a more flexible exchange rate regime (a common occurence in practice, as argued in Section 3). 
ized facts observed in exchange rate-based disinflations. The most common criticism of this type of model is that it relies critically on intertemporal consumption substitution, which is believed to be small or not significantly different from zero. Reinhart and Végh (1995a) have examined the empirical relevance of the "temporariness" hypothesis, by estimating the intertemporal elasticity of substitution for five chronic inflation countries (Argentina, Brazil, Israel, Mexico, and Uruguay). Using these estimates, they compute the predicted increases in consumption for seven major stabilization plans (the three Southern Cone tablitas, the Argentine 1985 Austral plan, the Brazilian 1986 Cruzado plan, the Israeli 1985 plan, and the Mexican 1987 plan) and compare them to the actual increases. They conclude that, in spite of low (but statistically significant) elasticities of substitution - ranging from 0.19 to 0.53 - this mechanism has a good explanatory power in four out of the seven episodes. It is the case, however, that nominal interest must fall substantially for this mechanism to be quantitatively important, which explains why the model appears to perform poorly for the Southern-Cone tablitas. ${ }^{59}$

If anything, however, the estimates provided by Reinhart and Végh (1995a) should probably be viewed as a lower bound for the importance of the "temporariness" hypothesis. The reason is that the model does not incorporate durable goods which, as argued in Section 3, appear to play a central role in the initial consumption boom. The presence of durable goods is likely to increase the quantitative importance of intertemporal substitution for two reasons. First, the introduction of durable goods might yield higher intertemporal elasticities of substitution, as found by Fauvel and Sampson (1991) for Canada. Second, in addition to intertemporal consumption substitution, durable goods introduce the possibility of intertemporal price substitution because goods can be stored (Calvo (1988)).

\section{Exchange-rate based stabilization II: durable goods, credit, and wealth effects}

The explanations discussed in the previous section rely on what we view as two key characteristics of chronic inflation processes: inflation persistence and lack of credibility. There are other elements, however, which may have played an important role in stabilization plans in chronic inflation countries. We first discuss the role of durable goods consumption and credit market segmentation. We then turn to a discussion of wealth effects, which may result from either supply-side responses or fiscal policy.

\footnotetext{
${ }^{59}$ It is worth pointing out that trying to explain all of the observed consumption booms may be misleading, as other factors - such as lower international interest rates - may account for part of the boom.
} 


\subsection{Durable goods}

As shown in Section 3, the consumption boom that characterizes exchange ratebased stabilization programs has been particularly evident in the behavior of durable goods. This pattern of durable goods consumption has inspired an alternative explanation for the boom-bust cycle put forward by De Gregorio, Guidotti, and Végh (1998) (henceforth DGV). This hypothesis, which is unrelated to inflation inertia or lack of credibility, is capable of generating a boombust cycle even in a fully-credible program.

Suppose that there are transactions costs associated with the purchase of durable goods. This implies that individuals buy durable goods only at discrete intervals of time. In the aggregate, however, sales of durable goods are smooth over time since different individuals purchase durable goods at different points in time. ${ }^{60}$ This is illustrated in Figure 7. There are four consumers (whose purchases of durable goods are represented by the squares labeled A, B, C, and D) who buy durable goods at different points in time (i.e., every four periods). Hence, before time 0, aggregate sales of durables goods are constant.

Consider now a stabilization plan implemented at time 0. Furthermore, suppose that there is a wealth effect associated with the stabilization (more on this below). Then, some consumers will be inclined to anticipate their purchase of durable goods and perhaps buy a more expensive durable good. In other words, next year's new Honda becomes today's new Mercedes. In terms of Figure 7, consumers $\mathrm{B}$ and $\mathrm{C}$ (who, in the absence of the stabilization plan, would have replaced the durable good at time $t=1$ and $t=2$, respectively) decide to buy the durable good at $t=0$ (the picture abstracts from "size" effects). Consumer $\mathrm{D}$, who just replaced his/her durable good at $t=-1$, also anticipates his/her purchase but to $t=1$. In this simple example, there are no purchases of durables at $t=3$ and $t=4$, due to the initial bunching of purchases at $t=0$ and $t=1$. The initial boom (in period 0 ) is thus followed by a bust in periods 2 and 3 . Hence, this model is capable of accounting for the boom-bust cycle without resorting to inflation inertia or lack of credibility. ${ }^{61}$

A key difference between this story and the previous two (inflation inertia and lack of credibility) lies in the policy implications. Under the temporariness (i.e., lack of credibility) hypothesis, the boom-bust cycle is a clear indication that policymakers have not done enough at the outset to convince the public that the program is sustainable over time. Hence, one would expect policymakers to worry when the initial boom emerges, and perhaps consider measures aimed at

\footnotetext{
${ }^{60}$ In the absence of transaction costs - and given that durable goods depreciate over time - consumers would find it optimal to buy in each period the amount of durable goods that they are planning to consume during that period. Buying a greater amount would imply a loss for next period. Technically, it is assumed that consumers follow $(\mathrm{S}, \mathrm{s})$ rules and choose optimally the trigger points.

${ }^{61}$ Furthemore, if idiosyncratic shocks were introduced into the picture, aggregate purchases of durable goods would eventually return to the pattern prevailing before the plan was implemented.
} 
enhancing the program's credibility. In the same vein, inflation inertia (due to backward-looking indexation) also reflects some unresolved institutional problems which clearly endanger the whole stabilization strategy (as in the Chilean tablita; see Edwards and Cox Edwards (1991)). In such a case, policymakers should try to cut the link between current and past inflation. In sharp contrast, the boom-bust cycle emphasized by DGV (1998) is a direct consequence of the policymakers' ability to implement a fully-credible stabilization plan. The eventual consumption bust is the natural counterpart of the initial "bunching" in consumption, and any policy measures aimed at counteracting it are likely to be suboptimal.

In DGV (1998), the wealth effect formally comes about because the fall in inflation leads to an increase in real money balances which, in turn, frees time spent in transacting to be used in productive activities. This channel is consistent with models (to be examined below) that emphasize supply-side effects of disinflation. The durable-goods consumption cycle described above, however, is independent of how this wealth effect comes about, and would also hold under alternative scenarios which may not involve, strictly speaking, a wealth effect. One such scenario, which we find particularly attractive and examine next, relies on the existence of credit market constraints.

\subsection{Credit market segmentation}

A boom in domestic absorption, which lies at the heart of the initial expansion and real exchange rate appreciation, can only happen if domestic residents are able to borrow from the rest of the world, or lower their holdings of foreign assets (i.e., capital repatriation). The examples examined so far rely on the fiction of a representative individual. There is thus no room for some individuals to borrow abroad and lend at home, while the rest engage in higher domestic borrowing and spending. Developing countries, however, are typically characterized by large segments of the population which do not have direct access to international borrowing and lending. ${ }^{62}$

A relevant scenario with two types of borrowers is one in which type I, say, has perfect access to international capital markets (like in the above examples), and type II can only borrow at home. In addition, type-II individuals borrow in terms of domestic currency and are constrained to loan contracts displaying a constant nominal interest rate or a constant string of nominal installments. These are, admittedly, very special loans but their simplicity may make them cost-effective for medium-ticket durable consumption loans (i.e., television sets).

In this setup, lower inflation/devaluation may induce a consumption boom, even though the program is fully credible. To see this, consider the realistic case in which borrowers pay back their debts in the form of a constant stream

\footnotetext{
${ }^{62}$ See, for instance, Rojas-Suarez and Weisbrod (1995) who show that domestic bank lending is more prevalent in developing than in developed countries.
} 
of nominal installments. Thus, abstracting from credibility and country-risk problems, and assuming that the real (and nominal) international interest rate is $r$, the domestic nominal interest rate, $i$, will be equal to $r+\varepsilon$. We now assume, for simplicity, that loans are given in perpetuity and that the rate of devaluation is expected to be constant. Hence, an individual who borrows a sum $S$ will have to pay an installment equal to $i S$ in perpetuity. Furthermore, normalizing the present price level, $P_{0}$, to unity, and assuming a constant real exchange rate, we get that domestic inflation will also be equal to $\varepsilon$. The real value of the installments is then given by

$$
\frac{(r+\varepsilon) S}{P_{t}}=\frac{(r+\varepsilon) S}{\exp (\varepsilon t)}, \quad t \geq 0,
$$

where $t=0$ is the time at which the loan is granted. Consequently, the higher is the rate of devaluation, the higher will be the nominal interest rate, $i$, and thus the higher will be the real value of the first few installments. When inflation is high, the real value of the first few installments could be exorbitantly large, deterring credit.

Figure 8 illustrates the effects of a lower inflation rate on the time path of real payments. In the three cases depicted, $r=0.03$. The rate of devaluation takes three different values: $0,0.17$, and 0.47 , so that $i=0.03,0.20$, and 0.50 , respectively. The figure shows how the rate of inflation/devaluation can dramatically affect the time path of real payments. When $i=0.03$, the path of real installments is flat. When $i=0.50$, real installments in the early periods are the highest. Naturally, changes in the inflation (devaluation) rate do not affect the present discounted value of real installments as of time 0 , which equals $S$. Formally, note that

$$
\int_{0}^{\infty} \frac{i S}{\exp (\varepsilon t)} \exp (-r t) d t=S,
$$

so that changes in $\varepsilon$ affect real payments, but not the value of the integral.

Therefore, a substantially lower rate of devaluation may make credit affordable to type-II individuals. The ensuing consumption boom puts upward pressure on retailing - a highly labor-intensive activity — contributing to further real appreciation of the currency. Notice that the boom so generated may be socially desirable because it signifies an improvement in the credit market. Furthermore, if the newly available credit is directed towards durable goods consumption - as is likely to be the case - purchases will fall later on during the program along the lines of DGV (1998), contributing to an eventual downturn in economic activity. Hence, this type of scenario should be quite successful in explaining several stylized facts.

Existence of credit segmentation may also help to rationalize these phenomena even in the case in which there are no loan-contract constraints on type-II individuals. This would be so, for example, if type-I individuals take the implementation of the stabilization plan as a signal that the government is starting to 
"get its house in order." High inflation reflects the existence of tensions among policy objectives. Hence, until a stabilization program is implemented, foreign investors and type-I individuals may feel that placing their funds in the country in question exposes them to some kind of surprise taxation (particularly, if the funds are placed in highly-visible domestic banks). ${ }^{63}$ Thus, by assuaging the investors' fears, a stabilization program - which enjoys some but not necessarily complete credibility - may bring about a lowering of interest rates for type-II individuals, stimulating expenditure. ${ }^{64}$

\subsection{Supply-side effects}

All the explanations examined so far are based on demand-side considerations. This is perhaps only natural considering that much of the literature was inspired by the Southern-Cone tablitas of the late 1970s where, to most casual observers, the most striking fact was the increase in consumers' demand for goods (particularly durable goods). In more recent programs - such as Mexico 1987 and Argentina's 1991 Convertibility plan - it has been argued that monetary stabilization may have played an important role in unleashing supplyside responses in labor and investment (see Rebelo (1993), Roldos $(1995,1997)$, Uribe (1997a), and Lahiri (1996a, 1996b)). ${ }^{65}$ While the evidence presented in Section 3 casts some doubts on the general empirical relevance of the investment channel, supply-side effects may well have contributed to the initial boom in some instances and thus deserve attention. ${ }^{66}$

The role of capital accumulation in generating a steady rise in the relative price of non-tradables (i.e., a real exchange rate appreciation) is emphasized by Rebelo (1993) in the Portuguese context. If reforms increase the economy's steady-state capital stock, then as the capital-labor ratio rises, the price of the capital-intensive good (the tradable good) falls. Roldos (1995) and Uribe (1997a) present models in which domestic money is needed to buy (or install) capital goods, in the spirit of Stockman (1981). As a result, inflation drives a wedge between the real return of foreign assets and that of domestic assets, which implies that the domestic capital stock is a decreasing function of the inflation rate. A reduction in the inflation rate thus leads to a higher desired capital stock, and hence to an expansion in aggregate demand and investment.

\footnotetext{
${ }^{63}$ Domestic banks play a key role in making funds available to type-II individuals, because their comparative advantage stems from their better knowledge of the local market.

${ }^{64}$ Again, if some of the higher consumption falls on durable goods, a boom-bust pattern may emerge along the lines of DGV (1998). Moreover, there is, in principle, no reason in this example for social welfare to be negatively affected by the rise in consumption.

${ }^{65}$ It should be noted that these programs were also accompanied by important structural reforms. As stressed in Section 3, it would be important - though far from trivial - to disentangle the effects of these reforms from those of the exchange rate-based stabilization per se. Clearly, we would not want to ascribe to monetary stabilization supply-side effects which may be due to real reforms.

${ }^{66}$ There is little systematic evidence on labor supply responses in exchange rate-based stabilization. For some evidence on Mexico and Argentina, see Roldos (1995).
} 
Since the supply of non-traded goods is assumed to be relatively inelastic in the short-run, the expansion in aggregate demand leads to an increase in the relative price of non-traded goods (i.e., a real appreciation) and a trade account deficit.

A somewhat unsatisfactory aspect of some of these models is that they rely on some features - gestation lags, adjustment costs, and particularly the assumption that the investment good be a "cash good" - which do not have a clear economic interpretation. In particular, there is no evidence that would seem to tie investment to the level of cash transactions. From a qualitative point of view, however, this assumption is not necessary for this type of model to generate the effects just described, as made clear by Lahiri (1996a). In his model, the nominal interest rate introduces a distortion between consumption and leisure (as in Roldos (1997)). When inflation falls, labor supply increases. This, in turn, leads to a rise in the desired capital stock and, hence, in investment. Rebelo and Végh (1995), however, argue that the assumption that investment be in some way related to cash transactions is critical for the quantitative performance of a broad class of models. ${ }^{67}$

A more fundamental problem of supply-side based models is that, given that the driving force behind such models are wealth effects, they cannot explain the late contraction observed in many programs. To this end, supply-side considerations must be supplemented by either lack of credibility or some nominal rigidity. ${ }^{68}$ To illustrate how supply-side effects may be combined with temporary stabilization to replicate some of the stylized facts of exchange ratebased stabilizations, we proceed to analyze a simple model which incorporates a consumption-leisure choice in the same cash-in-advance specification presented in Section 4.

Consider a one-good economy in which the representative household maximizes

$$
\int_{0}^{\infty} u\left(c_{t}^{T}, \ell_{t}\right) \exp (-\beta t) d t
$$

where $\ell_{t}$ denotes leisure, subject to the lifetime constraint (which already incorporates the cash-in-advance constraint $\left.m_{t}=\alpha c^{T}\right):{ }^{69}$

\footnotetext{
${ }^{67}$ Similar results would obtain if money were used as a factor of production (see Uribe (1997)). This channel could be rationalized by assuming — following the credit channel literature - that firms do not have access to capital markets and must resort to bank credit to finance the need for short-term working capital (see Bernanke and Gertler (1995) and, in the context of stabilization policies, the discussion below on Edwards and Végh (1997)). Bank-intermediated capital has been used to improve the quantitative predictions of some monetary models; see, for instance, Chari, Jones, and Manuelli (1995).

${ }^{68}$ See Rebelo and Végh (1995), Lahiri (1996a, 1996b), Mendoza and Uribe (1997), and Edwards and Végh (1997).

${ }^{69}$ The function $u($.$) is assumed to be strictly increasing and strictly concave, and goods are$ assumed to be normal.
} 


$$
b_{0}+m_{0}+\int_{0}^{\infty}\left(1-\ell_{t}\right) \exp (-r t) d t=\int_{0}^{\infty} c_{t}^{T}\left(1+\alpha i_{t}\right) \exp (-r t) d t .
$$

First-order conditions imply that (assuming $\beta=r$ ):

$$
\begin{aligned}
u_{c^{T}}\left(c_{t}^{T}, \ell_{t}\right) & =\hat{\lambda}\left(1+\alpha i_{t}\right), \\
\frac{u_{c^{T}}\left(c_{t}^{T}, \ell_{t}\right)}{u_{\ell}\left(c_{t}^{T}, \ell_{t}\right)} & =1+\alpha i_{t},
\end{aligned}
$$

where $\hat{\lambda}$ is the Lagrange multiplier associated with constraint (19). Note how the nominal interest rate introduces a wedge between consumption and leisure, as equation (21) makes clear. Taking into account the government's intertemporal budget constraint, it is easy to show that

$$
k_{0}+\int_{0}^{\infty}\left(1-\ell_{t}\right) \exp (-r t) d t=\int_{0}^{\infty} c_{t}^{T} \exp (-r t) d t .
$$

Two important observations, which illustrate some of the points noted above, follow easily from equations (20), (21), and (22). First, a permanent reduction in the rate of devaluation, and thus in $i$, would cause a once-and-for all increase in consumption and output. Hence, this would explain the initial expansionary effects, but not the eventual contraction, observed in exchange rate-based stabilizations. Second, if the utility function were separable (i.e., $u_{c^{T}} \ell()=$.0 ), then a temporary (i.e., non-credible) stabilization of the type studied in Section 4.2 would lead to a consumption cycle similar to that illustrated in Figure 6, Panel B, but to a permanent increase in output (i.e., a permanent fall in leisure). Hence, the output cycle cannot be rationalized with a separable utility function.

Suppose now that the cross-derivative is negative; that is, $u_{c^{T} \ell}()<$.0 . Then it follows from (20) and (21) that at time $T$, consumption falls and leisure increases (i.e., work effort decreases). This piece of information, together with (22) implies that at time 0 both consumption and labor effort rise. Hence, such a specification of preferences would lead to a boom-bust cycle in both consumption and output.

An extension of this simple model — which would generate the boomrecession cycle in output even with separable preferences - is to introduce a costly banking system and assume that firms need bank credit to pay the wage bill (Edwards and Végh (1997)). In such a framework, a fall in consumption at time $T$ leads to a fall in demand deposits and, hence, to a reduction in the supply of bank credit. The resulting "credit crunch" leads to higher lending rates, a lower level of bank credit, and a recession. More generally, the idea that the banking system may amplify both booms and busts through changes in bank credit appears quite attractive to explain the issues at hand, from both a theoretical and a quantitative point of view. 


\subsection{Fiscal policy}

The elimination of large public sector deficits is clearly a necessary condition for a lasting reduction in inflation. It is thus not surprising that programs in which the fiscal adjustment was either absent or short-lived got quickly off track, the best-known examples being the Argentine 1978 tablita and 1985 Austral plan, and the Brazilian 1986 Cruzado plan. In successful plans (like the Israeli 1985 plan and the Argentine 1991 Convertibility plan), however, the fiscal adjustment has often been quite important. Such adjustment typically involves some combination of tax increases and cuts in government spending. While this is consistent with the initial fall in public consumption shown in the stabilization time profile (Figure 1, Panel D), the panel regressions reported in Table 2 (column (5)) indicate that the coefficient on the "early" dummy is not significant.

Still, there is an important branch of the literature which has focused on the expansionary effects of the fiscal policies that often accompany major exchange rate-based stabilizations. In Helpman and Razin (1987), the reduction in the inflation tax generates a wealth effect due to the lack of Ricardian equivalence. In Drazen and Helpman (1988), the wealth effect comes through the expectation of a future reduction in government spending. Rebelo (1997) considers a scenario in which, in the absence of reforms, government expenditure increases, thus raising the present value of the resources needed to finance that spending. By bringing the fiscal situation in order, a stabilization leads to a wealth effect that may produce a boom even though taxes increase in the short run. ${ }^{70}$

Rebelo and Végh (1995) examine the effects of reductions in public consumption and increases in taxes in a two-sector, general equilibrium model. A fall in government consumption of tradable goods leads to a consumption boom and a real appreciation, but investment falls and the current account improves. A reduction in public consumption of non-tradables leads to a counterfactual real depreciation. Hence, cuts in fiscal expenditures seem to have limited power in explaining the stylized facts of exchange rate-based stabilization. On the other hand, tax increases are recessionary. Finally, as with supply-side effects, fiscal-based explanations would not be able to generate an eventual recession, unless of course the policy is reversed.

\subsection{And the winner is ...}

In the end, we would want to have a sense of whether a "winner" emerges among all the competing theories aimed at explaining the empirical regularities associated with exchange rate-based stabilization which have been examined in the last two sections. To focus on essentials, the above models have abstracted from features which, while "realistic", would have diverted attention away from

\footnotetext{
${ }^{70}$ See also Giavazzi and Pagano (1990) and Bertola and Drazen (1993), who analyze the possibly expansionary role of fiscal policy in the stabilizations of Denmark in 1982 and Ireland in 1987 .
} 
the key channels. While this is the logical route to follow, it makes a comparison across models difficult since not all channels are operating simultaneously. To remedy this, Rebelo and Végh (1995) have evaluated, both qualitatively and quantitatively, all the hypothesis examined in the last two sections (except for the one related to durable goods) in a single, two-sector model with a labor-leisure choice and capital accumulation. They conclude that, qualitatively, the only two hypotheses that may explain a boom-recession cycle are lack of credibility and price or wage stickiness (inflation inertia). (In their model, an initial wealth effect stemming from supply-side effects helps the inflation inertia hypothesis in generating an initial consumption boom.) This is, of course, consistent with the evaluation that follows from the simpler models analyzed above.

Quantitatively, however, Rebelo and Végh (1995) find that supply-side effects seem critical to account for any sizeable fraction of the observed outcomes. Still, baseline parameterizations fall short of explaining the observed consumption booms and real appreciations. While there are configurations of the technology that are consistent with the data, there is still little information to assess whether these configurations are empirically plausible. Hence, further work on the structure of the supply-side and on the differential response of the tradable and non-tradable goods sector - which would allow us to build more refined quantitative models - would be particularly useful.

Finally, it is worth stressing the importance of disentangling the effects of stabilization from other reforms. The reason is that we may be asking models to explain "too much" in quantitative terms. In other words, the poor quantitative performance of a broad class of models found by Rebelo and Végh (1995) may be due not to a lack of "good" models but rather to the fact that we may be trying to explain all of the observed consumption booms and real appreciation as a result of exchange rate-based stabilizations.

\section{Money-based stabilization}

The use of a money anchor to bring down chronic inflation has been much less common than the use of an exchange rate anchor. Available evidence, however, suggests that these stabilizations have led to an initial recession, higher real interest rates, and real exchange rate appreciation (Section 3). As discussed earlier, the monetary regimes prevailing in these plans have borne little resemblance to the textbook case of a "pure" money anchor (i.e., a clean floating exchange rate), and have ranged from dirty floating to dual exchange rate systems (with a pegged commercial rate). Nonetheless, a common feature of such regimes is that money has been, albeit to varying degrees, the predominant nominal anchor. Therefore, to fix ideas, we will focus on the textbook case of a pure money anchor. We will then argue that, qualitatively, deviations from this benchmark would not alter the basic results. 


\subsection{A simple model}

From an analytical point of view, the two key elements needed to reproduce the stylized facts illustrated in Section 3 are (i) an interest-rate elastic money demand and (ii) sticky prices. We will introduce these two critical elements in the simplest possible way. ${ }^{71}$

We generate an interest-rate elastic money demand by introducing money in the utility function. We will therefore keep the utility function postulated in (1), but assume that it takes a log-specification: ${ }^{72}$

$$
\int_{0}^{\infty}\left[\log \left(c_{t}^{T}\right)+\log \left(c_{t}^{N}\right)+\log \left(m_{t}\right)\right] \exp (-\beta t) d t .
$$

The household maximizes (23) subject to (2). The first-order conditions imply that (again, assuming that $\beta=r$ ):

$$
\begin{aligned}
c_{t}^{N} & =e_{t} c_{t}^{T}, \\
\frac{1}{m_{t}} & =\bar{\lambda} i_{t},
\end{aligned}
$$

where $\bar{\lambda}$ is the Lagrangean multiplier associated with lifetime constraint (2).

On the supply side, we follow Calvo's (1983) staggered-prices formulation - a continuous-time version of the overlapping-contracts models à la Fischer (1977) and Taylor $(1979,1980)$ — whereby the price level is sticky (i.e., it is a predetermined variable at each instant in time), output of home goods is demand-determined, and the rate of change in inflation is a negative function of excess aggregate demand:

$$
\dot{\pi}_{t}=-\xi\left(c_{t}^{N}-\bar{y}^{N}\right), \quad \xi>0 .
$$

Equation (26) can be derived by assuming that firms set prices in a nonsynchronous manner taking into account the future path of aggregate demand and the average price level prevailing in the economy (see Calvo (1983)). At any point in time, only a small subset of firms can change their price. The price level is therefore a predetermined variable. If excess demand develops at some point in time, a small subset of firms will change their price and inflation rises. The subset of firms that will change their price diminishes over time, which implies that inflation of home goods falls over time. Hence, the change in the

\footnotetext{
${ }^{71}$ In the absence of sticky prices, there would be no difference between money-based and exchange rate-based stabilization. The reason is that, under money-based stabilization, the real money supply could change at any point in time through changes in the price level.

${ }^{72}$ This model is a simplified version of Calvo and Végh (1994c). See also Dornbusch (1980) and Fischer (1986a, 1988).
} 
rate of inflation is negatively related to excess demand in the non-traded goods sector. $^{73}$

As in the previous section, the interest parity condition implies that $i_{t}=$ $r+\varepsilon_{t}$. Output of non-tradable goods is demand determined so that $c_{t}^{N}=y_{t}^{N}$ for all $t$. The resource constraint continues to be given by (4).

To solve the model, we proceed in two stages. In the first stage, we show that the path of real money balances, $m_{t}\left(=M_{t} / E_{t} P^{T *}\right)$, is governed by an unstable differential equation. Note that

$$
\frac{\dot{m}_{t}}{m_{t}}=\mu_{t}-\varepsilon_{t},
$$

where $\mu_{t}\left(\equiv \dot{M}_{t} / M_{t}\right)$ denotes the rate of growth of the money supply, which is the policy instrument in a money-based stabilization. Substituting into (27) the interest parity condition and first-order condition (25), we have that

$$
\frac{\dot{m}_{t}}{m_{t}}=\mu_{t}+r-\frac{1}{\lambda m_{t}} .
$$

Around the steady-state, equation (28) is an unstable differential equation. ${ }^{74}$ Hence, following an unanticipated and permanent reduction in $\mu_{t}, m_{t}$ adjusts instantaneously to its higher steady-state value. Hence, from (25), $i_{t}$ and thus $\varepsilon_{t}$ also adjust instantaneously to their lower steady-state values.

Intuitively, if $\varepsilon_{t}$ fell on impact below $\mu_{t}$, then $m_{t}$ would be increasing over time, which necessitates of a lower $i$ (and lower $\varepsilon$ ) to equilibrate the money market, which further increases $m_{t}$, and so on. Thus, for $m_{t}$ not to diverge, the rate of depreciation, and thus the nominal interest rate, must adjust instantaneously.

In the second stage, we form a dynamic system in real money balances in terms of home goods and the rate of inflation. To that effect, let us define real money balances in terms of home goods; that is, $n_{t}=M_{t} / P_{t}^{N}$. Then,

$$
\frac{\dot{n}_{t}}{n_{t}}=\mu_{t}-\pi_{t}
$$

The second dynamic equation follows from (26) taking into account (24) and that, from the definition of $m_{t}$ and $n_{t}, e_{t}=n_{t} / m_{t}$ :

$$
\dot{\pi}_{t}=\xi\left(\bar{y}^{N}-\frac{n_{t}}{m_{t}} c_{t}^{T}\right) .
$$

\footnotetext{
${ }^{73}$ Note that in this formulation, the price level of home goods $\left(P^{N}\right)$ is sticky (i.e., it is a predermined variable) but the inflation rate of non-tradable goods $(\pi)$ is fully flexible (i.e., it is a forward-looking variable). It is also worth stressing that the formulation embedded in (26) is not inconsistent with the one postulated in (8), where the level of the inflation rate of home goods depends positively on excess aggregate demand. The reason is that, in equilibrium, the staggered-prices formulation given by (26) may still generate a Phillips-curve relation in which inflation is above its steady-state value when excess aggregate demand develops.

${ }^{74}$ Notice that, as before, $\lambda$ is invariant to changes in $\mu_{t}$.
} 
Equations (29) and (30) constitute a system of differential equations in $n$ and $\pi$, for given $c_{t}^{T}, m_{t}$, and the policy variable $\mu_{t}$. Around the steady-state, the system is saddle-path stable, as it should be since $n$ is the only predetermined variable (Figure 9 depicts the corresponding phase diagram.) ${ }^{75}$

Suppose that initially (i.e., for $t<0$ ), the public expects the rate of money growth to remain constant forever at $\mu^{H}$. This initial steady-state is characterized by:

$$
\begin{aligned}
c_{s s}^{T} & =r k_{0}+y^{T}, \\
c_{s s}^{N} & =\bar{y}^{N} \\
e_{s s} & =\frac{\bar{y}^{N}}{r k_{0}+y^{T}}, \\
\pi_{s s} & =\mu^{H}, \\
i_{s s} & =r+\mu^{H}, \\
n_{s s} & =\frac{\bar{y}^{N}}{r+\mu^{H}}, \\
r_{s s}^{d} & =r,
\end{aligned}
$$

where, as before, the domestic real interest rate, $r^{d}$, is defined as $i-\pi$.

In terms of Figure 9, the initial steady-state is at point A. Suppose now that, at time 0 , policymakers announce a permanent and unanticipated reduction in the money growth rate from $\mu^{H}$ to $\mu^{L}$. The new steady-state becomes point $\mathrm{B}$ where real money balances in terms of home goods are higher and inflation is lower. On impact, the system jumps from point $\mathrm{A}$ to point $\mathrm{C}$ and then travels along the saddle path towards its new steady-state, point B.

The path of the main variables is illustrated in Figure 10. Real money balances (in terms of home goods) increase gradually over time (Panel B). On impact, inflation falls below its new steady-state value and then increases over time (Panel C). The path of the real exchange rate (Panel E) follows from the fact that $\dot{e}_{t} / e_{t}=\varepsilon_{t}-\pi_{t}$. The real exchange rate must fall (i.e., appreciate) on impact to allow for a subsequent real exchange rate depreciation. The initial fall in the real exchange rate is effected through a fall in the nominal exchange rate, given that the price level of home goods is a predetermined variable. The path of consumption of home goods (Panel D) can be derived from equation (24) and the path of the real exchange rate. Since consumption of traded goods does not change - and continues to be equal to permanent income of traded goods consumption of home goods falls on impact as the relative price of home goods (i.e., the inverse of the real exchange rate) increases. It then increases as home goods become cheaper over time. The path of the domestic real interest rate

\footnotetext{
${ }^{75}$ The determinant associated with the linear approximation around the steady-state is $-\xi n_{s s} c_{s s}^{T} / m_{s s}<0$, which indicates that there is one positive and one negative root.
} 
(Panel F) follows from the definition $r_{t}^{d}=i_{t}-\pi_{t}$. The domestic real interest rate increases on impact - as the inflation rate of home goods falls below the nominal interest rate - and then falls towards its unchanged steady-state.

What is the driving force behind these results? It is best to think about the equilibrium condition in the money market, which is given by:

$$
n_{t}=\frac{c_{t}^{N}}{i_{t}} .
$$

We think of the left-hand side of (38) as the real money supply in terms of non-tradable goods and of the right-hand side as real money demand. Upon the announcement of a lower rate of money growth, expected inflation and thus the nominal interest rate fall. For a given $c_{t}^{N}$, this increases real money demand in terms of home goods. Real money supply, $n\left(=M / P^{N}\right)$, however, cannot change on impact because neither $M_{t}$ (a policy variable) nor $P^{N}$ (a predetermined variable) change. Hence, the fall in the nominal interest rate generates an incipient excess demand for real money balances. To equilibrate the money market, consumption of home goods (and thus output) needs to fall. For consumption of home goods to fall, home goods must become more expensive (i.e., the real exchange rate must fall). Since consumption of home goods must return to its initial steady-state, the domestic real interest rate must increase to induce a rising path of consumption of home goods.

This simple model thus reproduces the main stylized facts associated with money-based stabilization illustrated in Section 3: an initial recession, a real exchange rate appreciation, and higher domestic real interest rates. The model does not exhibit, however, inflation persistence. To generate that result, we would need to introduce either inflation inertia or lack of credibility, along the lines of Section 4 (see Calvo and Végh (1994c)). The model also predicts no change in the trade and current account balances. As a first approximation, unchanged external accounts are not really at odds with the facts, as argued in Section 3. To generate an alternative prediction, we would need to get rid of the separability between $c^{N}$ and $c^{T}$, which would considerably complicate the solution method because the system would cease to be block-recursive.

\subsection{Extensions to other money-based regimes}

Would the basic results change if we deviate from the extreme case of a pure money anchor (i.e., a clean floating)? The answer is no. Consider first a dirty floating, whereby the monetary authorities intervene in foreign exchange markets to influence the nominal exchange rate. In the example just analyzed, policymakers might want, on impact, to buy foreign exchange (i.e., accumulate international reserves) in exchange for domestic money to prevent the nominal exchange rate from appreciating too much. In terms of the model, the effects of intervention could be captured in a very simple way by assuming that, on impact, policymakers increase the nominal money supply so as to prevent the 
nominal exchange rate - and thus the real exchange rate - from appreciating (while still reducing the rate of growth to $\left.\mu^{L}\right) .{ }^{76}$ Since $m\left(=M / E P^{T *}\right.$ ) jumps immediately to its higher steady-state value, it follows that a higher $M_{0}$ implies a higher $E_{0}$ (relative to the case in which the nominal money supply is not changed on impact). In other words, the larger the initial increase in the level of the money supply, the smaller the initial nominal and real appreciation. In terms of Figure 9, this implies that, depending on how much the money supply increases, the system would jump on impact to a point along the saddle path between points $\mathrm{C}$ and $\mathrm{B}$ and then proceed towards point B. Qualitatively speaking, then, the impact effects would be the same. Quantitatively, the initial real appreciation and thus the initial recession would be lessened.

An extreme case of the "intervention" policy just described is a situation in which the initial level of the money supply is increased as much as needed for the nominal exchange rate not to change on impact. In this case, the system would jump immediately to its new steady-state (Point B in Figure 9). Neither the nominal nor the real exchange rate would change and the initial recession would be avoided altogether. This case is typically ruled out as implausible on the basis that, in practice, a large initial increase in the stock of money would likely be interpreted as an increase in the rate of growth of money, which would severely affect the credibility of the whole program. Still, it helps rationalizing the monetary authorities' incentives to intervene in foreign exchange markets. From a theoretical point, if policymakers can manipulate at will the initial money stock, then generating an initial recession would make it necessary to introduce inflation inertia, along the lines analyzed in Section 3.

Consider now the case in which there are capital controls. From a monetary point of view, capital controls give policymakers the ability to have further control over the money supply (if they did not have it to begin with). In the case of a floating rate (or dirty floating), then it should make little difference. In fact, adding capital controls to the model above — by, say, assuming that the private sector's stock of net foreign assets is given and cannot change - would not change anything since the restriction would not be binding (recall that the current account is zero throughout the adjustment). Mixed regimes - such as dual exchange rates with a predetermined commercial rate - should also lead to an initial recession. ${ }^{77}$ The key is that the initial nominal money supply will still be a policy instrument (unlike a predetermined exchange rate regime in which the initial nominal money supply adjusts endogenously to satisfy real money demand). Hence, any disinflationary policy which leads to a reduction in expected inflation - and thus to an increase in real money demand - will lead to a "liquidity crunch" and an initial recession. In sum, the effects of disinflation

\footnotetext{
${ }^{76}$ Of course, this is not, strictly speaking, intervention since there is no accumulation of reserves (i.e., money is introduced through an "helicopter" drop).

${ }^{77}$ Models of dual exchange rates using the same type of framework emphasized throughout this chapter may be found in Obtsfeld (1986), Guidotti and Végh (1992), and Calvo, Reinhart, and Végh (1995).
} 
in any monetary regime which involves significant capital controls should be qualitatively similar to those of a textbook money-based stabilization. ${ }^{78}$

\subsection{Money anchor versus exchange rate anchor}

As noted earlier, a money anchor is much less common than an exchange rate anchor in stabilization programs in chronic inflation countries. Although far from being a panacea for stopping inflation, policymakers' revealed preference for an exchange rate anchor may be rationalized on a number of grounds.

First, the behavior of money velocity may be quite difficult to predict in the transition from high to low inflation, especially in chronic inflation countries where the distinction between monies and quasi-monies is particularly blurred. Therefore, as a practical matter, it may be quite difficult to gauge how "tight" a given monetary rule is likely to be, and whether a "stable" relationship will hold in the aftermath of disinflation. In contrast, using the exchange rate has the intrinsic advantage that, given the endogeneity of the money supply, there is no need in principle to have any information about money demand and velocity.

A second, and related, issue is that prolonged periods of high inflation lead to a high degree of dollarization of the economy. ${ }^{79}$ In such a situation, the "relevant" money supply (i.e., the one which affects inflation and real activity) is likely to include (the domestic-currency value of) foreign currency holdings and deposits. Since this component cannot be controlled by policymakers, a reduction in the domestic component of the money supply may have little effect on total liquidity and, hence, on inflation. In effect, policy simulations of moneybased disinflation for the case of Uruguay (Hoffmaister and Végh, 1996) suggest that reducing the rate of growth of either M1 or M2 (which do not include foreign currency deposits) results in an extremely slow disinflation compared to using the exchange rate. In sharp contrast, if policymakers could (which, of course, they cannot) control M3 (M2 plus foreign currency deposits), then the speed of disinflation would be roughly the same as that achieved with an exchange rate anchor.

A third issue is that, by the simple virtue of being a price rather than a quantity, the exchange rate provides a much clearer signal to the public of the government's intentions and actual actions than a money supply target. Thus, if the public's inflationary expectations are influenced to a large extent by the ability to easily track and continuously monitor the nominal anchor, the exchange rate has a natural advantage.

Based on the considerations just discussed, it should not come as a surprise

\footnotetext{
${ }^{78}$ As noted in Section 3, there may be regimes with a clean floating which do not necessarily have a monetary aggregate as the main nominal anchor (see Masson, Savastano, and Sharma (1997) for a taxonomy of monetary regimes). These regimes, however, have been rare in major stabilization programs. Still, Végh (1997) shows an example in which nominal and real interest rate rules are equivalent to a money-based regime.

${ }^{79}$ See Calvo and Végh (1992) and Savastano (1996).
} 
that, by and far, disinflation programs in chronic inflation countries have relied on the exchange rate as the main nominal anchor (with the August 1990 Peruvian program being the most notable exception). Revealed preferences, therefore, would seem to support the view - with which we would certainly agree - that the exchange rate should be viewed as the more suitable nominal anchor in chronic inflation countries. This is also consistent with Uribe's (1994) findings on the welfare costs of money-based versus exchange rate-based stabilization. By performing different simulations of Calvo and Végh's (1994c) model, he argues that exchange-rate based stabilization is generally less costly, in terms of welfare, than money-based stabilization.

An important caveat against the use of an exchange rate anchor is in situations of very little credibility. For instance, in a country in which a series of failed exchange rate-stabilizations has led the public to identify the initial boom and current account deficit as a signal of an unsustainable stabilization effort, it would probably be wise to try to switch strategies and opt for a money anchor. The main reason is that theory suggests (see Calvo and Végh, 1994c) that the effects of imperfect credibility differ drastically under each regime: lack of credibility is more disruptive under an exchange rate anchor because it reduces the benefits (inflation falls by less) at the same time that it increases the size of the real dislocations (the boom-bust cycle becomes more pronounced). In contrast, in money-based stabilization, lack of credibility reduces both the benefits (in terms of lower inflation) but also the initial recession. Hence, if the public is perceived as being highly skeptical, a money anchor may be less risky. ${ }^{80}$

\section{$7 \quad$ Balance of payments crises}

As argued in Section 3, most exchange rate-based stabilization programs end in balance of payments (BOP) crises (recall Table 1). These programs typically unleash dynamics - consumption booms, sustained real appreciation, current account deficits - which call into question their sustainability. ${ }^{81}$ This, in turn, fuels speculation of a possible abandonment of the exchange rate anchor. Once the survival of the program has been called into question, financial factors such as a large stock of short-term debt - often aggravate the situation and may induce self-fulfilling crises. Whether balance of payment crises are ultimately caused by worsening fundamentals or self-fulfilling elements is a matter of ongoing debate. ${ }^{82}$ But even if the ultimate demise of the peg responds to some self-fulfilling event, it is still the case that fundamentals go a long way in determining the potential vulnerability of the system (Obstfeld and Rogoff (1995)).

\footnotetext{
${ }^{80}$ Another argument for a money-anchor is given in Tornell and Velasco (1995), who argue that a money anchor might provide more fiscal discipline.

${ }^{81}$ Naturally, a fiscal desequilibrium will only reinforce the sense of unsustainability.

${ }^{82}$ See Krugman (1996) and the comments therein by Kehoe and Obtsfeld.
} 
Naturally, the potential for balance of payments crises is a more general issue and applies to any pegged exchange rate system, whether the peg is part of an explicit inflation stabilization program or not (as most recently exemplified by the South East Asian crises of the second half of 1997). However, even when the peg was not instituted as part of a program, crises tend to occur as the economy enters a recession, following a prolonged boom in economic activity, credit expansions, real exchange rate appreciation, and current account deficits (Kaminsky and Reinhart (1995)). ${ }^{83}$ These are, of course, essentially the same dynamics as those generated by exchange rate-based stabilizations (recall Figures 1 and 2). We suspect this is no coincidence, since it may be argued that pegged exchange rates keep inflation down (mainly by linking inflation of tradable goods to world inflation) at the expense of an appreciating currency. We would thus suspect that some of the mechanisms discussed in Sections 4 and 5 may help in explaining the dynamics leading to balance of payment crises in general.

This area has enjoyed a renaissance of sorts in the aftermath of the Mexican crisis. Researchers have gone back to Krugman's (1979) seminal paper on the mechanics of balance of payments crises and refined it in several important ways. Hence, after a brief discussion of liquidity considerations, we take Krugman's (1979) model as the starting point of this section. We then discuss the notion of current account sustainability. Finally, we examine the role of financial factors and lack of credibility in precipitating balance of payment crises.

\subsection{Liquidity}

Balance of payments crises take different forms. A common characteristic is that the government finds itself unable to comply with financial obligations. An example is when the government is committed to keeping a fixed exchange rate (against, say, the U.S. dollar), and the public wishes to exchange domestic money for dollars in an amount that exceeds the international reserves available for this operation. As a result, the government has to abandon its exchange rate policy. However, the loss of reserves may occur for other reasons. For instance, reserves may be lost if the country has short-term liabilities, bonds, that cannot be rolled over in the capital market, and exceed the level of available international reserves. ${ }^{84}$

A BOP crisis does not necessarily involve insolvency, i.e., the country's inability to pay. As a general rule, countries undergoing BOP crises have ample resources to meet their financial obligations. In practice, the problem is that the country does not have enough financial assets that can be swiftly activated

\footnotetext{
${ }^{83}$ See also Bordo and Schwartz (1996), Dornbusch, Goldfajn, and Valdes (1995), Eichengreen, Rose, and Wyplosz (1995, 1996), Frankel and Rose (1996), Obtsfeld (1995), and Sachs, Tornell, and Velasco (1996). For an early analysis of devaluation crises, see Harberger (1981).

${ }^{84}$ This was a key ingredient in the December 1994 balance of payments crisis in Mexico. See, for instance, Sachs, Tornell, and Velasco (1995) and Calvo and Mendoza (1996).
} 
to meet its financial obligations. Thus, at the core of a BOP crisis, there is typically a mismatch between the "liquidity" of financial obligations and that of government financial assets. This mismatch is associated with another dominant characteristic of BOP crises, namely, they take place within a relatively short period of time (normally within a month), a fact that contributes to dramatize the event. ${ }^{85}$

The world "liquidity" in the above paragraph is just a signpost, not a definition. A good definition of liquidity is highly elusive. We will discuss the concept in the context of a special environment. Let $p(t, v)$ be the output price of a given asset at time $t$, if the asset was placed on the market at time $v \leq t$. We say that the asset is perfectly liquid if $p(t, t)=p(t, v)$ for all $t$ and $v$ (and all states of nature). In other words, an asset is perfectly liquid if there is no advantage to the seller in announcing his/her intention to sell in advance of the actual transaction. Otherwise, if $p(t, t)<p(t, v)$, we say that the asset displays some illiquidity. The asset's degree of liquidity could be measured by

$$
\varsigma(t, v)=\frac{p(t, t)}{p(t, v)} .
$$

Some simple models assume only two types of assets, namely (i) perfectly liquid assets, and (ii) assets for which $\varsigma(t, v)=0$ for all $v<t$; that is, assets that would have no market value if they had to be liquidated in no time's notice. ${ }^{86}$ In this case, a BOP crisis would take place if the liabilities that the government is called upon to service at time $t$ exceed the stock of liquid assets.

In the models to be discussed here the liquidity properties of an asset are postulated, not explained.

\subsection{The Krugman model}

This is an elegant model that captures the essential features mentioned above. We will present a version along the lines of the utility-based models used in previous section of this chapter. For present purposes, it is enough to assume that all goods are fully tradable, and that the representative individual is endowed with a constant flow of tradable goods per unit of time. Hence, using the same notation, lifetime utility is given by

$$
\int_{0}^{\infty}\left[v\left(c_{t}^{T}\right)+z\left(m_{t}\right)\right] \exp (-\beta t) d t
$$

As in Section 4, let the country be fully-integrated in goods and capital markets and thus face a constant international price of the tradable good and a constant world real interest rate, $r$, which equals the subjective discount rate. The

\footnotetext{
${ }^{85}$ This should not be interpred to mean that the fundamental reasons behind a balance of payments crisis are so short-lived - just the symptoms are.

${ }^{86}$ Lucas's (1990) cash-in-advance model has this characteristic.
} 
consumer's intertemporal budget constraint is thus given by (2) (abstracting from the terms that relate to non-traded goods). The first-order conditions are therefore (5) and (7). Therefore, as before, (5) implies that, along a perfect foresight equilibrium path, consumption is constant.

The exchange rate is assumed to be fixed if there are enough reserves to sustain the value of the domestic currency (i.e., if reserves are above or at their "critical" level, which we assume to be zero). The exchange rate is sustained by intervening in the foreign exchange market. Thus, the fixed rate is abandoned once the public wants to turn domestic into foreign currency in an amount that exceeds the stock of liquid assets set aside for this operation. In Krugman (1979), these assets are identified with (international) reserves, $R$. While the fixed exchange rate regime lasts, perfect capital mobility implies that the domestic nominal interest rate equal the international one; that is, $i_{t}=r$. After the fixed rate is abandoned, the exchange rate is allowed to float, and exchange rate intervention is stopped. Hence, again denoting by $\varepsilon_{t}$ the rate of devaluation/inflation, perfect capital mobility implies that $i_{t}=r+\varepsilon_{t}$.

We assume that the central bank transfers net profits to the fiscal budget, which implies that the central bank's capital is constant. Hence, from the central bank's balance sheet, it follows that

$$
\dot{M}_{t}=E_{t} \dot{R}_{t}+N \dot{D} A_{t}
$$

where $M$ is high-powered money, $E$ is the nominal exchange rate (i.e., the price of foreign exchange in terms of domestic currency), $R$ denotes reserves denominated in foreign exchange, and NDA stands for net domestic assets (i.e., domestic credit). ${ }^{87}$

The government's only source of expenditures are lump-sump transfers to households. It finances an exogenously-given level of transfers, $\tau$, with central bank credit and proceeds from international reserves (which we assume earn the international interest rate, $r$ ). Thus,

$$
E_{t} \tau=N \dot{D} A_{t}+r E_{t} R_{t} .
$$

Since during the fixed-rate period, $i_{t}=r$ and hence, by (7), the demand for money is constant (implying $\dot{M}_{t}=0$ ), we have:

$$
\dot{R}_{t}=-\left(\tau-r R_{t}\right) .
$$

In other words, under fixed exchange rates the loss of international reserves equals the budget deficit (given by government transfers minus interest revenues from international reserves $).{ }^{88}$

\footnotetext{
${ }^{87}$ Equation (40) implicitely assumes - with no loss of generality - that the central bank does not monetize nominal capital gains on international reserves. Typically the central bank creates a fictitious non-monetary liability instead.

${ }^{88} \mathrm{It}$ is assumed that the initial fiscal deficit is positive; i.e., $\tau-r R_{0}>0$.
} 

$(41)$,

After fixed rates are abandoned, $\dot{R}_{t}=R_{t}=0$ and, and hence, by (40) and

$$
\dot{m}_{t}+\varepsilon_{t} m_{t}=\tau .
$$

Assuming, for simplicity, that the individual initially holds no foreign assets or liabilities, it follows from first-order condition (5) and the lifetime constraint that $c_{t}^{T}=r R_{0}+y^{T}$ for all $t$. Hence, combining first-order conditions (5) and (7) and solving for $m_{t}$, we get the familiar demand-for-money expression:

$$
m_{t}=L\left(i, r R_{0}+y^{T}\right), \quad L_{i}<0, L_{r R_{0}+y^{T}}>0 .
$$

For simplicity, we will focus on steady states (i.e., $\dot{m}_{t}=0$ ). Thus, by equations (43) and (44), we have that

$$
\varepsilon L\left(r+\varepsilon, r R_{0}+y^{T}\right)=\tau .
$$

The left-hand side of equation (45) corresponds to revenue from the creation of money at steady-state, while the right-hand side is the amount to be financed by these means. Clearly, equation (45) will in general display multiple equilibria because the demand for money is negatively-sloped with respect to $\varepsilon$. However, since equilibrium multiplicity is not a key theme in Krugman (1979), we will assume that the economy settles down on the lowest rate of devaluation consistent with equation (45), which will be indicated by $\varepsilon^{*}$. Clearly, if $\tau>0$, then after the currency peg is abandoned, the economy jumps to a higher inflation plateau, and stays there forever. It follows from expression (44) that at "switch point," i.e., the point in time $T$ at which the currency peg is abandoned, the demand for money collapses. This is a key feature of the model.

Figure 11 depicts the central characteristics of an equilibrium path for international reserves assuming that the government runs a fiscal deficit (i.e., $\left.\tau-r R_{0}<0\right)$ and that the nominal exchange rate is a continuous function of time (this assumption will be rationalized later). From 0 to $T$ reserves are driven by equation (42). The system is abandoned at time $T$ - and not when reserves reach zero - because, as pointed out above, at switch time the demand for money takes a sudden dip equal to $L\left(r, r R_{0}+y^{T}\right)-L\left(r+\varepsilon, r R_{0}+y^{T}\right)=\Delta R$. Since the exchange rate is assumed not to jump at time $T$, it follows that the government suffers a loss of reserves equal to $\Delta R$ at time $T$. Clearly, switch point $T$ is uniquely determined. Thus, the model is able to capture some of the main characteristics of a BOP crises outlined above.

To close we will now briefly discuss the continuity of the exchange rate path $E$. In the first place, we will constraint $E$ to be piece-wise continuous and everywhere right-hand differentiable. These are technical assumptions which help to make sure that the problem is well-defined in a mathematical sense, and that irrelevant nonuniqueness situations are ruled out. Notice that jumps in $E$ are not ruled out. 
Suppose that, contrary to our assumption above, $E$ jumps at $t \geq T$, and let $M_{t}^{-}$be the left liminf of $M$ at $t$. If $M_{t}^{-}>0$, then the representative individual suffers a capital loss on account of his/her money holdings at time $t$. Thus, assuming that the demand for money goes to zero as the nominal interest rate diverges to plus infinity, a plausible regularity condition, it follows that it will never be optimal to undergo that kind of capital loss, which implies that $M_{t}^{-}=0$. Thus, if $t>T$, there will be an excess supply of money at $t$, which is inconsistent with equilibrium. Suppose now that $t=T$, and, hence, the jump takes place exactly at switch point. Since $M_{t}^{-}=0$, then the BOP crisis would have occurred before time $T$, which is a contradiction. This proves that $E$ is continuous everywhere as assumed above.

Finally, it is worth stressing that, since the interest rate on international reserves is equal to the international interest rate, the current account will be zero at all times. Notice, however, that external balance equilibrium does not prevent the occurrence of a $\mathrm{BOP}$ crisis. This is worth keeping in mind when we discuss the current account approach below.

\subsection{Krugman model: critique and extensions}

We now extend the above model in several useful directions.

Bonds Domestic debt (outside the central bank) may be introduced and thus account for an element that has played a prominent role recently. Thus, equation (41) would become:

$$
E_{t} \tau=N \dot{D} A_{t}+r E_{t} R_{t}-i_{t} D_{t}+\dot{D}_{t},
$$

where $D$ stands for instant-maturity government debt outside the central bank (in nominal terms). Actually, bond issuance could completely finance the deficit and, thus, $N \dot{D} A_{t}=0$. Under those circumstances, no reserves would be lost during the fixed rates period. However, domestic debt $D$ would increase without bound and, at some point, no more debt could be placed in the market because, otherwise, the government would not satisfy its intertemporal budget constraint. This is an interesting example because it is not unusual for governments to try to mask the fiscal disequilibrium in this manner. International reserves, which are closely watched by the private sector, would in this fashion be insulated from fiscal disequilibrium (prior to the BOP crisis).

Sterilization The Krugman model assumes that the monetary authority makes no attempt at sterilizing the effects of reserve accumulation. Money supply is not a target. Thus, the model assumes that at switch time the monetary authority will not interfere with the run against domestic money and allow money supply to fall. In practice, money is not simply cash but includes bank deposits. Therefore, a fall in the money stock is normally associated with a cut in bank 
credit. This is a cause of trouble especially if the event is not fully anticipated. ${ }^{89}$ Of course, if bank credit is easily substitutable for other type of credit, the bank credit crunch would cause no major disruption. But in LDCs this is not the case. Consequently, the central bank is induced to intervene through open market operations to provide the bank credit that would disappear as a result of the collapse in money demand at switch time.

Flood, Garber, and Kramer (1996) argue that there are several important instances in which central banks have attempted to fully sterilize the collapse in money demand. Interestingly, they show that this policy, if anticipated, would lead to a BOP crisis happening immediately, i.e., at time 0 . There would be no fixed exchange rate period like the interval $[0, T)$ in the Krugman model. The proof is straightforward. For money to remain constant (i.e., full sterilization) at time $T$, after-crisis inflation should equal inflation before crisis (which is zero). But this would imply that there is no crisis and the exchange rate is constant forever. However, equation (42) implies that sooner or later international reserves will be driven down to zero, and a crisis will take place, a contradiction. Thus, the only possibility left is for the crisis to take place at $t=0$. In other words, the fixed exchange rate regime collapses upon the announcement.

To have a more vivid picture of this instantaneous crisis, let us assume that at the time of the announcement real monetary balances fall short of total reserves (implying that an attack against domestic currency cannot be successful unless it triggers an expansion of domestic credit). The government's announcement is followed by an immediate attack on the domestic currency. Since authorities try to stabilize the stock of money, they intervene increasing domestic credit. Given that the demand for money has collapsed, the additional liquidity infusion only results in a loss of international reserves. This will continue until reserves are depleted. At that point authorities lose control of the exchange rate. Since there are no reserves, the exchange rate is the adjustment variable. Hence, the currency will devalue (the price level will rise) until real monetary balances are consistent with the equilibrium expected rate of devaluation/inflation.

Anticipated sterilization although inconsistent with fixed rates under the above assumptions could, however, be sustained under other set of plausible assumptions. Flood, Garber, and Kramer (1996) and Kumhof (1997) show that fixed-rates-cum-sterilization is consistent with a situation in which government bonds are imperfect substitute with international bonds. Calvo (1996b) shows that the same holds if it is costly to move in and out of money.

Interest rate policy Another important aspect of reality which is not captured in Krugman's (1979) model is the possibility of the central bank actively defending the currency by raising short-term interest rates. Sweden,

\footnotetext{
${ }^{89}$ Under perfect foresight, everybody knows the exact timing of the BOP crisis. However, the model is easily and realistically extended to the case in which, say, the demand for money has a stochastic component and hence, there is always an element of surprise in the timing of the crisis (see Flood and Garber (1984)).
} 
for instance, raised short-term interest rates to around 500 percent per year in September 1992 to stave off a speculative attack (see, for instance, Krugman (1996)). More recently, both Hong Kong and Brazil sharply raised interest rates to defend their currencies in the aftermath of the South East Asian currency crisis. While not always successful, higher interest rates often buy time for the government to try to uphold the system's credibility by adopting more fundamental measures. Lahiri and Végh (1997) model interest rate policy by assuming that the government controls the interest rate on highly-liquid government debt - along the lines of Calvo and Végh (1995) - and show that by announcing a policy of higher interest rates in the event of a crisis, the crisis may be postponed until international reserves actually reach zero (i.e., at a point like $T^{*}$ in Figure 11). At that point, the central bank is forced to float but there is no run (i.e., the money supply remains constant). This result of "crisis with no run" might also explain situations in which central banks abandon a peg with no dramatic loss of international reserves.

\subsection{The current account approach}

This approach has become popular after Mexico's 1994 BOP crisis since some observers have claimed that the crisis originated in the fact that Mexico was spending "beyond its means". In other words, Mexico's current account deficit was "too large." (It is worth recalling that in Krugman's model a BOP crisis could take place even though the current account deficit is nil to the extent that a payments crisis involves a liquidity shortage, irrespective of the country's overall solvency.) More generally - and as shown in Section 3 - exchange ratebased stabilizations typically lead to large current account deficits. Whether or not such imbalances are sustainable is thus a critical question when it comes to evaluate the reasons behind these programs' collapse.

The sustainability literature is based on the budget-constraint equation for the country as a whole. ${ }^{90}$ To illustrate, let us denote by $f$ and $C A D$ net international debt and current account deficit (both as a share of GDP), respectively. Then,

$$
\dot{f}_{t}=C A D_{t}-\eta b_{t}
$$

where $\eta$ is the rate of growth of output. Sustainability analysis focuses on steady-states. Thus, setting $\dot{f}_{t}=0$, the steady-state - sustainable - current account deficit satisfies

$$
C A D_{s s}=\eta f_{s s}
$$

where, as in earlier sections, subscript "ss" denotes "steady-state." This equation establishes a relationship between steady-state debt and current account

\footnotetext{
${ }^{90}$ For an elaboration, see Milesi-Ferretti and Razin (1996).
} 
deficit. In the absence of growth (i.e., $\eta=0$ ), then the sustainable current account deficit is necessarily equal to zero. In contrast, with positive growth a sustainable current account deficit is possible.

This analysis is unable to give us a definite answer on $C A D_{s s}$ until we pin down $f_{s s}$. Recent experience shows that the capital market is reluctant to keep lending to LDCs exhibiting levels of indebtedness that exceed 80 percent of GDP (Williamson (1993)). Hence, this additional piece of information allows us to write the sustainability condition (48) as follows:

$$
C A D_{s s} \leq 0.8 \eta
$$

Thus, a country that can be expected to grow at 4 percent per year cannot sustainably run a current account deficit exceeding 3.2 percent. Since 4 percent growth was, if anything, an upper bound for Mexico, this analysis would conclude that its 8 to 9 percent current account deficits were grossly unsustainable.

Notice that $C A D_{t}=r f_{t}-T S_{t}$, where $T S$ denotes the trade surplus (including non-financial transfers) as a share of GDP, and $r f_{t}$ denotes debt service ( $r$ is the international rate of interest). Therefore, by equation (48),

$$
T S_{s s}=(r-\eta) f_{s s} .
$$

Thus, if we again set the growth rate to 4 percent (i.e., $\eta=0.04$ ) and, in addition, we assume the international interest rate to be 10 percent per annum (i.e., $r=0.10$ ), then, by (50), at the steady state the economy must run a trade balance surplus of $0.06 f_{s s}$ as a share of GDP. The trade balance surplus increases with the steady-state debt/GDP ratio, $f_{s s}$. In particular, at the upper bound for $f_{s s}$ ( 80 percent of GDP) the trade balance surplus would be 4.8 percent of GDP.

Presumably, the reason for capital markets to be unwilling to extend credit to LDCs beyond 80 percent of GDP is that it may become tempting for those countries to renege on their debt obligations. Temptation, in turn, is likely to be related to the sacrifice associated with servicing the debt. Gross sacrifice of servicing the debt can be measured by the associated trade balance surplus. The previous computation suggests that the capital market becomes nervous about a country's willingness to repay when debt service represents only about 5 percent of GDP. Notice that the net sacrifice from servicing the debt could be much less once one takes into account international penalties from debt delinquency.

Thus, one criticism of current account sustainability computations is that they are highly sensitive to the definition of sustainable debt/GDP ratios. Besides, the above example shows that the implied critical sacrifice levels are low when compared to other capital market transactions. For example, mortgages in the U.S. are easy for a household to get if total mortgage payments are less than 25 percent of the household's income. Thus, if this ratio were also relevant for countries' debt then, using the above parameters, the critical steady state debt/GDP ratio would be $4.16(=0.25 /(r-\eta)$, where $r-\eta=0.06)$. Therefore, 
recalling equation (48), a country growing at 4 percent per year could run a sustainable current account deficit of more than 16 percent of GDP! Of course, countries are not mere households because they are protected by sovereignty clauses. However, prior to crisis Mexico had given very clear signals that it wanted to belong to the First World and signed treaties that would have made it very costly to engage in strategic repudiation of international debt (or any debt, for that matter).

A more fundamental criticism is that steady-state computations could be very misleading for countries that are undergoing deep economic reforms. The current account deficit could in those instances be a temporary phenomenon associated with reform. Once we move away from the steady-state straightjacket, this approach has precious little to say.

Finally, the current account approach does not address the BOP-crises issue as such. If the utility function is separable in money and consumption as in expression (39), the demand for money would be impervious to solvency issues. Thus, if we further assume that the government runs no fiscal deficit and there is no expansion in domestic credit, then the currency will never be under attack and a BOP crisis will never take place.

\subsection{Financial considerations}

Financial factors are likely to play a key role in precipitating balance of payment crises. We now review several such factors, which we deem particularly relevant.

Volatility of monetary aggregates The Krugman model focuses on fiscal deficits as the key determinant of reserves losses. However, even in the absence of domestic credit expansion, international reserves in a fixed exchange rate regime may rise or fall as a consequence of fluctuations in the demand for money. This is not a minor consideration for LDCs since some of them exhibit substantially higher fluctuations in their demand for money than advanced industrial countries. To illustrate the significance of these considerations, let us examine the case in which the $(\log )$ demand for money follows a random walk and, to abstract from the effects highlighted in Krugman's model, let us assume that the demand for money is totally inelastic with respect to the nominal interest rate, and that there is fiscal balance. To simplify the exposition, we will continue making the assumption that domestic prices equal the nominal exchange rate, which is kept constant unless there is a BOP crisis.

Letting $m$ denote the demand for real monetary balances, then we postulate (in discrete time) that

$$
\log m_{t+1}=\log m_{t}+\iota_{t},
$$

where $m$ stands for real monetary balances and $\iota_{t}$ is an i.i.d. random variable. Under these circumstances, the demand for money can fall and create a BOP 
crisis even though there is no fiscal deficit. If $\iota_{t}$ exhibits a mean-zero normal distribution, then the larger its variance, the larger will be the probability of a BOP crisis given an initial level of international reserves. Estimates of equation (51) show Mexico, for instance, with a relatively high standard deviation (about 4 percent per month), while a country like Austria that has successfully pegged to the Deutsche Mark for about 15 years shows a standard deviation which is only about 1 percent per month (see Calvo (1996a)).

In addition, balance of payments problems could be exacerbated by external factors. For example, Calvo and Mendoza (1996) show that there is a significant effect from U.S. short-term interest rates on Mexico's demand for money (specifically, M2). This was reflected in a sizable fall in the demand for money during 1994 and, we suspect, lay at the heart of the Mexican difficulties at the end of the year.

Mexico and other Latin American countries experienced sizable capital inflows in the first half of the 1990s. As argued by Calvo, Leiderman and Reinhart (1993), about 50 percent of these flows stem from external factors, among which U.S. interest rates hold a prominent role. Capital inflows gave rise to an expansion in consumption and investment which, in turn, increased monetary aggregates. Thus, the above-mentioned link between domestic monetary aggregates and external rates of interest may stem from direct opportunity-cost or indirect absorption type considerations. Experience in several countries, and most notably in Mexico, suggests that the fluctuations in monetary aggregates provoked by external factors - and more specifically, by capital flows - could be substantial (see Calvo, Leiderman, and Reinhart (1996) and Calvo and Mendoza (1996)).

An equation like (51), enhanced by taking explicit account of external factors, would be needed to assess the implication of different reserve levels. To illustrate, consider the simple case in which external factors are fully captured by the random term in equation (51). We proceed as follows. Let $v_{t}=m_{t} / R_{t}$, where $R$ stands for international reserves, and $m$ is interpreted as the monetary base. Hence, a BOP crisis in period $t+1$ will take place if $m_{t}-m_{t+1}>R_{t}$. Or, equivalently, if

$$
\log \frac{m_{t+1}}{m_{t}}=\iota_{t+1}<\log \frac{v_{t}-1}{v_{t}} .
$$

Clearly, the probability of a BOP crisis is an increasing function of $v$. Notice that this "vulnerability" index is totally independent of the popular index given by the ratio of reserves to one-month worth of imports. The latter hails back to periods in which reserves were held to ensure smooth trade, while the index developed here is associated with the probability of a BOP crisis as a result of financial fluctuations.

In the above example there exists a direct connection between $m$ and $R$ because we assume $m$ stands for base money (i.e., monetary liabilities of the central bank). If instead $m$ stood for $M 2$, the connection is more indirect 
and depends on how the central bank reacts to shocks in the larger monetary aggregates. If the central bank is not responsible for banking problems but defends the exchange rate parity by intervening and swapping base money for international reserves, then the same analysis developed above is applicable, except that one would need to derive the demand for base money from equation (51) - which would now apply to $M 2$ - minimum reserve requirements, and an equation describing the demand for banks' excess liquidity.

In turn, if the central bank is responsible for ensuring adequate banks' liquidity, then the central bank may be led to expand domestic credit whenever M2 falls. In the extreme case in which banks are fully insulated from any liquidity loss as a consequence of a fall in M2, then M2 is equivalent to base money and the above example is fully applicable. It is worth noting, however, that in practice M2 is much larger than money base and, hence, the probability of a $\mathrm{BOP}$ crisis, given international reserves, is likely to be even higher (unless the volatility of M2 is substantially lower than that of base money).

However, by providing liquidity to offset the fall in M2 the central bank does not prevent M2 from falling. Thus, if a central bank is keen on not letting monetary aggregates fall, then it will increase domestic credit even more and provoke a large loss of reserves after just a small contraction in monetary aggregates. This seems to have been the case in Mexico during 1994. As noted above, Calvo and Mendoza (1996) show that the demand for M2 fell in 1994. Since banks held sizable domestic public debt in their portfolios, rolling back private debt could have been prevented simply by an open market operation that lowered domestic public debt in banks' portfolios by an amount equal to the fall in M2. However, the central bank went beyond that and prior to crisis succeeded in stabilizing the level of M2. This meant a sizable expansion of banks' credit to the private sector (more than 40 percent from January to December 1994). This is quite remarkable given that these measures were undertaken concurrently with a sizable loss of international reserves. This illustrates how much a central bank may be willing to risk in order to safeguard the financial system. Similar behavior was observed in Thailand and Malaysia during the more recent currency crises in South East Asia.

Short-maturity Debt. As pointed out above, the BOP crisis literature has on the whole ignored the role of domestic debt, and followed Krugman (1979) in assuming that fiscal deficits are fully monetized. However, the assumption that fiscal deficits are fully monetized is becoming increasingly unrealistic as governments have started to have access to international capital markets. It has thus become increasingly possible to finance fiscal deficits by floating domestic or international public debt. The maturity structure of this debt varies across countries but it is perhaps fair to say that emerging-markets' governments are likely to exhibit a debt maturity structure slanted towards the short end of the spectrum. Mexico again shows an extreme case in this respect: in December 
1994 about US $\$ 10$ billion domestic debt was due to mature in January, and about US $\$ 30$ billion during 1995 (these are large numbers compared to the US\$6 billion stock of international reserves held by Mexico prior to crisis).

As argued in Calvo (1997) the demand for emerging markets' assets (including public debt) could be highly volatile for two basic reasons. In the first place, the effective rate of return on these assets depends on policy - like everywhere else - but with the added complication that policy in emerging markets is itself highly volatile, reflecting imperfect knowledge of structural parameters and, most importantly, relatively unstable political equilibria. The instability of the latter has likely increased after the breakdown of communism. Therefore, assessing the "state of nature" in an emerging market could be quite costly. It is not enough to know the particulars of the investment project since, in general, its profitability will depend on government regulations. Thus, a project could be very lucrative and yet be unattractive to foreign investors if, for instance, profits are expected to be subject to high taxes (either directly or through the imposition of, for example, foreign exchange controls). Consequently, assessing the state of nature in a given emerging market is likely to entail large "fixed" costs.

The second basic ingredient for high volatility of demand for emerging markets' assets is the so-called "globalization" phenomenon, which is characterized by the fact that investors diversify their portfolios across a large number of emerging markets. Portfolio diversification, in the absence of Tequila or contagion effects, helps to lower portfolio risk. Interestingly, however, the benefit from portfolio diversification does not depend on specific knowledge about the actual state of nature in these economies. For risk hedging, it is enough that the return on the different assets across countries not be perfectly correlated. Thus, for instance, by the law of large numbers, risk could become very low if the different investment projects were stochastically mutually independent.

It is intuitive, and can be rigorously shown in a canonical example (Calvo (1997)), that under the above circumstances (i.e., high information costs and globalization), (i) investors will be very sensitive to "news" about expected returns, and (ii) their incentives to learn about the state of nature in each emerging market will eventually decrease as the number of emerging markets rises. Consequently, in a globalized capital market, investment in emerging markets' assets is likely to be highly sensitive to rumors and relatively unresponsive to "fundamentals."

The above-mentioned phenomenon poses no direct threat of a BOP crisis to the extent that it only involves fluctuations in stock market prices. However, if a large share of domestic debt is coming due in the short run, adverse changes in investors' sentiments about a given emerging market may cause a BOP crisis, particularly if the exchange rate is held fixed. The only available policy under those circumstances (short of devaluing) is to raise interest rates on newly-issued domestic debt. Unfortunately, since investors are ill-informed about fundamentals, the interest rate hike could possibly be taken as a sign of 
weakness and not of strength, since they may feel that higher interest rates are due to the "market" being aware of serious difficulties. Furthermore, even if investors were better informed, the bonds-attack could lead to socially-costly crises.

As an illustration, consider a simple two-period example in which all public debt has one-period maturity and the international riskless interest rate is zero. We assume that debt can be repaid in full, independently of the repayment schedule. However, output is a function of the debt-repayment schedule. Suppose that the economy is controlled by a social planner and is subject to the standard intertemporal budget constraint. Under these circumstances, a social planner will choose the optimal debt-repayment schedule by maximizing the social utility function subject to the budget constraint. A social optimum is attained if the country can freely choose the share of total debt that will be repaid each period. However, if bond-holders insist on getting fully repaid in the first period, we assume that the effort to comply with the financial obligation is so counterproductive that output next period would fall to zero. Thus, even though the country is able to fully repay its outstanding debt in period 1 , no rescheduling would now be possible because potential investors (rationally) expect output to be zero in period 2. Thus, the existence of large short-term maturity debt may give rise to multiple equilibria, and make the country vulnerable to socially costly bond-attacks (see Calvo (1997)) and Cole and Kehoe (1996)).

Domestic debt and credibility In addition, the existence of domesticcurrency denominated public debt can generate BOP difficulties if the exchange rate policy is not fully credible. Suppose the government announces a fixed exchange rate but the public believes that the currency will be devalued next period by $\varepsilon$ times 100 with probability $p$. Then, if investors are risk neutral (in terms of foreign currency) the nominal interest rate satisfies:

$$
\frac{1+i_{t}}{1+\varepsilon} p+\left(1+i_{t}\right)(1-p)=1+r
$$

where $i$ and $r$ and are the domestic and international one-period interest rates, respectively. Clearly, if $\varepsilon$ and $p$ are positive numbers, then the domestic interest rate will exceed the international one. This phenomenon is called the "peso problem" and is a common feature of exchange-rate based stabilization programs.

Suppose the government has a fixed debt level $d$ and that, under full credibility (i.e., $\varepsilon=0$ ), the fiscal deficit is zero (i.e., $\tau-r R_{t}+r d=0$ ). Assuming, for simplicity, that fiscal deficits are fully monetized, it follows that, if there is an expectation of a devaluation (but the currency is not devalued), the discrete version of equation (42) would be given by

$$
R_{t+1}-R_{t}=-\left(\tau-r R_{t}+i_{t} d\right)
$$


with the fiscal deficit now being positive since $i_{t}>r$ due to the peso problem. Hence, the peso problem may put into motion Krugman's BOP-crisis machinery. ${ }^{91}$ Thus, lack of credibility may result in an unsustainable balance of payments even though "fundamentals" could be fully in line with a sustainable situation.

Credibility, the demand for money and fiscal deficits Credibility problems may be reflected through other more subtle, but equally important phenomena. As argued in Section 3, there is typically a consumption boom in the early stages of an exchange rate-based stabilization. Therefore, the demand for money will contain a cyclical component associated with the stabilization program. Higher monetization at the start of the program may give the impression to policymakers that the program enjoys a high degree of credibility. An argument one commonly hears from policymakers is that higher monetization reflects the return of flight capital due to the higher confidence inspired by the stabilization plan. While this is partially true, policymakers may wrongly conclude that the higher stock of real monetary balances is a permanent positive shock. However, if monetization is provoked by the expectation that the program will be abandoned in the non-too-distant future, then the real stock of money will eventually collapse, possibly generating a BOP crisis.

In a recent study, Talvi (1996) shows that if tax revenue is an increasing function of consumption, then prior to crisis the fiscal deficit could shrink, giving the false impression that the fiscal house is in order. In an example, Talvi (1996) shows that the fiscal deficit is nil before the crisis, only to explode afterwards. This pattern of the fiscal deficit is understandably quite confusing to the average policymaker. It is not unusual for the initial slackening of the fiscal constraint to be read as an indication that tax evasion has fallen and, hence, that the higher fiscal revenue has a significant permanent component. As a result, considerable political pressure is built up for more government spending. Unfortunately, if imperfect credibility is the key reason for the initial consumption boom and policymakers give in to pressures to increase government expenditure, then after-crisis fiscal deficits could reach dangerously high levels - which will become apparent only after a crisis erupts and policymakers have little room to manoeuver.

\section{Concluding remarks}

We have concluded our long journey through the fascinating world of inflation stabilization and balance of payment crises in developing countries. After examining the possible rationale behind the existence of chronic inflation in many

\footnotetext{
${ }^{91}$ A related scenario is discussed by Guidotti and Végh (1998). In their model, the Krugman machinery is put into motion by the probability of a devaluation associated with a fiscal consolidation.
} 
developing countries, we carried out some simple econometric exercises which support the existence of two main puzzles in the area of inflation stabilization. First, exchange rate-based stabilization leads to an initial boom in real GDP, private consumption, and durable goods consumption. The recession typically associated with disinflation programs appears only later in the programs. Second, money-based stabilization leads to an early recession, suggesting that the timing of the contraction depends on the nominal anchor which is used (the "recession-now-versus-recession-later" hypothesis). We did not, however, find support for the existence of an investment cycle in exchange rate-based stabilizations. Nor did we find evidence of a significant fall in public consumption around the time of stabilization.

We then reviewed the main theories aimed at explaining these puzzles. We first focused on theories that emphasize expansions in demand: inflation inertia, lack of credibility (temporary policy), and durable goods. The first, inflation inertia, relies on an fall in real interest rates to generate the initial boom. However, within an optimizing framework and in the absence of any wealth effect, this theory would require some implausible parameter configurations to rationalize the initial boom. Also, it would have a hard time explaining the boom in programs in which real interest rates rise on impact. The second, lack of credibility, conforms quite well with the stylized facts. Quantitatively, however, it faces the problems of low intertemporal elasticities of substitution. The third, which relies on the timing of purchases of durable goods, may also reproduce the consumption cycle. Its quantitative relevance has not been evaluated yet.

We then turned to explanations that rely on wealth effects. The first emphasizes supply-side responses - both in labor supply and investment - to the removal of the inflation distortion. While these theories can explain the boom, they cannot explain the late recession. In addition, the fact that the investment cycle was not found significant casts some doubts on the relevance of this mechanism. A second source of wealth effects - cuts in government spending — faces a similar problem. Quantitatively, however, supply-side effects appear to be a critical component of any story aimed at explaining the empirical regularities associated with exchange rate-based stabilization.

To explain the stylized facts of money-based stabilization, we resorted to an optimizing version of traditional sticky-prices model à la Taylor-Fischer. A reduction in the rate of money growth decreases expected inflation and thus the nominal interest rate. This induces an incipient excess demand for real money balances. To restore money-market equilibrium, consumption (and thus output) of home goods needs to fall. This is effected through a real appreciation of the domestic currency. It is worth stressing that sticky prices are essential to this type of model. Without this feature, money-based stabilization would yield the same results as exchange rate-based stabilization. Hence, a model designed to explain both the stylized facts of exchange rate-based and moneybased stabilization - and, in particular, the recession-now-versus-recessionlater hypothesis - requires sticky prices and an interest-rate elastic money 
demand (see Calvo and Végh (1994c)).

Since most exchange rate-based stabilizations end in full-blown balance of payment crises - typically accompanied by banking crises — we took a detailed look at both the mechanics and causes of balance of payments crises in the final leg of our journey (Section 7). While the starting point of this section was Krugman's (1979) seminal paper on balance of payments crises, most of the issues touched upon have come to light after the December 1994 Mexican crisis, and represent very much research in progress. It was argued that simple extensions of Krugman's (1979) model may account for some missing links in the original story: (i) bond-financing may mask the fiscal problems by preventing reserve losses; (ii) imperfect substitutability between domestic and foreign assets opens the door for the central bank to sterilize the effects of reserve losses on money supply; and (iii) an active interest rate policy allows the central bank to postpone the abandonment of the peg and avoid a run in the final stages.

We then analyzed the current account approach; that is, the view that large current account deficits may be unsustainable and lead to balance of payments crises. While this channel could provide a concrete link between the dynamics of exchange rate-based stabilizations and their demise, it still has precious little to say outside the steady-state. In addition, the mechanics through which a BOP crisis would occur are unclear. Finally, we highlighted the role of financial considerations and credibility as contributing factors in unleashing balance of payments crises. Under high information costs and globalization, demand for emerging markets' assets is likely to be highly sensitive to rumors and relatively unresponsive to fundamentals. Changes in investors' sentiments could make it difficult for the government to roll-over a large stock of short-term debt, leading to a bond-led attack. A large stock of short-term debt may also result in selffulfilling crises. Lack of credibility in the peg - and thus high nominal interest rates - may also put into motion Krugman-type machinery in the face of a large stock of domestic debt.

Where do we go from here? In the area of inflation stabilization, much empirical work remains to be done on the empirical regularities of disinflation in chronic inflation countries. Numerous problems need to be addressed, including sample selection and small samples for money-based programs. Small samples for successful exchange rate-based programs also pose a problem since the econometric finding of a late recession is clearly influenced by events in failed programs. A critical aspect in econometric work is to control for other domestic factors, such as trade and structural reforms. Disentangling the effects of stabilization from other reforms is important not only to make sure that the empirical regularities remain such, but also because we may be asking theoretical models to explain "too much", quantitatively speaking. It would also be important to document in a systematic way the behavior of the home goods-sector relative to the traded-goods sector. Some available evidence suggests that the initial boom is much more evident in the home-goods sector. The behavior of investment should also be looked at in more detail. The goal of this research agenda would 
be to establish how much needs to be explained and then build more refined quantitative models to evaluate the alternative hypotheses, along the lines of Rebelo and Végh (1995).

It is clear that we are still far away from a good understanding of the links between the dynamics of exchange rate-based stabilizations and their ultimate demise. While Krugman's (1979) model and variations thereof provide a good description of the mechanics of BOP crises, they offer in general little insights into the more fundamental causes of such crises - over and above the obvious implication that a deterioration in the fiscal balance during a program will put into motion Krugman-type dynamics. We feel that the notion of current account sustainability needs substantial refinement before it can offer a consistent and complete account of the facts, but is an area definitely worth pursuing.

In this respect, a productive area of research would be to focus on the role of the financial and banking sectors in amplifying the expansionary cycle and possibly contributing to the downturn and eventual crisis. A particularly relevant channel has to do with the real estate market. A sizeable fraction of the lending boom goes to finance real estate operations (see, for instance, Guerra (1997a)). These loans are usually made using as collateral temporarily-high asset prices. In the context of the temporariness hypothesis, Guerra (1997b) shows an example in which the fall in asset prices (i.e., land prices) before the abandonment of the program may trigger a banking crisis. While this does not explain the end of the program, it does provide a link between the dynamics of these programs and banking crises.

\section{References}

[1] Adams, C. and D. Gros (1986) "The consequences of real exchange rate rules for inflation: Some illustrative examples", IMF Staff Papers, 33: 439-476.

[2] Agénor, P.R. (1994) "The behavior of real interest rates in exchange ratebased stabilization programs", IMF Working Paper 94/75.

[3] Agénor, P.R., and P. Montiel (1996) Development Macroeconomics. New Jersey: Princeton University Press.

[4] Aizenman, J. (1987) "Inflation, tariffs, and tax enforcement costs", Journal of International Economic Integration, 2: 12-28.

[5] Aizenman, J. (1992) "Competitive externalities and the optimal seigniorage segmentation", Journal of Money, Credit, and Banking, 24: 61-71.

[6] Alesina, A. and A. Drazen (1991) "Why are stabilizations delayed?", American Economic Review, 81: 1170-1188. 
[7] Ball, L. (1994) "What determines the sacrifice ratio", in: N.G. Mankiw, ed., Monetary Policy. Chicago: University of Chicago Press, 155-182.

[8] Barkai, Haim, "The Role of Monetary Policy in Israel's 1985 Stabilization Effort," IMF Working Paper 90/29 (1990).

[9] Bernanke, B.S. and M. Gertler (1995) "Inside the black box: the credit channel of monetary policy transmission", Journal of Economic Perspectives, 9: 27-48.

[10] Bertola, G. and A. Drazen (1993) "Trigger points and budget cuts: Explaining the effects of fiscal austerity", American Economic Review, 83: $11-26$.

[11] Bordo, M.D., and A.J. Schwartz, (1996) "Why clashes between internal and external stability goals end in currency crises", Open Economies Review, 7: 437-468.

[12] Bruno, M. (1993) Crisis, stabilization, and economic reform: Therapy by consensus. Oxford: Oxford University Press.

[13] Bruno, M., and W. Easterly (1995) "Inflation crises and long-run growth", mimeo, World Bank.

[14] Bruno, M. and S. Fischer (1986) "The inflationary process: shocks and accommodation", in: Y. Ben-Porath, ed., The Israeli economy: Maturing through crises. Cambridge: Harvard University Press, 347-371.

[15] Bruno, M. and R. Melnick (1994) "High inflation dynamics: Integrating short-run accommodation and long-run steady-states", mimeo, The World Bank and Bank of Israel.

[16] Bufman, G., and L. Leiderman (1995) "Israel's stabilization: Some important policy lessons", in: R. Dornbusch and S. Edwards, eds., Reform, Recovery, and Growth: Latin America and the Middle East. Chicago: The University of Chicago Press, 177-215.

[17] Cagan, P. (1956) "The monetary dynamics of hyperinflation", in: M. Friedman, ed., Studies in the quantity theory of money. Chicago: University of Chicago Press, 25-117.

[18] Calvo, G.A. (1983) "Staggered prices in a utility-maximizing framework", Journal of Monetary Economics, 12: 383-98.

[19] Calvo, G.A. (1986) "Temporary stabilization: predetermined exchange rates", Journal of Political Economy, 94: 1319-1329.

[20] Calvo, G.A. (1988) "Costly trade liberalizations: Durable goods and capital mobility," IMF Staff Papers, 35: 461-473. 
[21] Calvo, G. (1992) "Are high interest rates effective for stopping high inflation? Some skeptical notes," The World Bank Economic Review, 6: 55-69.

[22] Calvo, G. (1996a) "Capital flows and macroeconomic management: Tequila lessons", International Journal of Finance and Economics, 1: 207223.

[23] Calvo, G. (1996b) "On the resilience of money demand under duress: Notes from the BOP crisis front", mimeo, University of Maryland.

[24] Calvo, G.A. (1997) "Varieties of capital market crises", in: G.A. Calvo and M. King, eds., The debt burden and its consequences for monetary policy. London: Macmillan, forthcoming.

[25] Calvo, G.A. and A. Drazen (1997) "Uncertain duration of reform: Dynamic implications", NBER Working Paper No. 5925, forthcoming in Macroeconomic Dynamics.

[26] Calvo, G.A, L. Leiderman, and C.M. Reinhart (1993) "Capital inflows and real exchange rate appreciation in Latin America: the role of external factors", IMF Staff Papers, 40: 108-151.

[27] Calvo, G.A., L. Leiderman, and C.M. Reinhart (1996) "Inflows of capital to developing countries in the 1990s," Journal of Economic Perspectives, 10: $123-139$.

[28] Calvo, G.A., and E. Mendoza (1996), "Mexico's balance of payments crisis: A chronicle of a death foretold", Journal of International Economics, 41: $235-264$.

[29] Calvo, G.A., C.M. Reinhart, and C.A. Végh (1995) "Targeting the real exchange rate: Theory and evidence", Journal of Development Economics, 47: 97-133.

[30] Calvo, G.A., and C.A. Végh (1992) "Currency Substitution in Developing Countries: An Introduction" Revista de Analisis Economico, 7: 3-27.

[31] Calvo, G.A. and C.A. Végh (1993) "Exchange rate-based stabilisation under imperfect credibility", in: H. Frisch and A.Worgotter, eds., OpenEconomy Macroeconomics. London: MacMillan Press, 3-28.

[32] Calvo, G.A. and C.A. Végh (1994a) "Stabilization dynamics and backward-looking contracts", Journal of Development Economics, 43: 5984 .

[33] Calvo, G.A. and C.A. Végh (1994b) "Inflation stabilization and nominal anchors", Contemporary Economic Policy, 12: 35-45. 
[34] Calvo, G.A. and C.A. Végh (1994c) "Credibility and the dynamics of stabilization policy: A basic framework", in: C. Sims, ed., Advances in Econometrics, Vol. II. Cambridge: Cambridge University Press, 377-420.

[35] Calvo, G.A. and C.A. Végh (1995) "Fighting inflation with high interest rates: The small-open economy case under flexible prices", Journal of Money, Credit and Banking, 27: 49-66.

[36] Canavese, A.J., and G. Di Tella (1988) "Inflation stabilization or hyperinflation avoidance? The case of the Austral Plan in Argentina, 1985-1987", in: M. Bruno, G. Di Tella, R. Dornbusch, and S. Fischer, eds., Inflation stabilization: The experience of Israel, Argentina, Brazil, Bolivia, and Mexico. Cambridge, Mass.: MIT Press, 153-190.

[37] Cardoso, E., (1991) "From inertia to megainflation: Brazil in the 1980s", in: M. Bruno, S. Fischer, E. Helpman, and N. Liviatan, eds., Lessons of Economic Stabilization and its aftermath. Cambridge, Mass.: MIT Press, 143-186.

[38] Chadha, B., P. Masson, and G. Meredith (1992) "Models of inflation and the costs of disinflation", IMF Staff Papers, 39: 395-431.

[39] Chari, V.V., L. Jones, and R.E. Manuelli (1995) "The growth effects of monetary policy", Quarterly Review, Federal Reserve Bank of Minneapolis, Fall, 18-32.

[40] Cole, H.L. and T.J. Kehoe (1996), "A self-fulfilling model of Mexico's 1994-1995 debt crisis", Journal of International Economics, 41: 309-330.

[41] Corbo, V. (1985) "Reforms and macroeconomic adjustments in Chile during 1974-84", World Development, 13: 893-916.

[42] Corbo, V., J. De Melo, and J. Tybout (1986) "What went wrong with the recent reforms in the Southern Cone?", Economic Development and Cultural Change, 34: 607-640.

[43] Correia, I., and P. Teles (1996) "Is the Friedman rule optimal when money is an intermediate good?", Journal of Monetary Economics, 38: 223-244.

[44] De Gregorio, J., P.E Guidotti, and C.A.Végh (1998) "Inflation stabilization and the consumption of durable goods", Economic Journal, forthcoming.

[45] De Melo, M., C. Denizer, and A. Gelb (1995) "From plan to market: Patterns of transition", mimeo, World Bank.

[46] De Pablo, J.C. (1974) "Relative prices, income distribution and stabilization plans: The Argentine experience, 1967-1970", Journal of Development Economics, 1: 167-189. 
[47] Diaz-Alejandro, C.F. (1981) "Southern-Cone stabilization plans," in: W.R. Cline and S. Weintraub, eds., Economic stabilization in developing countries. Washington: The Brookings Institution, 119-141.

[48] Dornbusch, R. (1980) Open Economy Macroeconomics. New York: Basic Books.

[49] Dornbusch, R. (1982) "Stabilization policies in developing countries: what have we learned?" World Development, 10: 701-708.

[50] Dornbusch, R. (1995) "Progress report on Argentina", in: R. Dornbusch and S. Edwards, eds., Reform, Recovery, and Growth: Latin America and the Middle East. Chicago: The University of Chicago Press, 223-238.

[51] Dornbusch, R., I. Goldfajn, and R. Valdes (1995) "Currency crises and collapses", Brookings Papers on Economic Activity, 2: 253-315.

[52] Dornbusch, R. and M.H. Simonsen (1987) Inflation stabilization with incomes policy support: a review of recent experience in Argentina, Brazil, and Israel. New York: Group of Thirty.

[53] Dornbusch, R., F. Sturzenegger, and H. Wolf (1990) "Extreme Inflation: Dynamics and Stabilization", Brookings Papers on Economic Activity, 2: $1-84$.

[54] Dornbusch, R. and A. Werner (1994) "Mexico: stabilization, reform, and no growth", Brookings Papers on Economic Activity, 1: 253-315.

[55] Drazen, A. and E. Helpman (1988) "Stabilization with exchange rate management under uncertainty", in E. Helpman, A. Razin, and E. Sadka, eds., Economic effects of the government budget. Cambridge, Mass.: MIT Press, 310-327.

[56] Drazen, A. and V. Grilli (1993) "The benefits of crises for economic reforms", American Economic Review, 83: 598-607.

[57] Easterly, W. (1996) "When is stabilization expansionary", Economic Policy, 22: 67-107.

[58] Easterly, W., P. Mauro, and K. Schmidt-Hebbel (1995) "Money demand and seigniorage-maximizing inflation", Journal of Money, Credit and Banking, 27: 583-603.

[59] Easterly, W., and K. Schmidt-Hebbel (1994) "Fiscal adjustment and macroeconomic performance: A synthesis," in: W. Easterly, C.A. Rodriguez, and K. K. Schmidt-Hebbel, eds., Public sectors deficits and macroeconomic performance. Oxford: Oxford University Press, 15-78. 
[60] Echenique, F. and A. Forteza (1997) "Are stabilization programs expansionary?", mimeo, Berkeley and Universidad de la Republica (Uruguay).

[61] Edwards, S. (1991) "Stabilization and Liberalization Policies in Central and Eastern Europe: Lessons from Latin America," NBER Working Paper No. 3816 .

[62] Edwards, S. and A. Cox Edwards (1991) Monetarism and Liberalization: The Chilean Experiment. Chicago: University of Chicago Press.

[63] Edwards, S. and G. Tabellini (1991) "Explaining fiscal policies and inflation in developing countries", Journal of International Money and Finance, 10: S16-S48.

[64] Edwards, S. and C.A. Végh (1997) "Banks and macroeconomic disturbances under predetermined exchange rates", Journal of Monetary Economics, forthcoming.

[65] Eichengreen, B., A.K. Rose, and C. Wyplosz (1995) "Exchange market mayhem: The antecedents and aftermath of speculative attacks", Economic Policy, 21: 249-312.

[66] Eichengreen, B., A.K. Rose, and C. Wyplosz (1996) "Contagious currency crises", NBER Working Paper no. 5681.

[67] Fauvel, Y. and L. Samson (1991) "Intertemporal substitution and durable goods: An empirical analysis, Canadian Journal of Economics, 24: 192205.

[68] Favaro, E. (1996) "Peru's stabilization under a floating exchange rate", mimeo, World Bank.

[69] Feenstra, R. (1985) "Anticipated devaluations, currency flight, and direct trade controls in a monetary economy", American Economic Review, 75: $386-401$.

[70] Fernandez, R. (1985) "The expectations management approach to stabilization in Argentina, 1976-82", World Development, 13: 871-892.

[71] Finch, M.H.J. (1979) "Stabilisation policy in Uruguay since the 1950s", in: R. Thorp and L. Whitehead, eds., Inflation and Stabilisation in Latin America. New York: Holmes and Meier Publishers, 144-180.

[72] Fischer, S. (1977) "Long-term contracts, rational expectations, and the optimal money supply rule", Journal of Political Economy, 85: 191-205.

[73] Fischer, S. (1986a) "Exchange rate versus money targets in disinflation", in: Indexing, inflation and economic policy. Cambridge, Mass.: MIT Press, 247-262. 
[74] Fischer, S. (1986b) "Contracts, credibility, and disinflation", in: Indexing, inflation and economic policy. Cambridge, Mass.: MIT Press, 221-245.

[75] Fischer, S. (1988) "Real balances, the exchange rate, and indexation: real variables in disinflation," Quarterly Journal of Economics, 53: 27-49.

[76] Fischer, S., R. Sahay, and C.A. Végh (1996) "Stabilization and growth in transition economies: the early experience", Journal of Economic Perspectives, 10: 45-66.

[77] Fischer, S., R. Sahay, and C.A. Végh (1997) "Modern high inflation", mimeo, International Monetary Fund.

[78] Flood, R.P., and P.M. Garber (1984), "Collapsing exchange rate regimes: Some linear examples," Journal of International Economics, 17: 1-13.

[79] Flood, R.P., P.M. Garber, and C. Kramer (1996), "Collapsing exchange rate regimes: Another linear example" Journal of International Economics, 41: 223-234.

[80] Foxley, A. (1980) "Stabilization policies and stagflation: the cases of Brazil and Chile," World Development, 8: 887-912.

[81] Frankel, J.A., and A.K. Rose (1996) "Currency crises in emerging markets: Empirical indicators", NBER Working Paper No. 5437.

[82] Friedman, M. (1969) "The optimum quantity of money", in: The Optimum quantity of money and other essays. Chicago: Aldine Polishing Company, 1-50.

[83] Garber, P.M. (1982) "Transition from inflation to price stability," Carnegie-Rochester Conferences Series on Public Policy, 16: 887-912.

[84] Ghezzi, P. (1996) "Exchange rate-based stabilization: when to switch anchors? (mimeo, University of California at Berkeley).

[85] Giavazzi, F. and M. Pagano (1990) "Can severe fiscal contractions be expansionary? Tales of two small european countries, NBER Macroeconomics Annual, Cambridge, Massachusetts: MIT Press, 75-111.

[86] Gordon, R.J. (1982) "Why stopping inflation may be costly: Evidence from fourteen historical episodes", in: R.E. Hall, ed., Inflation: causes and effects. Chicago: University of Chicago Press, 11-40.

[87] Gould, D.M. (1996) "Does the choice of nominal anchor matter?" Federal Reserve Bank of Dallas Working Paper No. 9611. 
[88] Guerra, A. (1997a) "Residential real estate booms, financial deregulation and capital inflows: An international perspective," mimeo, Banco de Mexico.

[89] Guerra, A. (1997b) "Asset inflation and financial crisis: The temporariness hypothesis", mimeo, Banco de Mexico.

[90] Guidotti, P.E., and C.A. Végh (1992) "Macroeconomic interdependence under capital controls: A two-country model of dual exchange rates", Journal of International Economics, 32: 353-367.

[91] Guidotti, P.E., and C.A. Végh (1993) "The optimal inflation tax when money reduces transactions costs: A reconsideration," Journal of Monetary Economics, 31:189-205.

[92] Guidotti, P.E. and C.A.Végh (1998) "Losing credibility: The stabilization blues", International Economic Review, forthcoming.

[93] Hanson, J. and J.de Melo (1985) "External shocks, financial reforms, and stabilization attempts in Uruguay during 1974-1983," World Development, 13: 917-939.

[94] Harberger, A.C. (1981) "In step and out of step with the world inflation: A summary history of countries, 1952-1976", in: M.J. Flanders and A. Razin, eds., Development in an inflationary world. New York: Academic Press, 35-46.

[95] Harberger, A.C. (1982) "The Chilean economy in the 1970s: Crisis, stabilization, liberation, reform", Carnegie-Rochester Conference Series on Public Policy, 17: 115-152.

[96] Helpman, E. and A. Razin (1987) "Exchange rate management: intertemporal trade-offs", American Economic Review, 77: 107-123.

[97] Heymann, D. (1991) "From sharp disinflation to hyperinflation, twice: The Argentine experience", in: M. Bruno, S. Fischer, E. Helpman, and N. Liviatan, eds., Lessons of Economic Stabilization and its aftermath. Cambridge, Mass.: MIT Press, 103-130.

[98] Heymann, D. and A. Leijonhufvud (1995) High inflation. Oxford: Clarendon Press.

[99] Hirschman, A. (1963) Journeys toward progress: Studies of economic policy-making in Latin America. Cambridge, Mass.: Harvard University Press.

[100] Hoffmaister, A. and C.A. Végh (1996) "Disinflation and the recession-nowversus-recession-later hypothesis: Evidence from Uruguay," IMF Staff Papers, 43: 355-394. 
[101] Jones, M., Sanguinetti, P., and M. Tommasi (1997) "Political and institutional determinants of fiscal outcomes in the Argentine provinces", mimeo, Universidad de San Andres (Argentina).

[102] Kafka, A. (1967), "The Brazilian stabilization program, 1964-66", Journal of Political Economy, 75 (supplement): 596-634.

[103] Kaminsky, G.L. and L. Leiderman (1996) "High real interest rates in the aftermath of disinflation: Is it lack of credibility," mimeo (Board of Governors of the Federal Reserve System and Tel-Aviv University), forthcoming in Journal of Development Economics.

[104] Kaminsky, G. and C.M Reinhart (1995) "The twin crises: The causes of banking and balance of payment problems", mimeo, Board of Governors of the Federal Reserve System and University of Maryland.

[105] Keynes, J.M. (1924) Monetary reform. New York: Harcourt, Brace.

[106] Kiguel, M. and N. Liviatan (1989) "The old and the new in heterodox stabilization programs" Working Paper WPS 323, Country Economics Department, The World Bank.

[107] Kiguel, M., and N. Liviatan (1992) "The business cycle associated with exchange rate based stabilization", The World Bank Economic Review, 6: 279-305.

[108] Kiguel, M., and N. Liviatan (1996) "Stopping three big inflations: Argentina, Brazil, and Peru", in: R. Dornbusch and S. Edwards, eds., Reform, Recovery, and Growth: Latin America and the Middle East. Chicago: The University of Chicago Press, pp. 369-408.

[109] Kimbrough, K. (1986) "The optimum quantity of money rule in the theory of public finance", Journal of Monetary Economics, 18: 277-284.

[110] Krugman, P. (1979) "A model of balance-of-payment crisis", Journal of Money, Credit and Banking, 11: 311-325.

[111] Krugman, P. (1996) "Are currency crises self-fulfilling?", NBER Macroeconomics Annual, Cambridge, Mass.: MIT Press, 345-378.

[112] Kumhof, M. (1997) "Balance of payments crises: The role of short-term debt", mimeo, University of Maryland.

[113] Kydland, F.E., and C.E. Zarazaga (1997) "Is the business cycle of Argentina "different"?, Economic Review, Federal Reserve Bank of Dallas, Fourth quarter, 21-36.

[114] Lahiri, A. (1996a) "Exchange rate based stabilization under real frictions: The role of endogenous labor supply," mimeo, UCLA. 
[115] Lahiri, A., (1996b) "Disinflation programs under policy uncertainty: Insights for exchange-rate based stabilization programs", mimeo, UCLA.

[116] Lahiri, A. (1997) "Controlling capital flows: targeting stocks versus flows", mimeo, UCLA.

[117] Lahiri, A. and C.A. Végh (1997) "Krugman balance of payments crises: Are they for real?", mimeo, UCLA.

[118] Leiderman, L. (1993) Inflation and disinflation: The Israeli experiment. Chicago: The University of Chicago Press.

[119] Lizondo, J.S. (1991) "Real exchange rate targets, nominal exchange rate policies, and inflation", Revista de Análisis Económico, 6: 5-22.

[120] Lucas, R.E. Jr., (1990) "Liquidity and interest rates", Journal of Economic Theory, 50: 237-264.

[121] Masson, P.R., M.A. Savastano, and S. Sharma (1997) "The scope for inflation targeting in developing countries" IMF Working Paper 97/130.

[122] Medeiros, C. (1994) "A case of a monetary stabilization program: The Dominican Republic's economic program, 1990-1993", mimeo, International Monetary Fund.

[123] Meltzer, A. (1994) "Book review: Heterodox policy and economic stabilization", Journal of Monetary Economics, 34: 581-600.

[124] Mendoza, E. and M. Uribe (1996) "The syndrome of exchange rate-based stabilizations and the uncertain duration of currency pegs", International Finance Discussion Papers No. 548, Board of Governors of the Federal Reserve System.

[125] Milesi-Ferretti, G.M and A. Razin (1996) Current-account sustainability. Princeton Studies in International Finance No. 81.

[126] Modiano, E.M. (1988) "The Cruzado first attempt: The Brazilian stabilization program of February 1986", in: M. Bruno, G. Di Tella, R. Dornbusch, and S. Fischer, eds., Inflation stabilization: The experience of Israel, Argentina, Brazil, Bolivia, and Mexico. Cambridge, Mass.: MIT Press, 215-258.

[127] Mondino, G., F. Sturzenegger, and M. Tommasi (1996) "Recurrent high inflation and stabilization: A dynamic game", International Economic Review, 37: 981-996.

[128] Montiel, P., and J. Ostry (1991) "Macroeconomic implications of real exchange rate targeting in developing countries", IMF Staff Papers, 38: 872-900. 
[129] Obstfeld, M. (1985) "The capital inflows problem revisited: A stylized model of Southern-Cone disinflation," Review of Economic Studies, 52: 605-625.

[130] Obstfeld, M. (1986) "Capital controls, the dual exchange rate and devaluation", Journal of International Economics, 20: 1-20.

[131] Obstfeld, M. (1995) "International currency experience: new lessons and lessons relearned," Brooking Papers on Economic Activity, 1: 119-220.

[132] Obstfeld, M. and K. Rogoff (1995) "The mirage of fixed exchange rates", Journal of Economic Perspectives, 9: 73-96.

[133] Okun, A.M. (1978) "Efficient disinflationary policies", American Economic Review, Papers and Proceedings: 68: 348-352.

[134] Ostry, J. and C.M. Reinhart (1992) "Private saving and terms of trade shocks", IMF Staff Papers, 39: 495-517.

[135] Pazos, F. (1972) Chronic Inflation in Latin America. New York: Prager Publishers.

[136] Phelps, E. (1973) "Inflation in the Theory of Public Finance", Swedish Journal of Economics, 75: 67-82.

[137] Ramos, J. (1986) Neoconservative economics in the Southern Cone of Latin America, 1973-1983. Baltimore: The Johns Hopkins University Press.

[138] Rebelo, S. (1993) "Inflation in fixed exchange rate regimes: The recent Portuguese experience," in: F. Torres and F. Giavazzi, eds., Adjustment and growth in the european monetary union. Cambridge: Cambridge University Press, 128-149.

[139] Rebelo, S. (1997) "What happens when countries peg their exchange rates? (The real side of monetary reforms)", NBER Working Paper No. 6168 .

[140] Rebelo, S. and C.A. Végh (1995) "Real effects of exchange rate-based stabilization: an analysis of competing theories," NBER Macroeconomics Annual, 125-174.

[141] Reinhart, C.M. and C.A. Végh (1994) "Inflation stabilization in chronic inflation countries", mimeo, International Monetary Fund.

[142] Reinhart, C.M. and C.A. Végh (1995a) "Nominal interest rates, consumption booms, and lack of credibility: a quantitative examination," Journal of Development Economics, 46: 357-378. 
[143] Reinhart, C.M., and C.A. Végh (1995b) "Do exchange rate-based stabilizations carry the seeds of their own destruction? mimeo, IMF.

[144] Rodriguez, C.A.(1982) "The Argentine stabilization plan of December 20th", World Development, 10: 801-811.

[145] Rojas-Suarez, L., and S.R. Weisbrod (1995) "Financial fragilities in Latin America: The 1980s and 1990s", Occasional Paper No. 132, International Monetary Fund.

[146] Roldos, J. (1995) "Supply-side effects of disinflation programs", IMF Staff Papers, 42: 158-183.

[147] Roldos, J. (1997) "On gradual disinflation, the real exchange rate, and the current account", Journal of International Money and Finance, 16: $37-54$.

[148] Sachs, J., A. Tornell, and A. Velasco (1995) "The collapse of the Mexican peso: what have we learned," NBER Working Paper No. 5142.

[149] Sachs, J., A. Tornell, and A. Velasco (1996) "Financial crises in emerging markets: The lessons from 1995", NBER Working Paper No. 5576.

[150] Sahay, R. and C.A. Végh (1996) "Inflation and stabilization in transition economies: An analytical interpretation of the evidence", Journal of Policy Reform, 1: 75-108.

[151] Sanguinetti, P. (1994) "Intergovernmental transfers and public sector expenditure: A game theoretic-approach" Estudios de Economia (Universidad de Chile), 21: 181-212.

[152] Santaella, J. and A. Vela (1996) "The 1987 Mexican disinflation program: An exchange rate-based stabilization?", IMF Working Paper 96/24.

[153] Sargent, T. (1982) "The ends of four big inflations", in: R.E. Hall, ed., Inflation: causes and effects. Chicago: University of Chicago Press, 41-97.

[154] Savastano, M.A. (1996) "Dollarization in Latin America: recent evidence and policy issues, in: P. Mizen and E.J. Pentecost, eds., The macroeconomics of international currencies: theory, policy and evidence. London: Edward Elgar.

[155] Stockman, A. (1981) "Anticipated inflation and the capital stock in a cash-in-advance economy", Journal of Monetary Economics, 8: 387-393.

[156] Talvi, E. (1995) "Fiscal policy and the business cycle associated with exchange rate-based stabilizations: Evidence from Uruguay's 1978 and 1991 programs," Working Paper Series 313, Inter-American Development Bank. 
[157] Talvi, E. (1996) "Exchange rate-based stabilization with endogenous fiscal response", Working Paper Series 324, Inter-American Development Bank, forthcoming in the Journal of Development Economics.

[158] Taylor, J.B. (1979) "Staggered wage setting in a macro model", American Economic Review, Papers and Proceedings, 69: 108-113.

[159] Taylor, J.B. (1980) "Aggregate dynamics and staggered contracts", Journal of Political Economy, 88: 1-23.

[160] Taylor, J.B. (1983) "Union wage settlements during a disinflation", American Economic Review, 73: 981-993.

[161] Tornell, A. and A. Velasco (1995) "Fixed versus flexible exchange rates: Which provides more fiscal discipline? NBER Working Paper No. 5108.

[162] Uribe, M. (1994) "Comparing the welfare costs and the initial dynamics of alternative temporary stabilization policies," mimeo, Board of Governors of the Federal Reserve System.

[163] Uribe, M. (1995) "Real exchange rate targeting and macroeconomic instability", International Finance Discussion Papers No. 505, Board of Governors of the Federal Reserve System.

[164] Uribe, M. (1997a) "Exchange-rate-based inflation stabilization: The initial real effects of credible plans", Journal of Monetary Economics, 39: 197-221.

[165] Uribe, M. (1997b) "A note on the analytics of credible exchange rate-based disinflation when money facilitates firms' transactions", mimeo, Board of Governors of the Federal Reserve System.

[166] Végh, C.A. (1989) "Government spending and inflationary finance: A public finance approach", IMF Staff Papers, 36: 657-677.

[167] Végh, C.A. (1992) "Stopping high inflation: An analytical overview", IMF Staff Papers, 39: 626-695.

[168] Végh, C.A. (1997) "Monetary policy, interest rate rules, and inflation targets", mimeo, UCLA.

[169] Velasco, A., (1993) "A model of endogenous fiscal deficits and delayed fiscal reforms", C.V. Starr Center Report 93-4, New York University.

[170] Venegas-Martinez, F. (1997) "Temporary stabilization: A stochastic analysis", mimeo, CIDE (Mexico).

[171] Viana, L. (1990) "Uruguay's stabilization plan of 1968", mimeo, CERES, Uruguay. 
[172] Wicker, E. (1986) "Terminating hyperinflation in the dismembered Hapsburg monarchy;" American Economic Review, Vol. 76, 350-364.

[173] Williamson, J. (1993) "Issues posed by portfolio investment in developing countries", in: S. Claessens and S. Gooptu, eds., Portfolio investment in developing countries, Discussion paper No. 228, The World Bank.

[174] Woodford, M., (1990) "The optimum quantity of money", in: B.F. Friedman and F.H. Hahn, eds., Handbook of Monetary Economics. Amsterdam: North-Holland, 1067-1152.

[175] Zarazaga, C., (1996) "Recurrent hyperinflations in a dynamic game with imperfect monitoring in the appropriation of seignorage", mimeo, Federal Reserve Bank of Dallas. 
Table 1 Major Exchange Rate-Based Inflation Stabilization Plans

\begin{tabular}{|c|c|c|c|c|c|c|}
\hline \multirow[b]{2}{*}{ Programs } & \multirow[b]{2}{*}{ Beginning and Ending Dates } & \multirow[b]{2}{*}{ Exchange Rate Arrangement } & \multicolumn{3}{|c|}{ Inflation Rate 1/ } & \multirow[b]{2}{*}{ Did the program end in crisis? } \\
\hline & & & initial 2/ & Lowest & $\begin{array}{c}\text { Date } \\
\text { achieved }\end{array}$ & \\
\hline Brazil 1964 & March 1964-August 1968 & Fixed exchange rate, with periodic devaluations & 93.6 & 18.9 & May 1968 & $\begin{array}{l}\text { No. In spite of switching to a regime of minidevaluations } \\
\text { after the Augut } 1968 \text { devaluation, inflation remained } \\
\text { stable around } 20 \% \text { per year until } 1974 \text {. }\end{array}$ \\
\hline Argentina 1967 & March 1967-May 1970 & Fixed exchange rate & 26.4 & 5.7 & Feb. 1969 & $\begin{array}{l}\text { Yes. The initial } 14 \% \text { devaluation was followed by } \\
\text { further devaluations and an } 82 \% \text { decline in reserves. }\end{array}$ \\
\hline Uruguay 1968 & June 1968-December 1971 & Fixed exchange rate & 182.9 & 9.5 & June 1969 & $\begin{array}{l}\text { Yes. The initial } 48 \% \text { devaluation was followed by } \\
\text { successive devaluations and an } 81 \% \text { decline in reserves. }\end{array}$ \\
\hline Chilean tablita & February 1978-June 1982 & $\begin{array}{l}\text { Feb. 1978-June 1979: pre-announced crawling peg } \\
\text { June 1979-June 1982: fixed exchange rate }\end{array}$ & 52.1 & 3.7 & May 1982 & $\begin{array}{l}\text { Yes. About } 65 \% \text { percent of reserves were lost and } \\
\text { by February } 1983 \text { the currency had depreciated by } 55 \% \text {. }\end{array}$ \\
\hline Uruguayan tablita & October 1978-November 1982 & Pre-announced crawling & 41.2 & 11.0 & Nov. 1982 & $\begin{array}{l}\text { Yes. By March } 1983 \text { the central bank had lost } 90 \% \text { of } \\
\text { its reserves and the peso had devalued by } 70 \% \text {. }\end{array}$ \\
\hline Argentine tablita & December 1978-February 1981 & Pre-announced crawling peg & 169.9 & 81.6 & Feb. 1981 & $\begin{array}{l}\text { Yes. By April } 1982 \text {, the currency had } \\
\text { depreciated by } 410 \% \text { and reserves fell by } 71 \% \text {. }\end{array}$ \\
\hline Israel 1985 & July 1985 -present & Exchange rate policy had four stages $3 /$ & 445.4 & 7.8 & Nov. 1995 & No. Inflation has continued to decline gradually. \\
\hline Austral (Argentina) & June 1985-September 1986 & $\begin{array}{l}\text { June 1985-March 1986: fixed exchange rate } \\
\text { March 1986-Sept. 1986: crawling peg }\end{array}$ & $1,128.9$ & 50.1 & June 1986 & $\begin{array}{l}\text { Yes. By September } 1987 \text {, reserves had fallen by } 75 \% \\
\text { and monthly inflation was above } 10 \text { percent. }\end{array}$ \\
\hline Cruzado (Brazil) & February 1986-November 1986 & Fixed exchange rate & 286.0 & 76.2 & Nov. 1986 & $\begin{array}{l}\text { Yes. By March 1987, reserves had fallen by } 58 \% \\
\text { and by December 1987, monthly inflation had reached } 21 \% \text {. }\end{array}$ \\
\hline Mexico 1987 & December 1987-December 1994 & $\begin{array}{l}\text { Feb. 1988-Dec. 1988: fixed exchange rate 4/ } \\
\text { Jan. 1989-Nov. 1991: preannounced crawling peg } \\
\text { Nov. 1991-Dec. 1994: exchange rate band }\end{array}$ & 159.0 & 6.7 & Sept. 1994 & $\begin{array}{l}\text { Yes. Between February } 1994 \text { and January } 1995 \text {, reserves } \\
\text { fell by } 85 \% \text { and, following the December } 1994 \text { devaluation, } \\
\text { the peso depreciated by about } 100 \text { percent in four months. }\end{array}$ \\
\hline Uruguay 1990 & December 1990-present & $\begin{array}{l}\text { Exchange rate band with a declining rate } \\
\text { of devaluation }\end{array}$ & 133.7 & 24.4 & Dec. 1996 & $\begin{array}{l}\text { No. Uruguay was not much affected by the Mexican crisis, } \\
\text { and inflation has continued to decline gradually. }\end{array}$ \\
\hline \multicolumn{2}{|c|}{ Convertibility (Argentina) April 1991-present } & $\begin{array}{l}\text { Currency board with a one-to-one parity } \\
\text { to the U.S. dollar. }\end{array}$ & 267.0 & -0.3 & May 1996 & $\begin{array}{l}\text { No. As the Mexican crisis of December } 1994 \text { spilled over, } \\
\text { reserves fell by } 52 \% \text { between mid-1994 and March 1995, but } \\
\text { the fixed parity was maintained. }\end{array}$ \\
\hline
\end{tabular}

Notes: Unless otherwise noted, all pegs are against the U.S. dollar. The fall in reserves is measured with respect to peak reserves during program. Data end in Dec. 1996.

1/ Twelve-month inflation rate.

2/ Twelve-month inflation rate in the month in which the program was implemented.

3/ On July 1985, the New Israeli Shekel was pegged to the US dollar; in August 1986 the dollar peg was replaced by a peg to a basket of currencies. The second phase of the program consisted of a

sequence of devaluations during 1987-early 1989. In January 1989 a band with a fixed central parity was introduced. In December 1991 a crawling band was introduced.

4/ The exchange rate fixing followed some initial devaluations between Dec. 15 and Feb. 29, 1988

Source: Reinhart and Vegh (1995b), based on data from International Financial Statistics (IMF) and case studies cited in the text. 
Table 2 Exchange rate-based stabilization: Panel regressions

\begin{tabular}{|c|c|c|c|c|c|}
\hline & \multicolumn{5}{|c|}{ Dependent variables } \\
\hline & $\begin{array}{l}\text { Growth in } \\
\text { real GDP }\end{array}$ & $\begin{array}{l}\text { Growth in } \\
\text { real private } \\
\text { consumption }\end{array}$ & $\begin{array}{l}\text { Growth in } \\
\text { real durables } \\
\text { consumption }\end{array}$ & $\begin{array}{l}\text { Growth in } \\
\text { real fixed } \\
\text { investment }\end{array}$ & $\begin{array}{l}\text { Growth in } \\
\text { real public } \\
\text { consumption }\end{array}$ \\
\hline & $(1)$ & $(2)$ & $(3)$ & (4) & $(5)$ \\
\hline Early dummy & $\begin{array}{l}1.84^{* *} \\
(0.73)\end{array}$ & $\begin{array}{l}3.33^{* *} \\
(1.57)\end{array}$ & $\begin{array}{l}14.74^{*} \\
(7.89)\end{array}$ & $\begin{array}{l}0.80 \\
(3.76)\end{array}$ & $\begin{array}{l}-3.78 \\
(2.58)\end{array}$ \\
\hline Late dummy & $\begin{array}{l}-3.49^{* * *} \\
(0.82)\end{array}$ & $\begin{array}{l}-4.60^{* *} \\
(1.93)\end{array}$ & $\begin{array}{l}-29.61^{* * *} \\
(10.01)\end{array}$ & $\begin{array}{l}-4.46 \\
(4.62)\end{array}$ & $\begin{array}{l}-5.42^{*} \\
(3.19)\end{array}$ \\
\hline Libor (real) & $\begin{array}{l}-0.31^{* *} \\
(0.14)\end{array}$ & $\begin{array}{l}-0.68^{* *} \\
(0.31)\end{array}$ & $\begin{array}{l}-3.31^{* *} \\
(1.59)\end{array}$ & $\begin{array}{l}-2.81^{* * *} \\
(1.59)\end{array}$ & $\begin{array}{l}-1.18^{* *} \\
(0.52)\end{array}$ \\
\hline OCED growth & $\begin{array}{l}0.71^{* * *} \\
(0.20)\end{array}$ & $\begin{array}{l}-0.21 \\
(0.47)\end{array}$ & $\begin{array}{l}1.97 \\
(2.44)\end{array}$ & $\begin{array}{l}1.97 \\
(2.44)\end{array}$ & $\begin{array}{l}0.75 \\
(0.78)\end{array}$ \\
\hline Terms of trade & $\begin{array}{l}-0.03 \\
(0.02)\end{array}$ & $\begin{array}{l}0.02 \\
(0.03)\end{array}$ & $\begin{array}{l}-0.18 \\
(0.20)\end{array}$ & $\begin{array}{l}-0.18 \\
(0.20)\end{array}$ & $\begin{array}{l}-0.04 \\
(0.05)\end{array}$ \\
\hline No. of obs. & 64 & 64 & 64 & 64 & 64 \\
\hline
\end{tabular}

Note: All dependent variables are expressed in per capita terms. The sample includes Argentina, Chile, Israel, and Mexico for the period 1978-1993. Standard errors in parenthesis. Method of estimation was a 2-step GLS procedure which allows for groupwise and cross-group heteroscedasticity and groupwise autocorrelation. The regressions include fixed effects (not reported). Significance at the 10,5, and 1 percent level is indicated by one, two, and three stars, respectively 
Table 3. Major Money-Based Inflation Stabilization Plans

\begin{tabular}{|c|c|c|c|c|c|}
\hline \multirow[b]{2}{*}{ Programs } & \multirow[b]{2}{*}{ Beginning and Ending Dates } & \multirow[b]{2}{*}{ Monetary/exchange rate policy } & \multicolumn{3}{|c|}{ Inflation Rate 1/ } \\
\hline & & & initial 2/ & Lowest & $\begin{array}{c}\text { Date } \\
\text { achieved }\end{array}$ \\
\hline Chile 1975 & April 1975-December 1977 & $\begin{array}{l}\text { Control of monetary aggregates was cornerstone. } \\
\text { Exchange rate adjusted by past inflation } 3 /\end{array}$ & 394.3 & 63.4 & Dec. 1977 \\
\hline Bonex (Argentina) & December 1989-February 1991 & $\begin{array}{l}\text { Drastic cut in liquidity through forced rescheduling of domestic debt. } \\
\text { Floating exchange rate. }\end{array}$ & $4,923.3$ & 287.3 & Feb. 1991 \\
\hline Collor (Brazil) & March 1990-January 1991 & $\begin{array}{l}\text { Sharp liquidity squeeze through freeze of } 70 \% \text { of financial assets. } \\
\text { Tight monetary policy. Exchange rate had a passive role } \\
\text { and simply accommodated inflation. }\end{array}$ & $5,747.3$ & 1119.5 & Jan. 1991 \\
\hline Dominican Rep. 1990 & August 1990-present & $\begin{array}{l}\text { Aug. 1990-Dec. 1990: Exchange controls/black markets } \\
\text { Jan. 1991-July 1991: dual exchange rates } \\
\text { July 1991: exchange market unification and floating }\end{array}$ & 60.0 & 2.5 & Nov. 1993 \\
\hline Peru 1990 & August 1990-present & Control of monetary aggregates; dirty floating. & $12,377.8$ & 10.2 & Sept. 1995 \\
\hline
\end{tabular}

Note: Data end in December 1996.

1/ Twelve-month inflation rate.

2/ Twelve-month inflation rate in the month in which the program was implemented.

3/ Significant measures toward lifting capital controls enacted only in June 1979 (Edwards and Cox Edwards (1991))

Sources: International Financial Statistics (IMF), Edwards and Cox Edwards (1991), Medeiros (1994), Kiguel and Liviatan (1996), and Favaro (1996). 
Table 4. Real GDP per capita growth before and after stabilization

\begin{tabular}{|l|c|c|c|c|}
\hline \multirow{2}{*}{} & \multicolumn{2}{|c|}{ Individual regresssions } & \multicolumn{2}{|c|}{ Joint regression } \\
\cline { 2 - 5 } & Exchange & Money- & Exchange & Money- \\
\cline { 2 - 5 } & rate-based & based & rate-based & based \\
\cline { 2 - 5 } & $(1)$ & $(2)$ & \multicolumn{2}{|c|}{3 (1) } \\
\hline \multirow{2}{*}{$\mathrm{T}-2$} & -0.46 & $-6.86^{* * *}$ & -0.71 & $-6.96^{* * *}$ \\
& $(1.09)$ & $(1.56)$ & $(1.18)$ & $(1.66)$ \\
\hline \multirow{2}{*}{$\mathrm{T}-1$} & 0.94 & $-4.18^{* * *}$ & 0.47 & $-4.45^{* * *}$ \\
& $(1.08)$ & $(1.59)$ & $(1.13)$ & $(1.59)$ \\
\hline \multirow{2}{*}{$\mathrm{T}$} & $2.00^{*}$ & $-10.83^{* * *}$ & 1.42 & $-10.98^{* * *}$ \\
& $(1.03)$ & $(1.60)$ & $(1.11)$ & $(1.58)$ \\
\hline \multirow{2}{*}{$\mathrm{T}+1$} & $2.91^{* * *}$ & $-3.84^{* *}$ & $2.34^{* *}$ & $-3.87^{* *}$ \\
& $(1.03)$ & $(1.55)$ & $(1.11)$ & $(1.58)$ \\
\hline \multirow{2}{*}{$\mathrm{T}+2$} & -0.21 & $-3.20^{*}$ & -0.61 & -2.84 \\
& $(1.04)$ & $(1.71)$ & $(1.11)$ & $(1.76)$ \\
\hline \multirow{2}{*}{$\mathrm{T}+3$} & 0.49 & -0.83 & -0.26 & -1.12 \\
& $(1.10)$ & $(1.71)$ & $(1.20)$ & $(1.77)$ \\
\hline \multirow{2}{*}{$\mathrm{T}+4$} & $-1.99^{*}$ & 0.39 & $-2.33^{* *}$ & 0.49 \\
& $(1.11)$ & $(1.64)$ & $(1.17)$ & $(1.71)$ \\
\hline \multirow{2}{*}{ Libor (real) } & $-0.62^{* * *}$ & $-0.58^{* * *}$ & \multicolumn{2}{|c|}{$-0.60^{* * *}$} \\
& $(0.13)$ & $(0.13)$ & \multicolumn{2}{|c|}{$(0.13)$} \\
\hline \multirow{2}{*}{ OCED growth } & $0.55^{* * *}$ & $0.57^{* * *}$ & \multicolumn{2}{|c|}{$-0.55^{* * *}$} \\
& $(0.16)$ & $(0.17)$ & \multicolumn{2}{|c|}{$0.013^{*}$} \\
\hline \multirow{2}{*}{ Terms of trade } & $0.012^{*}$ & $0.013^{*}$ & \multicolumn{2}{|c|}{$20067)$} \\
\hline No. of observations & $(0.0069)$ & $(0.0067)$ & \multicolumn{2}{|c|}{$(0067)$} \\
\hline
\end{tabular}

Note: Dependent variable is real GDP per capita growth. The sample comprises Argentina, Brazil, Chile, Dominican Republic, Israel, Mexico, Peru, and Uruguay for the period 1971-1995. Standard errors in parenthesis. Method of estimation was a 2-step GLS procedure, which allows from groupwise and crossgroup heteroscedasticity and groupwise autocorrelation. All regressions include fixed country effects (not reported). Significance at the 10, 5, and 1 percent level is indicated by one, two, and three stars, respectively. 
Table 5. Real GDP per capita growth: Panel estimates

\begin{tabular}{|l|c|c|c|}
\hline & OLS & Fixed effects & 2-step GLS \\
\hline & $(1)$ & $(2)$ & $(3)$ \\
\hline Exchange rate-based stabilization: & $2.31^{* *}$ & $2.40^{* *}$ & $1.73^{* *}$ \\
Early dummy & $(0.96)$ & $(1.03)$ & $(0.75)$ \\
\hline Exchange rate-based stabilization: & $-2.33^{* *}$ & $-2.18^{*}$ & $-1.64^{* *}$ \\
Late dummy & $(1.10)$ & $(1.16)$ & $(0.80)$ \\
\hline Money-based: & $-4.90^{* * *}$ & $-5.46^{* *}$ & $-6.29^{* * *}$ \\
Early dummy & $(1.40)$ & $(1.44)$ & $(1.30)$ \\
\hline Money-based: & 1.59 & 0.72 & -1.89 \\
Late dummy & $(1.66)$ & $(1.69)$ & $(1.22)$ \\
\hline Libor (real) & $-0.50^{* * *}$ & $-0.61^{* * *}$ & $-0.62^{* * *}$ \\
& $(0.13)$ & $(0.14)$ & $(0.13)$ \\
\hline OCED growth & $0.55^{* * *}$ & $0.45^{* *}$ & $0.62^{* *}$ \\
& $(0.19)$ & $(0.19)$ & $(0.16)$ \\
\hline Terms of trade & $0.01^{*}$ & 0.005 & 0.01 \\
& $(0.006)$ & $(0.015)$ & $(0.007)$ \\
\hline Adjusted R ${ }^{2}$ & 0.18 & 0.25 & - \\
\hline No. of observations & 200 & 200 & 200 \\
\hline
\end{tabular}

Note: Dependent variable is expressed in per capita terms. The sample includes Argentina, Brazil, Chile, Dominican Republic, Israel, Mexico, Peru, and Uruguay for the period 1971-1995. Standard errors in parenthesis. The 2step GLS procedure allows for groupwise and cross-group heteroscedasticity and groupwise autocorrelation. The regressions include fixed effects (not reported). Significance at the 10, 5, and 1 percent level is indicated by one, two, and three stars, respectively 
Figure 1. Exchange rate-based stabilization

A. Inflation and Devaluation

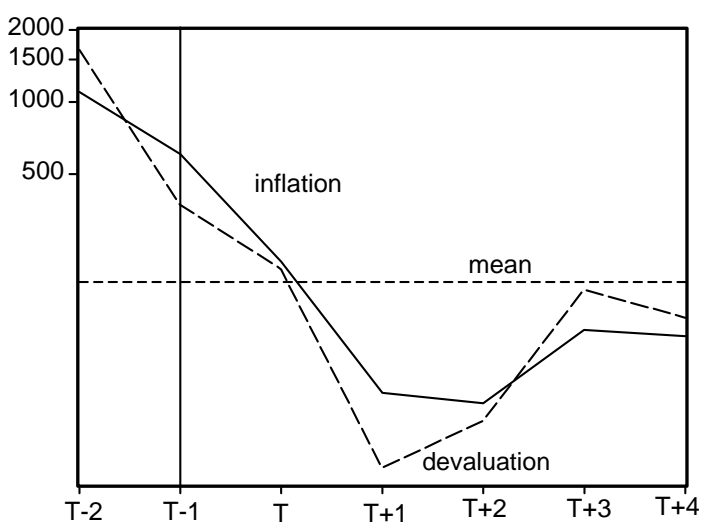

C. Current Account

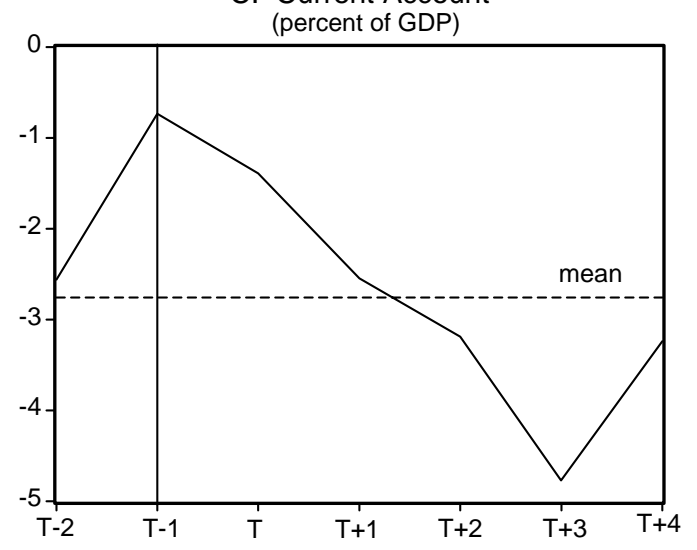

E. Real Lending Rate

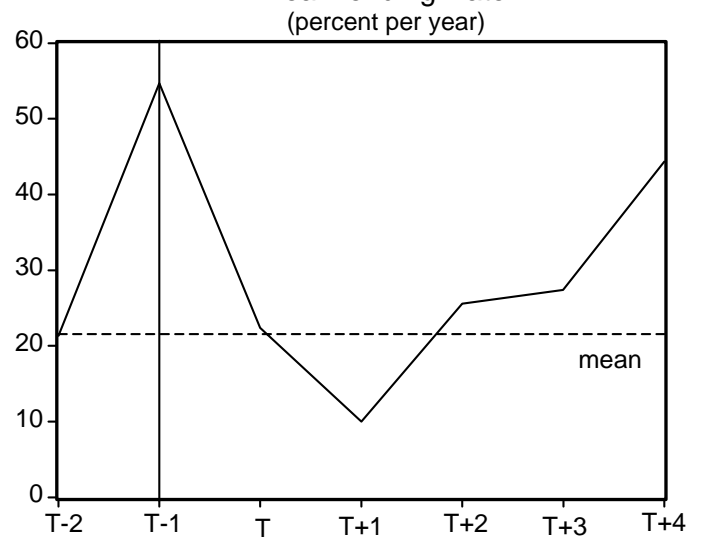

B. Real Exchange Rate (index number, T-1=100)

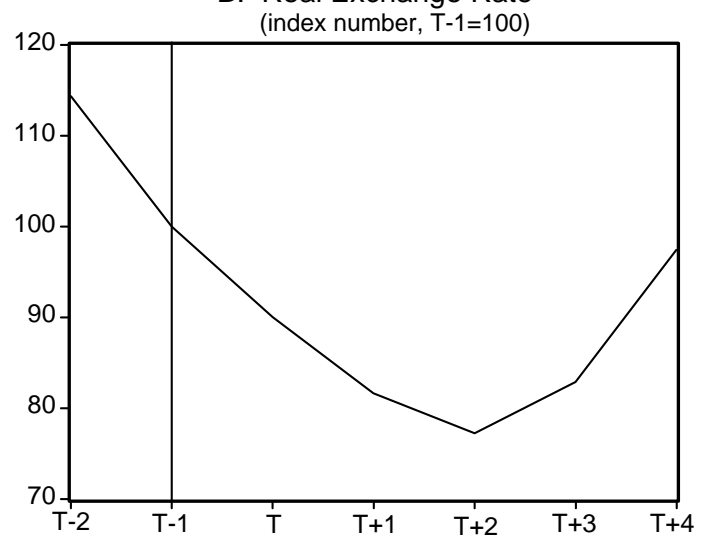

D. Public Consumption Growth (percent per year)

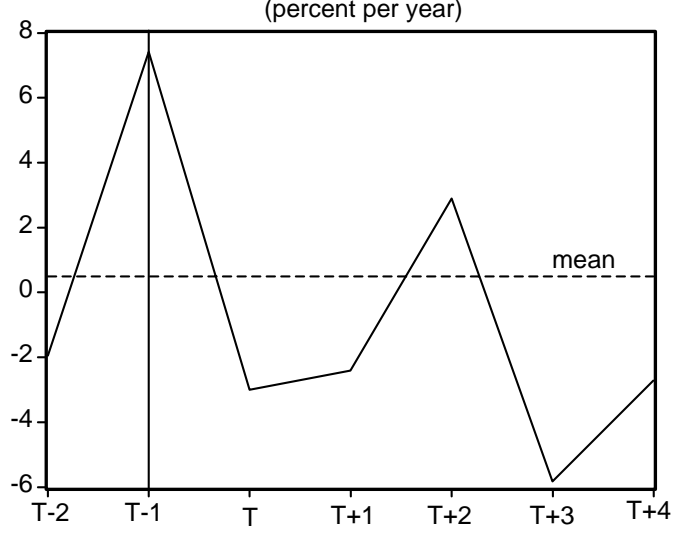

F. Real Deposit Rate

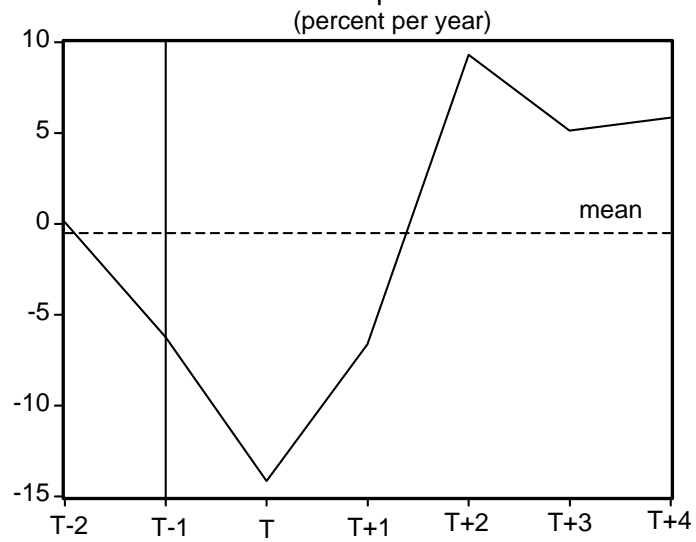

Souce: See text 
Figure 2. GDP, consumption, and investment in exchange rate-based stabilization

A. Real GDP Growth (percent per year)

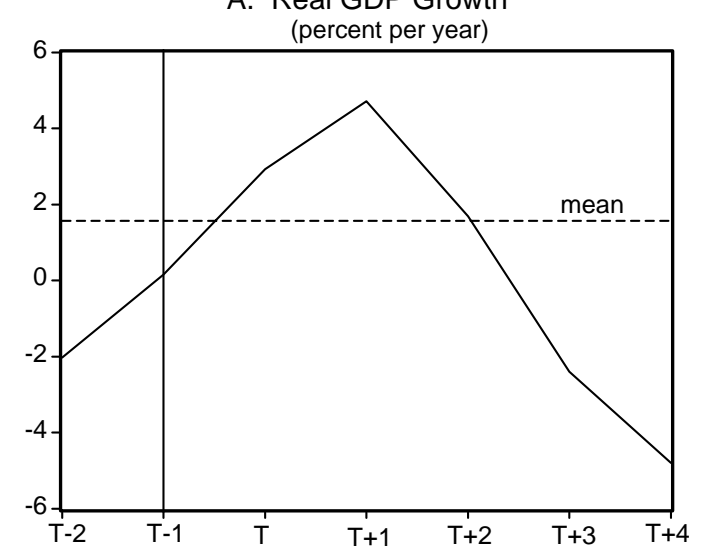

C. Durables Consumption Growth

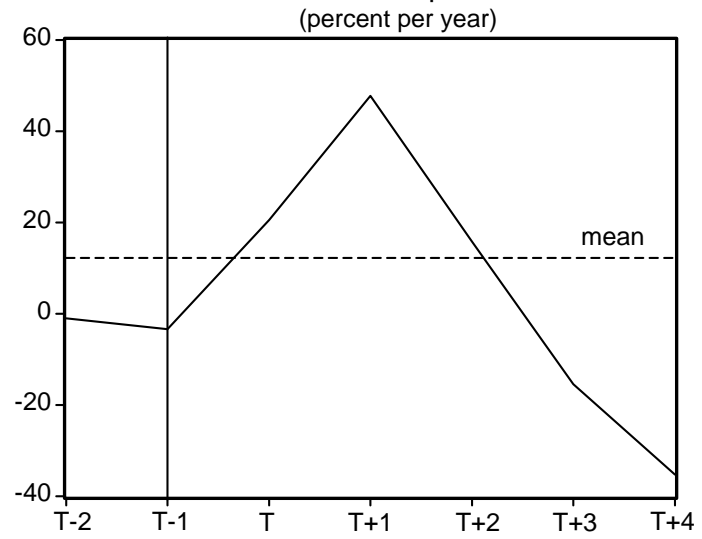

E. Private Consumption to GDP

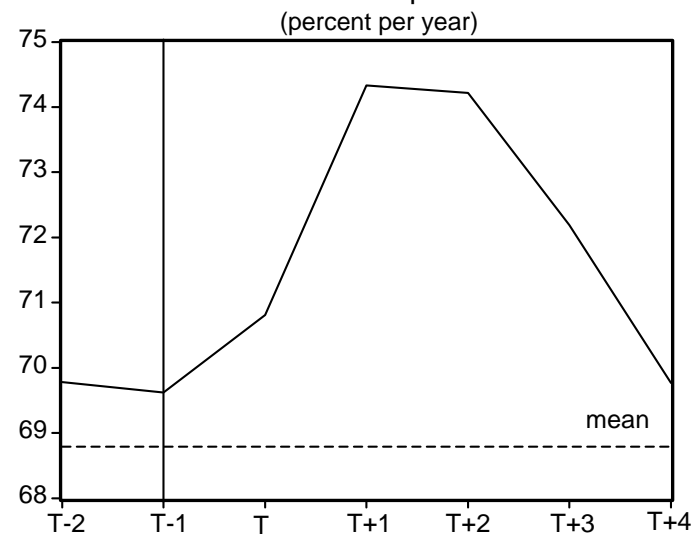

B. Private Consumption Growth

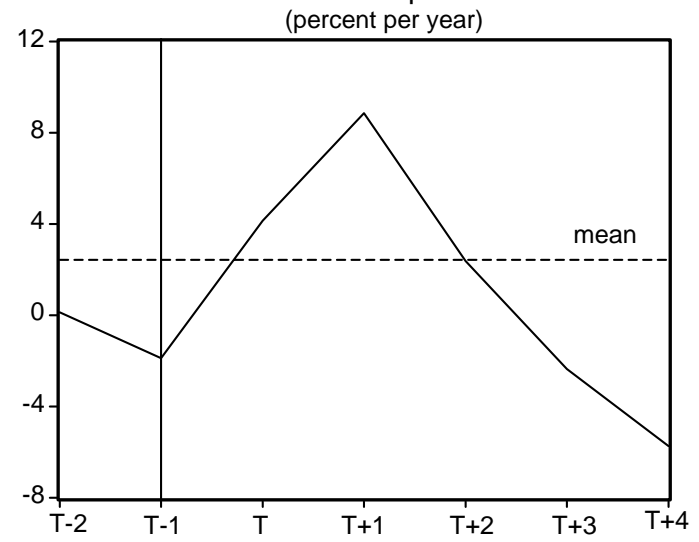

D. Fixed Investment Growth

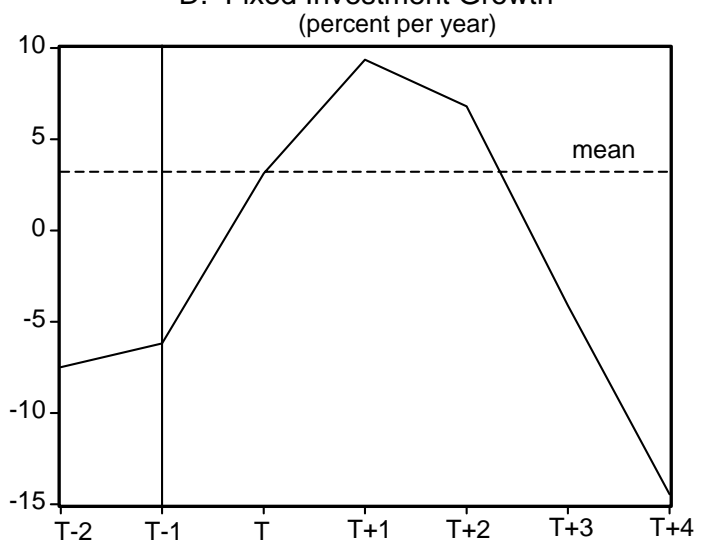

F. Fixed Investment to GDP

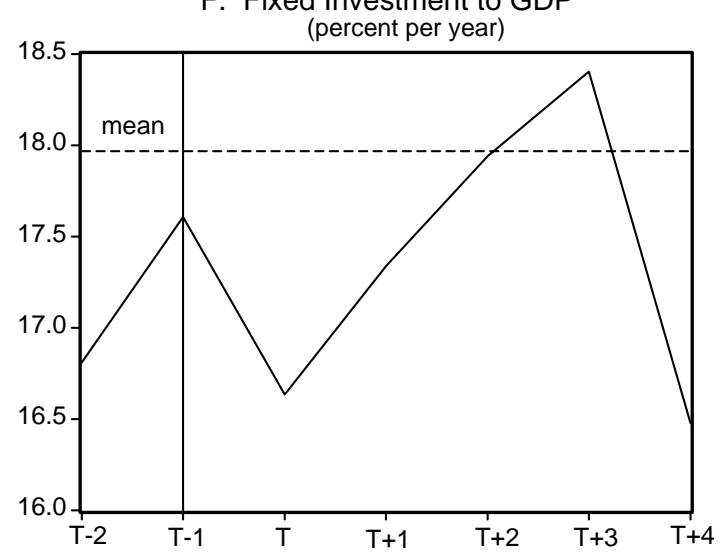

Source: See text 
Figure 3. Money-based stabilization

A. Inflation and money growth

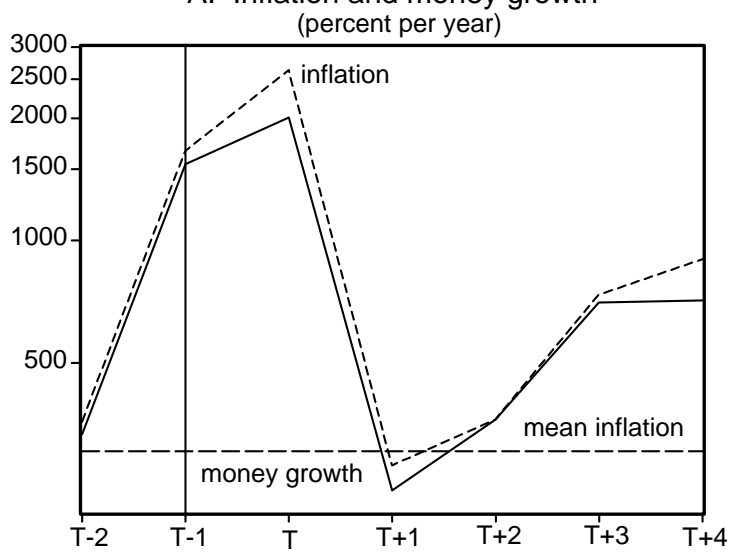

C. Real Exchange Rate

(index number, T-1=100)

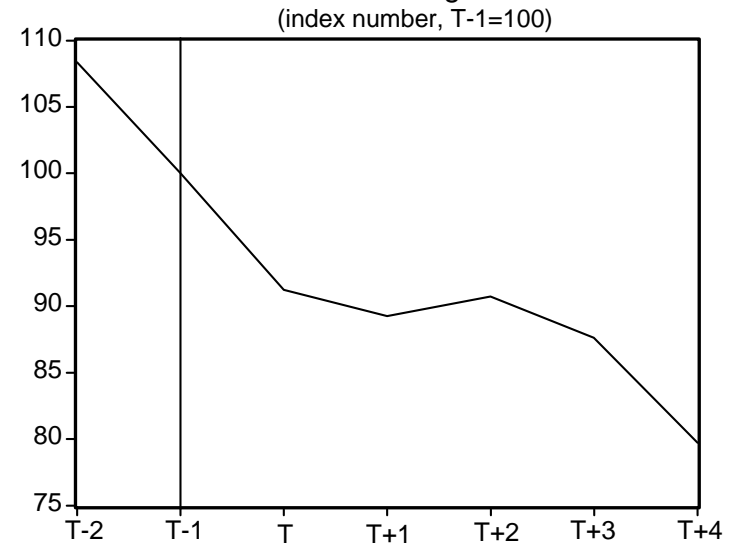

B. Real GDP Growth (percent per year)

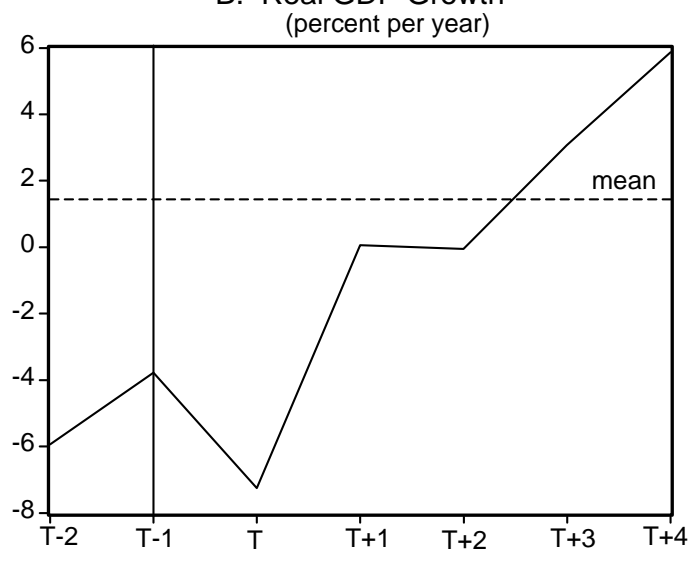

F. Current Account

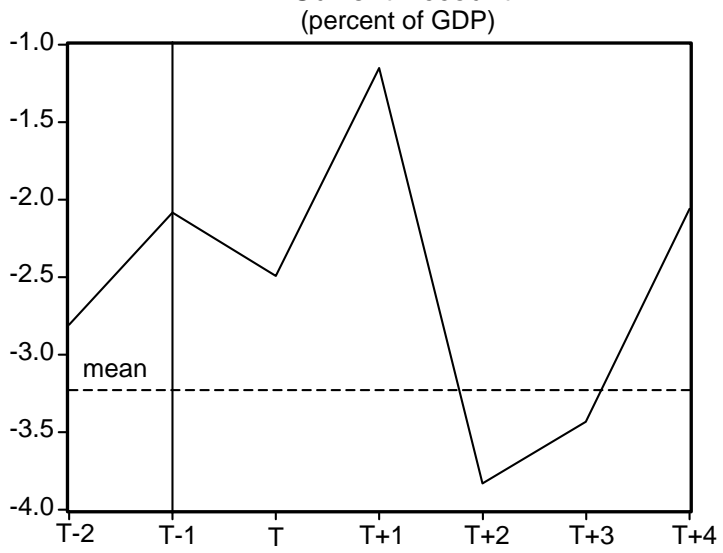

Source: See text 
Figure 4. Inflation inertia: Dynamic system

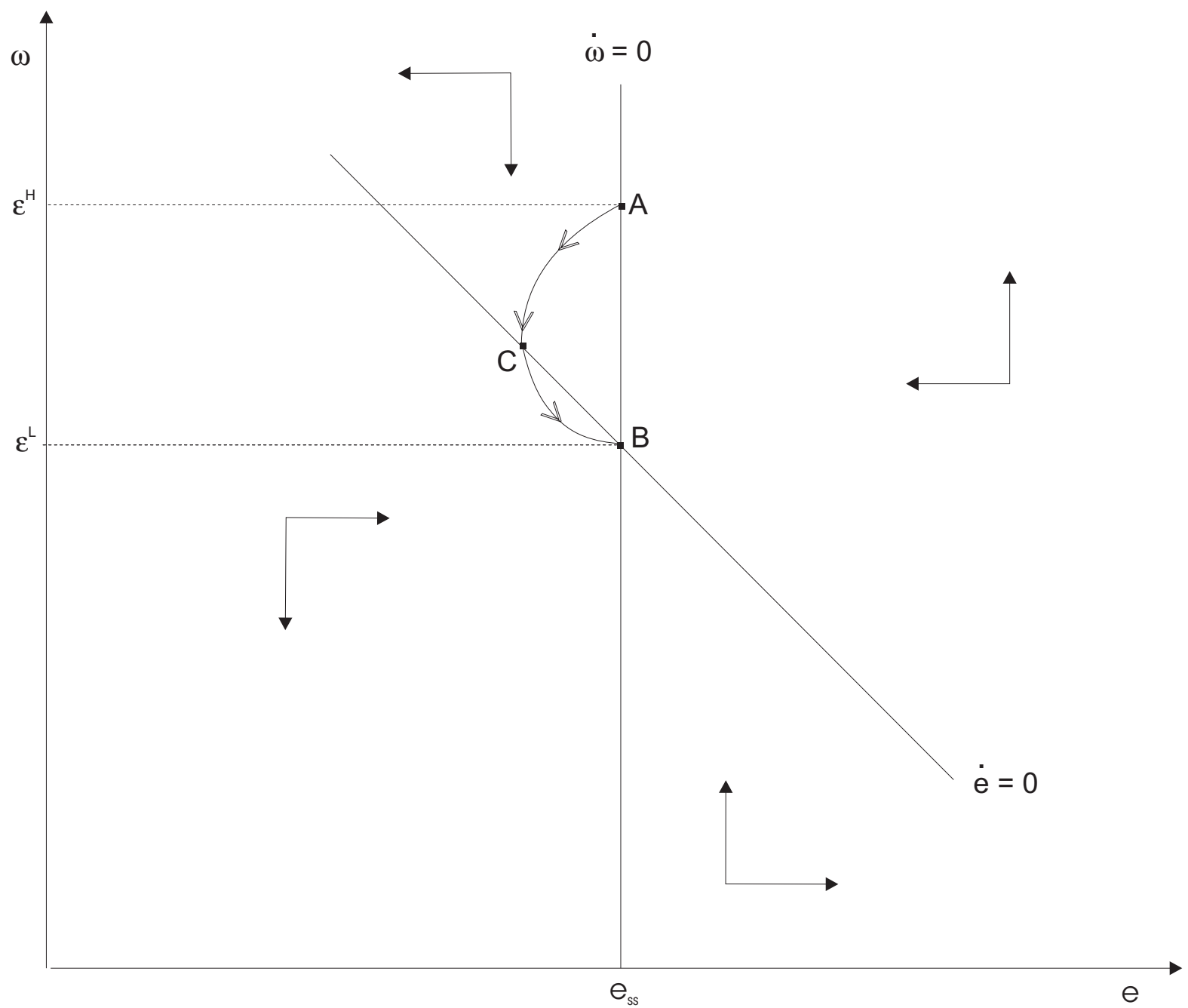


Figure . Disinflation un er inflation inertia

A. ate of e aluation

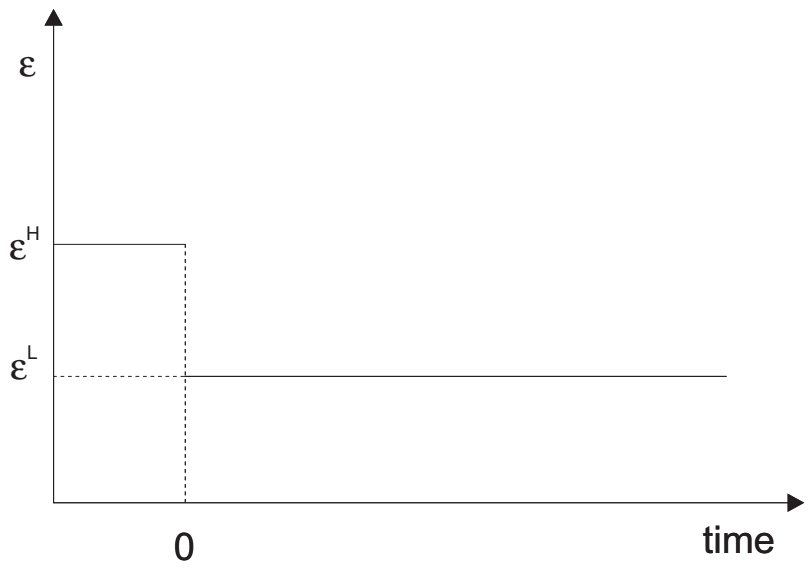

C. eal e c ange rate

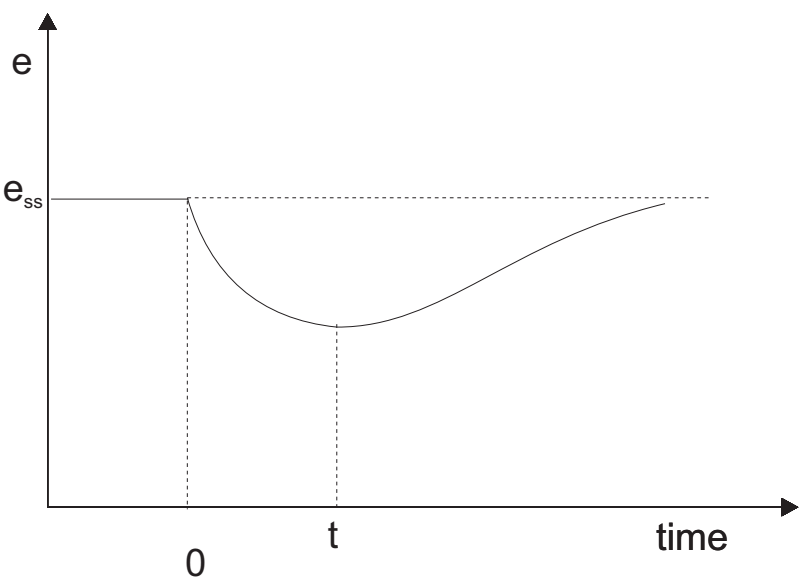

. Inflation rate

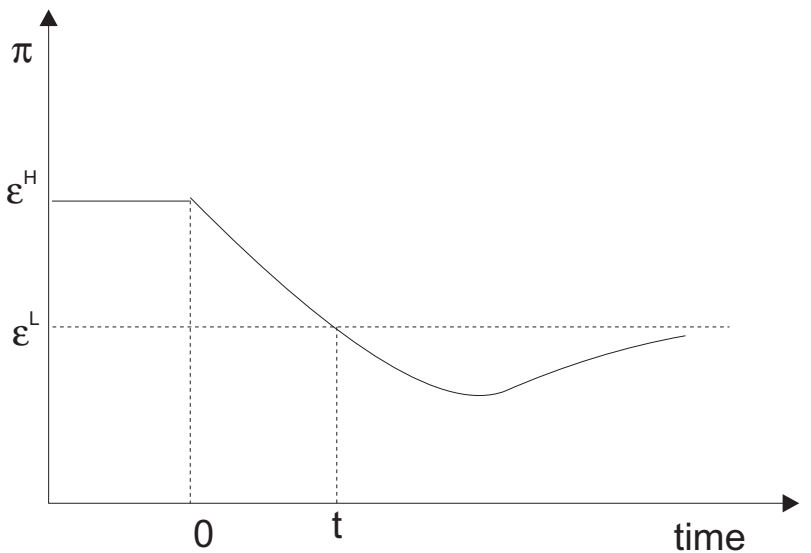

B. ominal age gro $t$

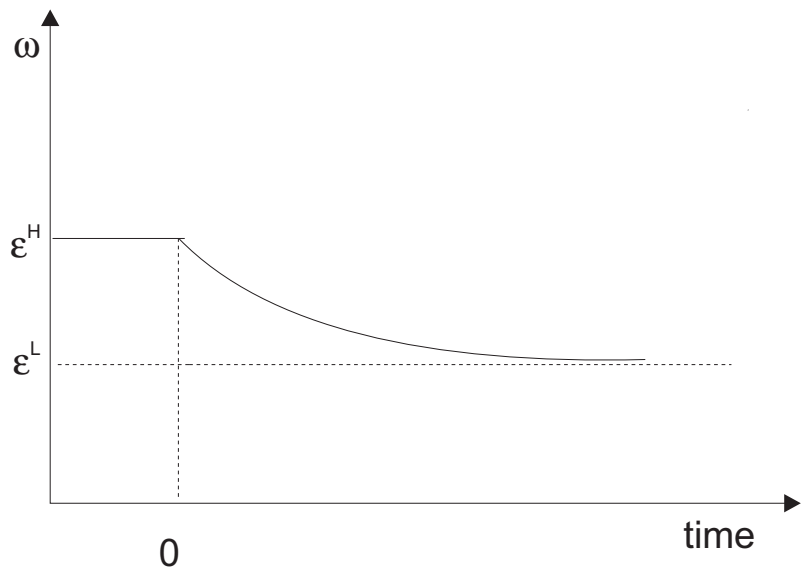

D. Consum tion of ome goo s

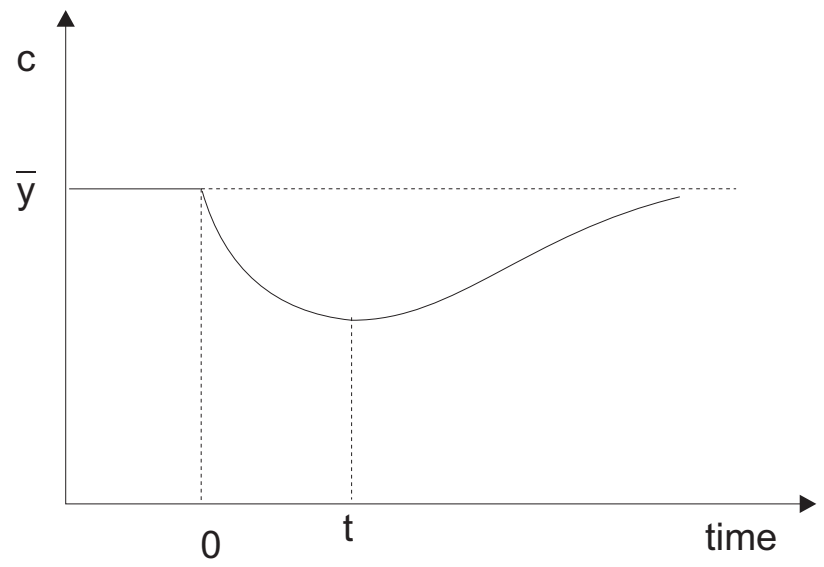

F. Domestic real interest rate

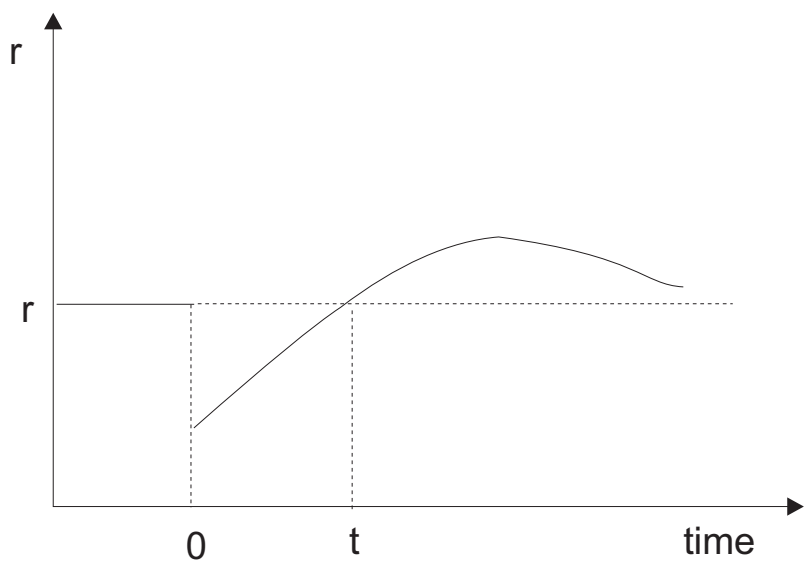


Figure . em orary ta ili ation

A. ate of e aluation

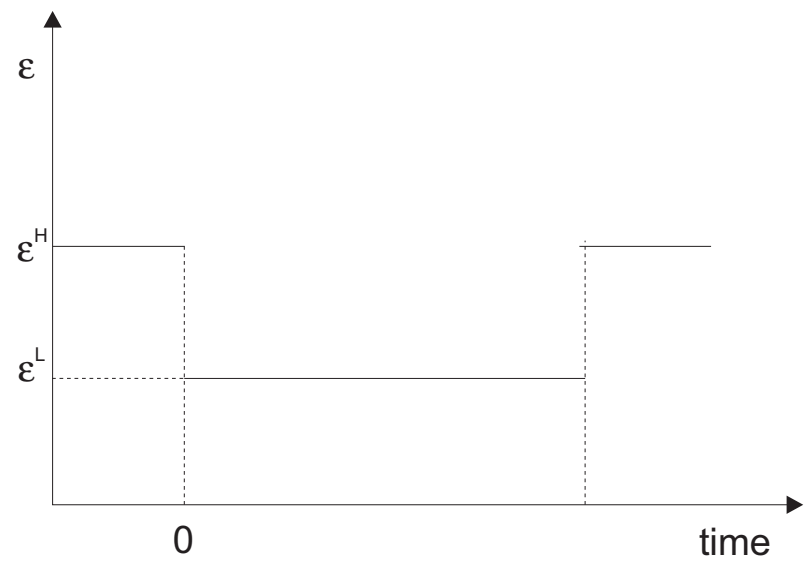

C. Current account

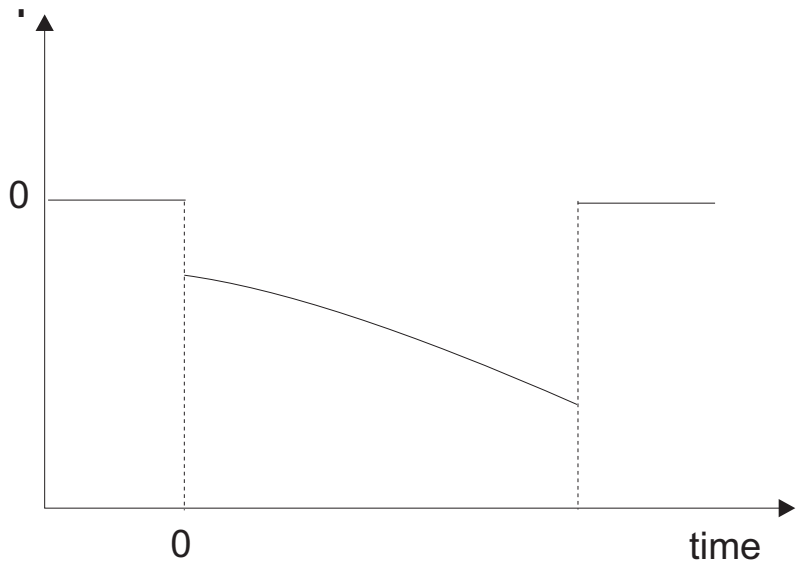

B. Consum tion of tra e goo s

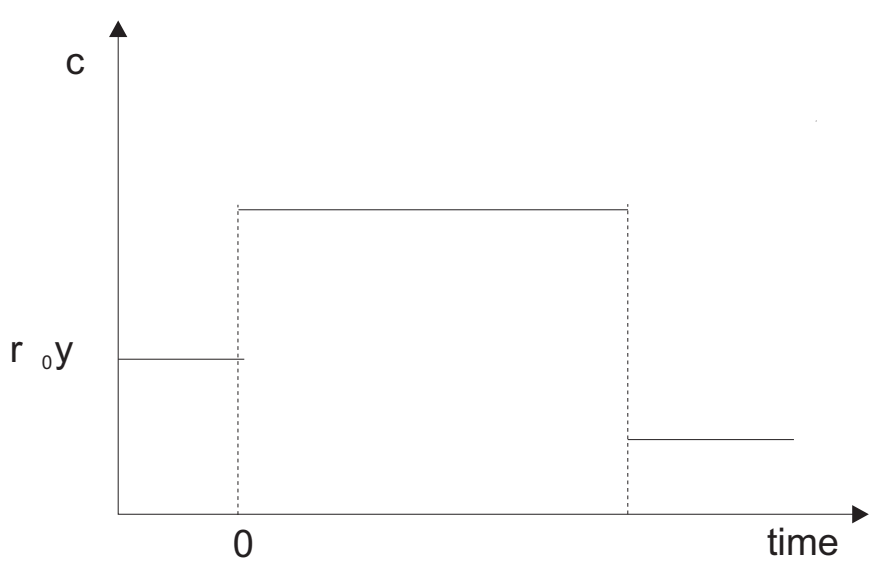

D. eal e c ange rate

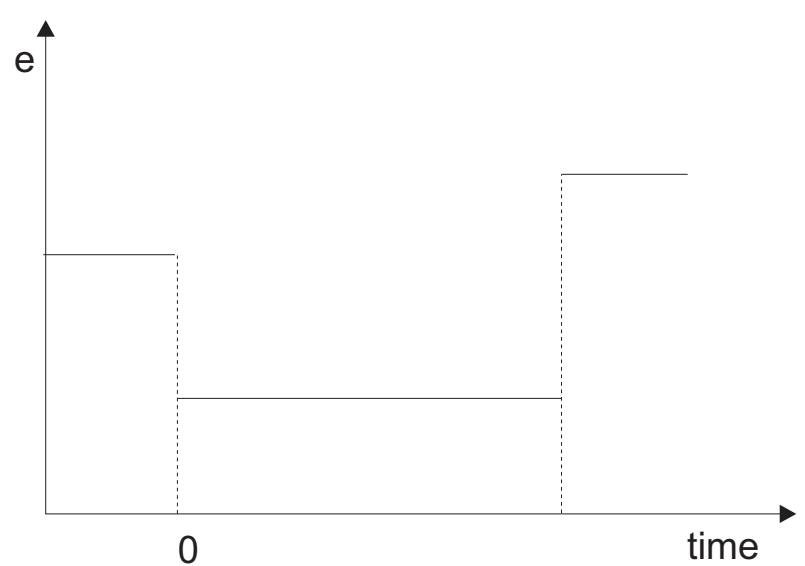


Figure. Consum tion of ura le goo s

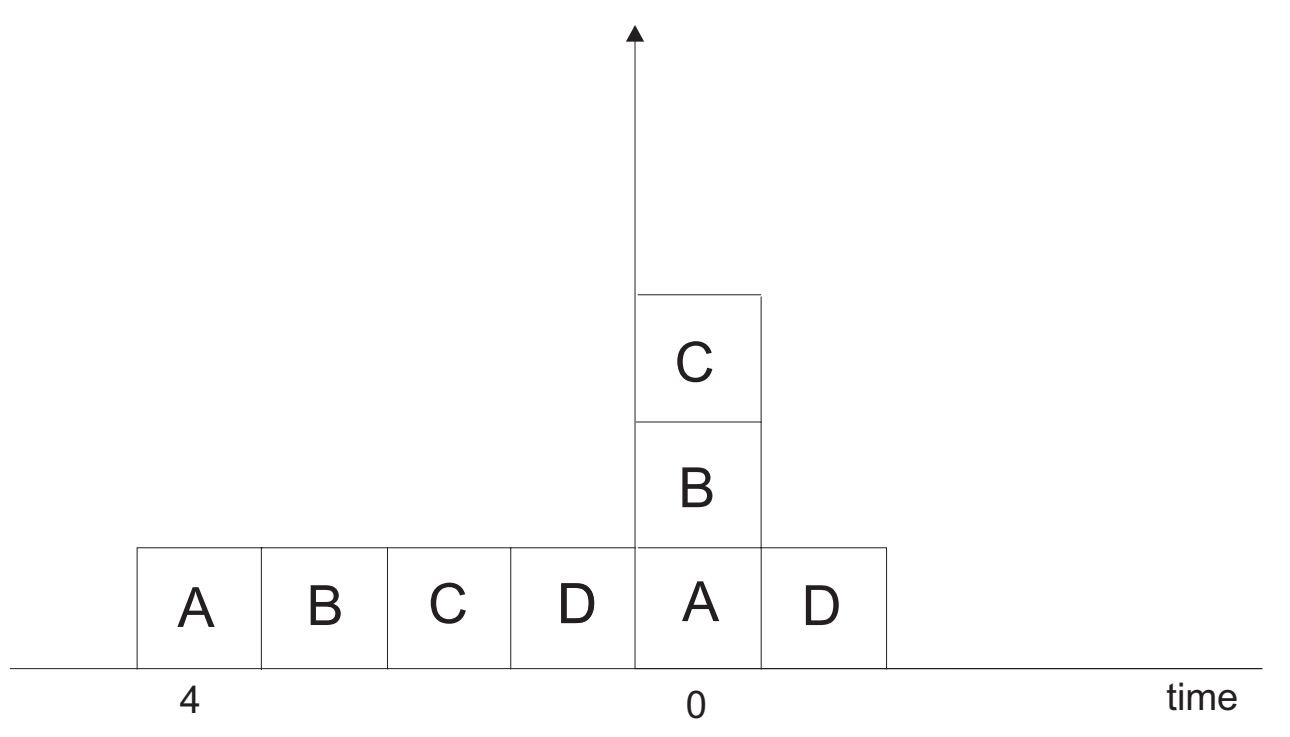


Figure 8. Real installments for various nominal interest rates

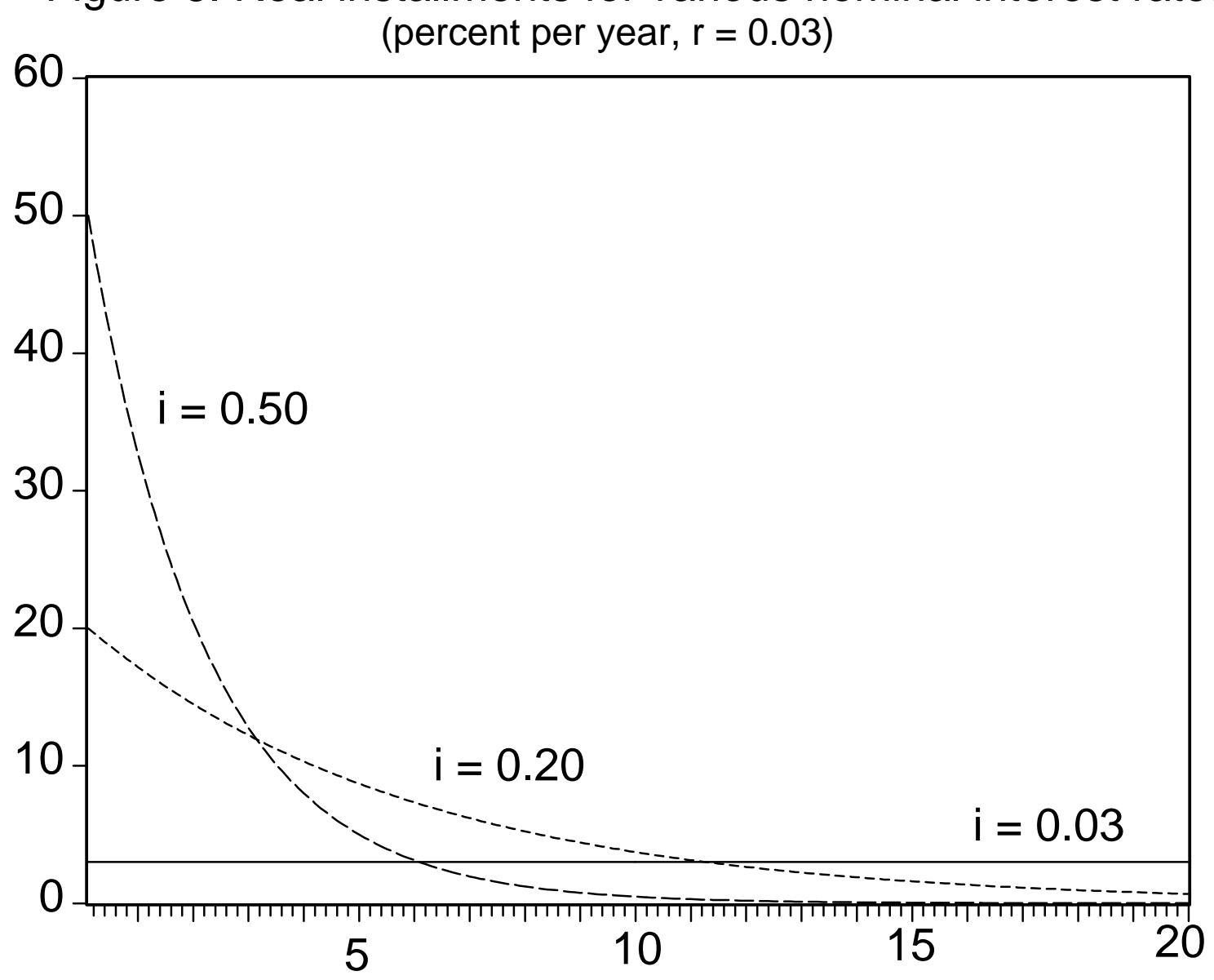

Source: See text. 
Figure . oney ase sta ili ation: Dynamic system

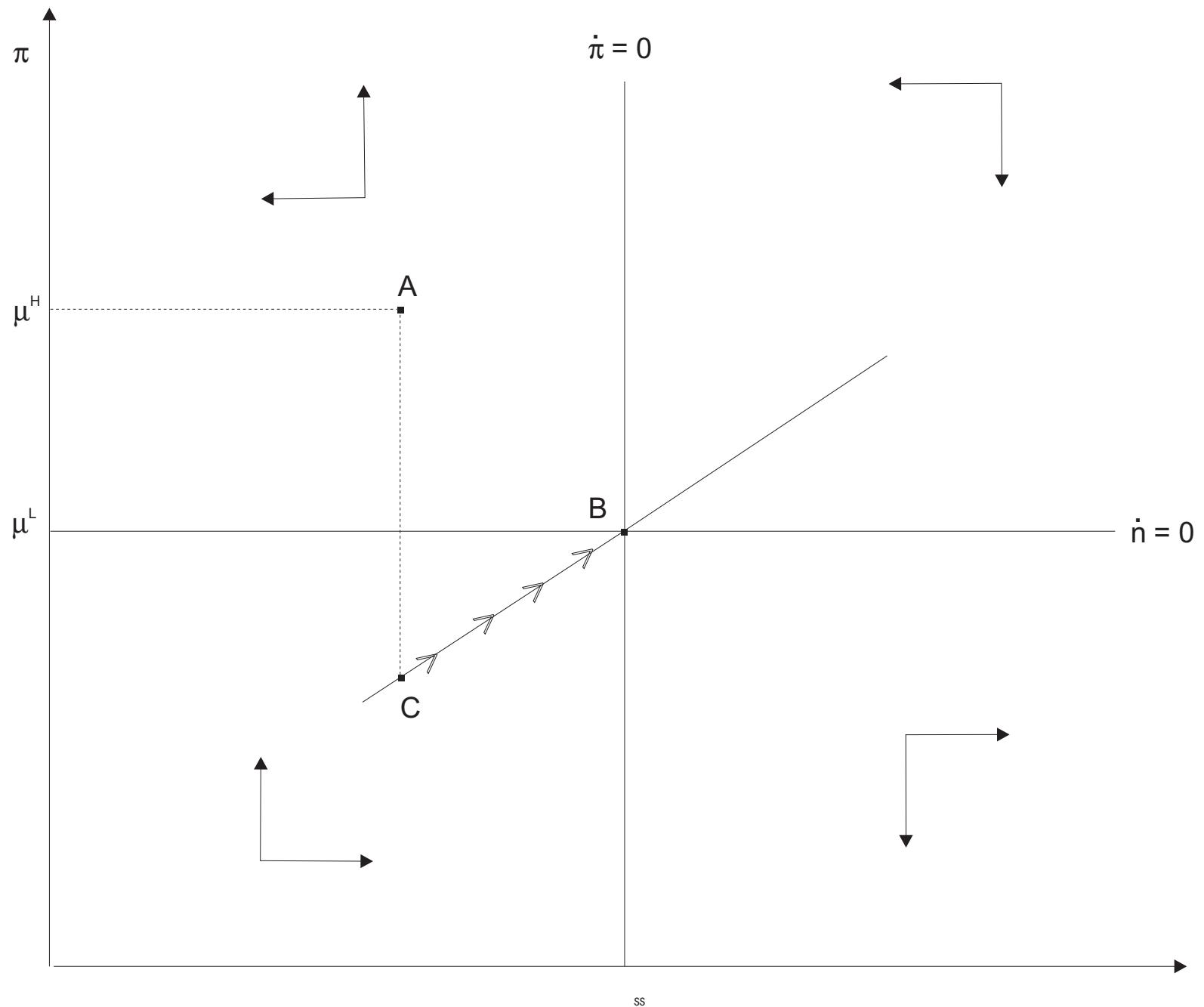


Figure 0 . oney ase sta ili ation: ime at s

A. ate of monetary gro $t$

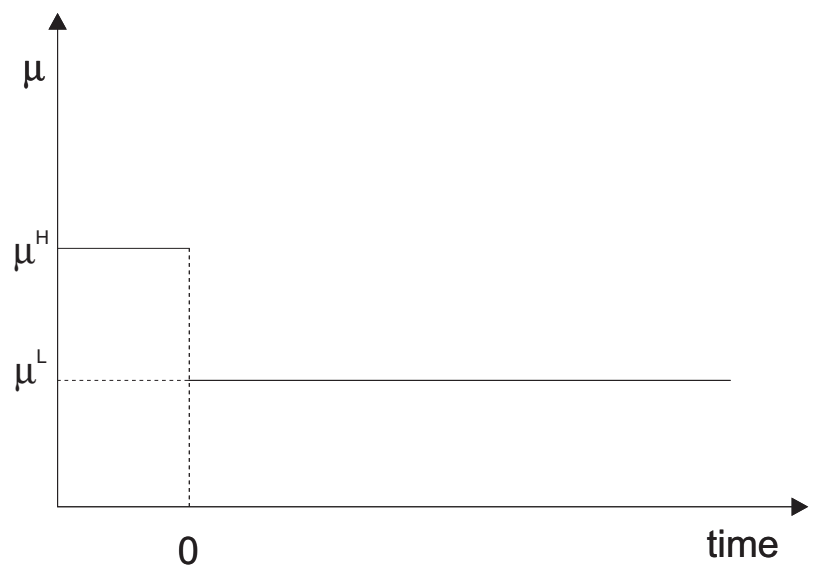

C. Inflation rate

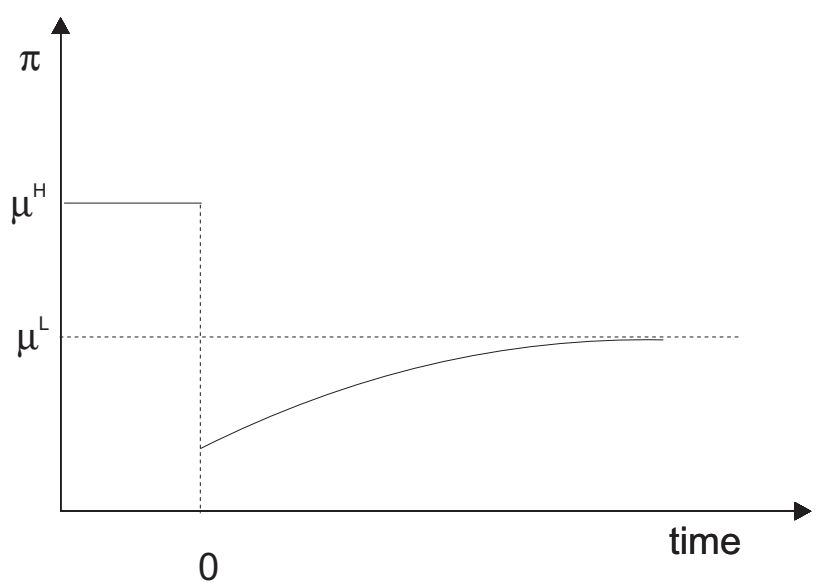

- eal e c ange rate

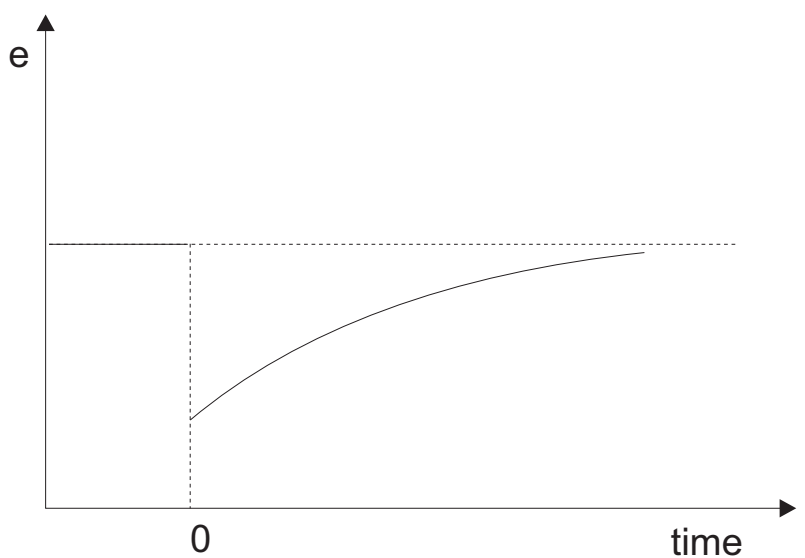

B. eal money alances

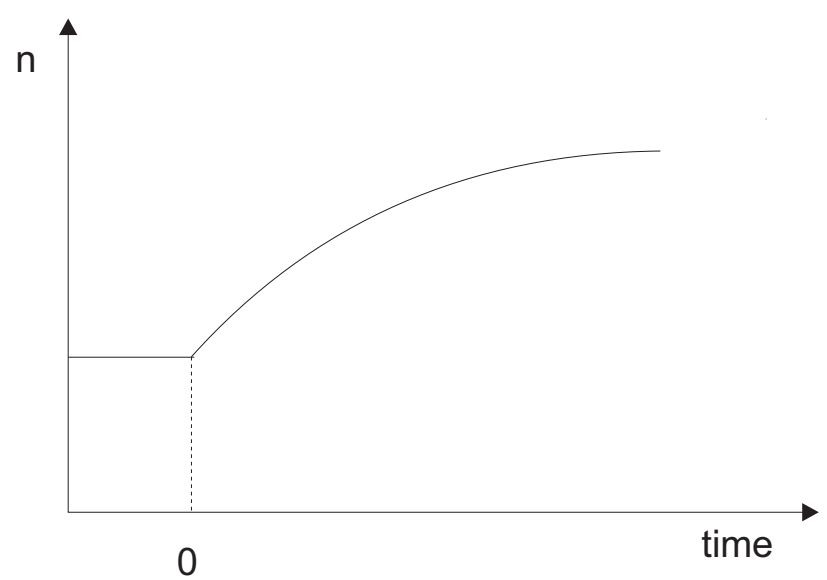

D. Consum tion of ome goo s

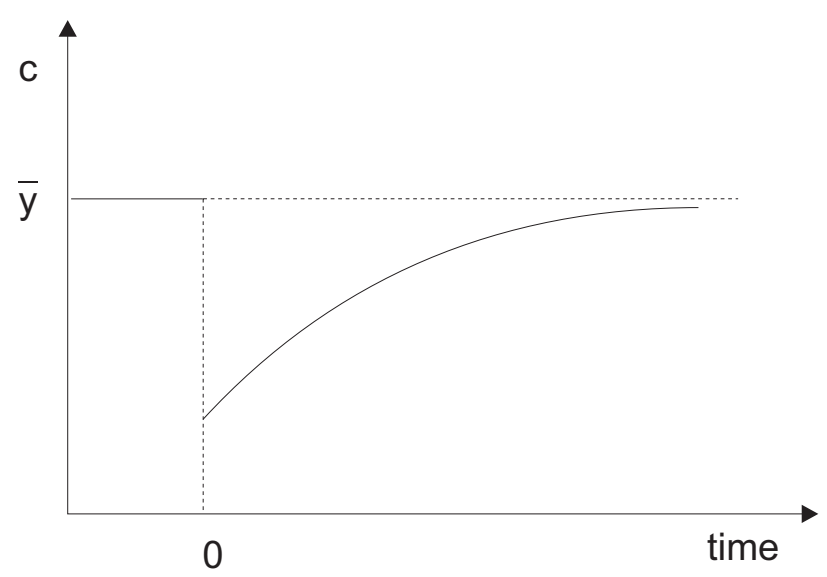

F. Domestic real interest rate

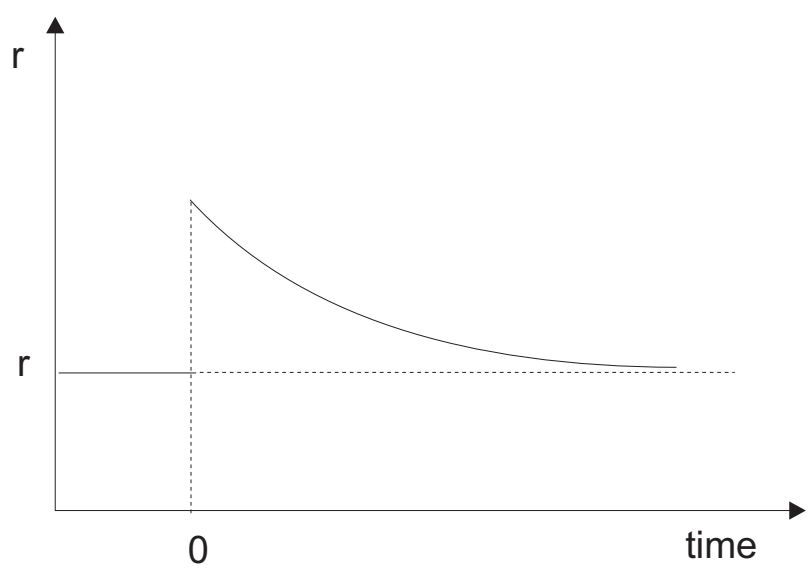


Figure . rugman crisis

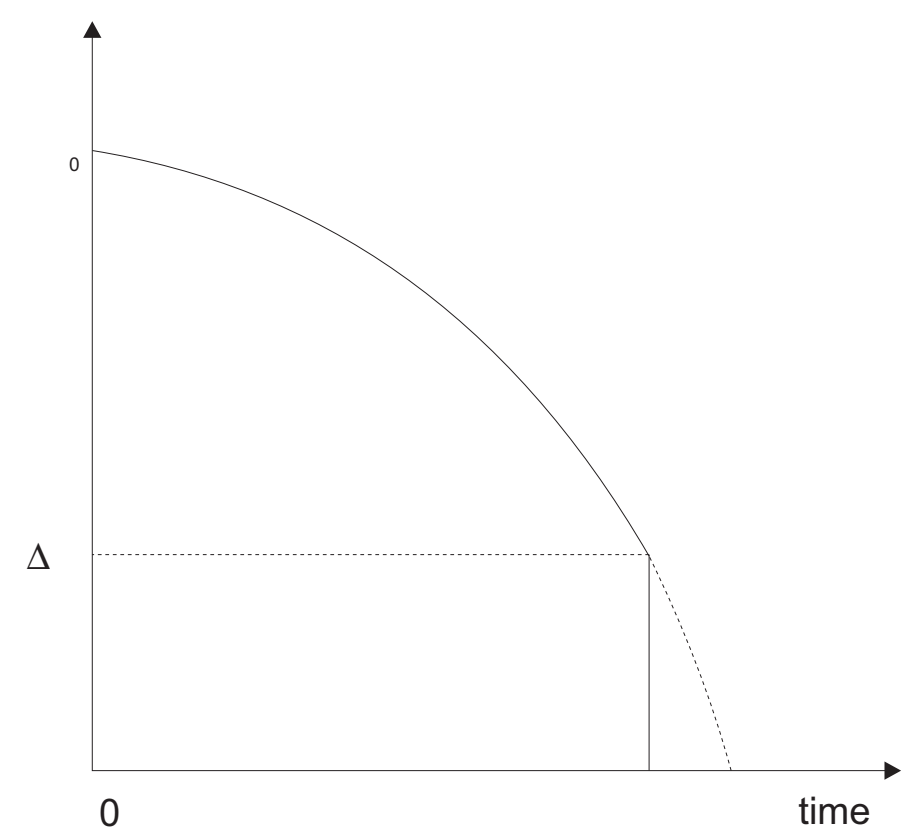

